\title{
ipen
}

AUTARQUIA ASSOCIADA À UNIVERSIDADE DE SÃO PAULO

\section{OBTENÇÃO DE BIOPOLÍMEROS DE GELATINA POR RADIAÇÃO IONIZANTE}

\author{
Patrícia Yoko Inamura Takinami
}

Tese apresentada como parte dos requisitos para obtenção do Grau de Doutor em Ciências na Área de Tecnologia Nuclear - Aplicações

Orientadora:

Profa. Dra. Nélida Lucia del Mastro 


\title{
INSTITUTO DE PESQUISAS ENERGÉTICAS E NUCLEARES
}

Autarquia associada à Universidade de São Paulo

\section{OBTENÇÃO DE BIOPOLÍMEROS DE GELATINA POR RADIAÇÃO IONIZANTE}

\author{
Patrícia Yoko Inamura Takinami \\ Tese apresentada como parte dos \\ requisitos para obtenção do Grau de \\ Doutor em Ciências na Área de Tecnologia \\ Nuclear - Aplicações \\ Orientadora: \\ Profa. Dra. Nélida Lucia del Mastro
}

Versão Corrigida

Versão Original disponível no IPEN 
Para o meu amor, Fernando por todo seu amor, apoio, incentivo e paciência, que sempre recebi incondicionalmente 


\section{AGRADECIMENTOS}

Minha profunda gratidão a minha orientadora, Dra. Nélida Lucia del Mastro, por sua orientação, confiança, conselhos e inspiração. Sempre me incentivando em todos os desafios e paciência para concluir este projeto.

A Deus por estar presente em todos os momentos, emanando sabedoria, amor, vida, alegria, provisão e harmonia infinita para vencer mais esse desafio.

Aos meus pais Yoshio e Tiemi, que sem eles não estaria aqui hoje e por sempre estarem presentes, incentivando, apoiando e me tornando uma pessoa melhor.

A Cecília e Ernesto que sempre estiveram presentes me incentivando, apoiando em todos os momentos para a concretização deste trabalho.

Ao IPEN, especialmente ao Centro de Tecnologia das Radiações, representada pela Dra. Margarida M. Hamada, gerente do CTR, gerentes adjuntos Dra. Mônica B. Mathor e Dr. Wilson A. P. Calvo pelo constante apoio e pré-disposição em ajudar e buscar soluções.

Ao Dr. Mohamad Al-Sheikhly pela coorientação, inspiração, sabedoria, paciência e pela valiosa colaboração no período em que estive na University of Maryland (UMCP) para conclusão da pesquisa com valiosos conselhos e apontamentos. E também por disponibilizar os laboratórios, equipamentos, e apresentar a outros profissionais e pesquisadores que me ajudaram, pois sem eles seria impossível realizar esta pesquisa.

Ao Dr. Wyatt N. Vreeland do National Institute of Standards and Technology (NIST) pela colaboração e orientação no uso do Asymmetric flow field flow fractionation (AF4) e conselhos técnicos e a Dra. Dianne Poster do mesmo instituto (NIST) pela colaboração e apoio. 
Aos meus irmãos Yoshiko, Hideyoshi, Akiko e Katsuyoshi, cunhados Enzo, Márcio, Carol e Kiyomi e sobrinhos Kazuo e Clarissa que sempre estiveram presentes e me apoiam em todos os momentos.

Aos meus avós, Fumio, Kikuo, Tsuruyo que estão presentes em espírito, e que sempre me incentivaram a ser uma pessoa do bem e minha avó Sadaco, que me trata com tanto zelo e carinho.

Aos tios Mutsumi e Kayo pelo apoio e convicção do meu sucesso, mesmo a distância, mas sempre presentes.

Aos meus primos, tios e toda família por sempre estarem presentes, compartilhando de todos os momentos, pela torcida, apoio e carinho.

A Dra. Esperidiana A. B. Moura pela atenção e carinho.

Aos engenheiros Elizabeth S. R. Somessari e Carlos G. da Silveira pelo constante auxílio no processamento por irradiação das amostras.

Aos alunos de iniciação científica que auxiliaram durante essa jornada: Kléber Shimazaki, Amicia Y. Seguiura, Carlos T. S. Kasawa e Felipe H. Kraide.

À Claudia R. Nolla e ao Marcos C. da Silva pela ajuda nos assuntos administrativos.

Aos colegas do laboratório, pela ajuda na realização deste trabalho e pelos vários momentos de descontração: Amanda, Ana Carolina, Bruna, Flávio, Fernando, Gustavo, Luana, Michel, Nelson, Rejane, Renato, Rodrigo e Vanessa (IPEN) e Slavica, Channel, Yasmin, Laila, Cameron e Jake (UMCP).

Aos demais profissionais e bolsistas do Centro de Tecnologia das Radiações, pelo convívio harmonioso e enriquecedor.

A Capes pelo auxílio financeiro.

Ao CNPq, pelo auxílio financeiro para o doutorado sanduiche.

A todos que contribuíram para realização deste trabalho, quanto na minha formação. 
"CRIATI-

VIDADE

É A INTE-

LIGÊNCIA

SE DIVER-

TINDO."

Albert Einstein

"Success isn't just about what you accomplish in your life it's about what you inspire others to do."

Unknown 


\title{
OBTENÇÃO DE BIOPOLÍMEROS DE GELATINA POR RADIAÇÃO IONIZANTE
}

\author{
Patrícia Yoko Inamura Takinami
}

\section{RESUMO}

A gelatina (GEL) é um biopolímero biodegradável e biocompatível que forma naturalmente coloides semissólidos ou hidrogéis em soluções aquosas. Sendo um polímero hidrofílico, a GEL possui propriedades estruturais e físico-mecânicas que a distinguem de polímeros hidrofílicos sintéticos. São essas características que inspiraram o desenvolvimento do presente trabalho. Para analisa-las foram desenvolvidos filmes e hidrogéis de GEL utilizando radiação ionizante mediante diferentes técnicas: irradiação por ${ }^{60} \mathrm{Co}$, feixe de elétrons (EB) e/ou EB pulsado. $\mathrm{Na}$ elaboração de filmes a base de GEL foram incorporados diferentes aditivos, tais como glicerol (GLY), álcool polivinílico (PVA), hidroxitolueno butilado (BHT), acrilamida e/ou fibra vegetal. Esse produto - filmes a base de GEL - foi analisado quanto às suas propriedades mecânicas, cor, absorção de água, entre outros; e irradiado com doses de 10 a $60 \mathrm{kGy}$, dependendo do aditivo. Na síntese radioinduzida de nano-hidrogéis de GEL, polietileno glicol (PEG) e a mistura (MIX) de ambos os aditivos, GEL e PEG, foram analisados a dimensão, massa molar e morfologia das nanopartículas. Houve aumento significativo da fração gel com o aumento da dose de radiação nas amostras de GEL/fibra. Os filmes a base de GEL com 10\% PVA irradiados a $20 \mathrm{kGy}$ apresentaram a maior resistência à perfuração. A adição de antioxidante BHT influenciou em algumas das propriedades dos filmes a base de GEL nas condições aplicadas. Em relação aos nano-hidrogéis houve redução do raio hidrodinâmico da MIX irradiada com ${ }^{60} \mathrm{Co}$ de $68 \pm 25 \mathrm{~nm}$ (2 kGy) para $35 \pm 4 \mathrm{~nm}(5 \mathrm{kGy})$. Tanto nos filmes quanto nos nano-hidrogéis de GEL, a radiação mostrou ser uma ferramenta conveniente na modificação de materiais poliméricos.

Palavras-chave: Gelatina, ${ }^{60} \mathrm{Co}$, feixe de elétrons, feixe de elétrons pulsado, biomateriais, nano-hidrogéis. 


\title{
OBTENTION OF GELATIN BIOPOLYMERS BY IONIZING RADIATION
}

\author{
Patrícia Yoko Inamura Takinami
}

\begin{abstract}
The gelatin (GEL) is a biocompatible and biodegradable biopolymer, which naturally forms semi-solid colloids or hydrogels in aqueous solutions. As a hydrophilic polymer, the GEL has structural and physico-mechanical properties that distinguish it from synthetic hydrophilic polymers. The study of these properties led to the development of the present work. Thus, GEL-based films and hydrogels were developed using ionizing radiation technology by different techniques: irradiation with ${ }^{60} \mathrm{Co}$, electron beam (EB) and/or pulsed EB. The GEL based-films enriched with different additives, such as glycerol (GLY), polyvinyl alcohol (PVA), butylated hydroxytoluene (BHT), acrylamide and/or vegetal fiber, were irradiated with doses from 10 to $60 \mathrm{kGy}$, depending on the additive; some parameters like mechanical properties, color, and water absorption were analyzed. In the radio-induced synthesis of GEL nanohydrogels, polyethylene glycol (PEG) and the mixture (MIX) of additives, PEG and GEL, the size, molar mass and surface morphology of the nanohydrogels were analyzed. There was a significant increase of gel fraction with increase of the radiation dose for the GEL/fiber samples. The GEL based-films with 10\% PVA irradiated at 20 kGy showed the highest puncture strength. The addition of antioxidant BHT affected on some GEL based-films properties on applied conditions. Regarding the nanohydrogels, there was a decrease of hydrodynamic radius of MIX irradiated with ${ }^{60} \mathrm{Co}$ from $68 \pm 25 \mathrm{~nm}(2 \mathrm{kGy})$ to $35 \pm 4 \mathrm{~nm}$ (5 kGy). The radiation proved to be a convenient tool in the modification of polymeric materials for both, GEL films and hydrogels.
\end{abstract}

Keys words: Gelatin, ${ }^{60} \mathrm{Co}$, electron beam, pulsed electron beam, biomaterials, nanohydrogels. 


\section{SUMÁRIO}

Página

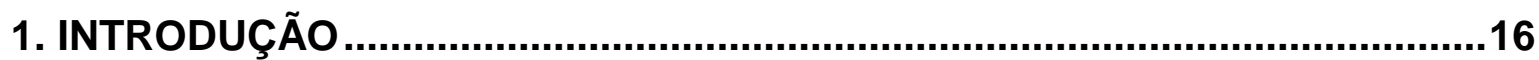

2. OBJETIVO

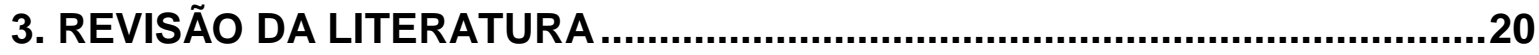

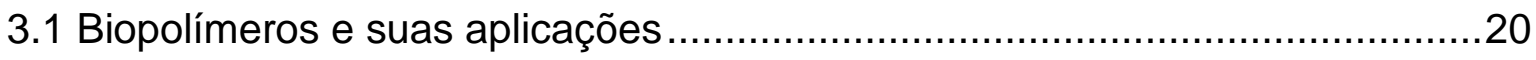

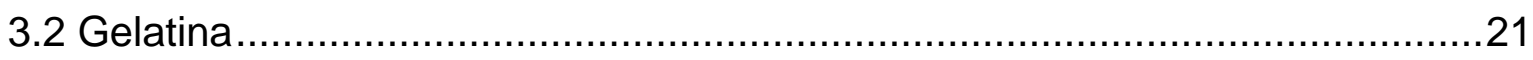

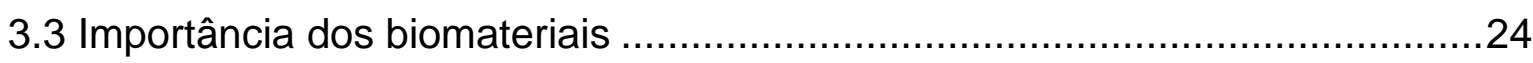

3.4 Modificação de polímeros por ação da radiação ionizante ............................27

3.5 Hidrogéis poliméricos e suas aplicações..................................................29

3.6 Plastificantes e aditivos utilizados nos filmes a base de gelatina ......................31

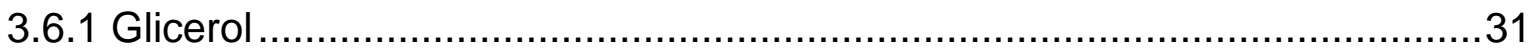

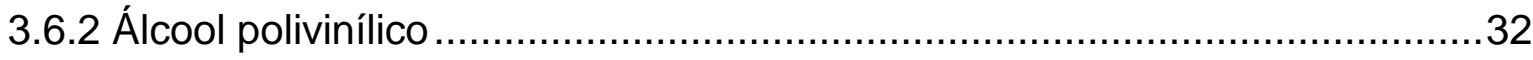

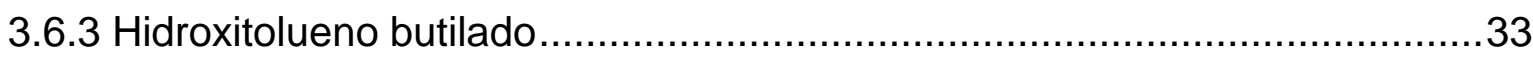

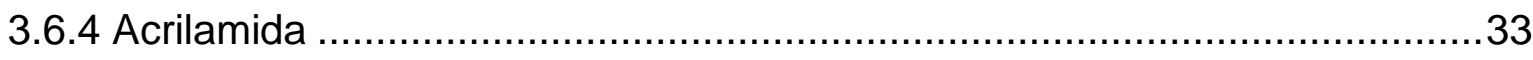

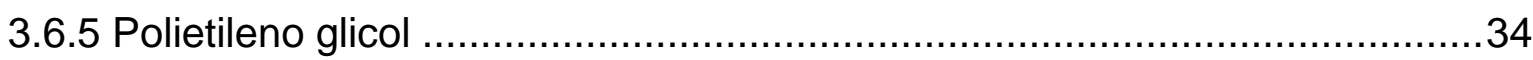

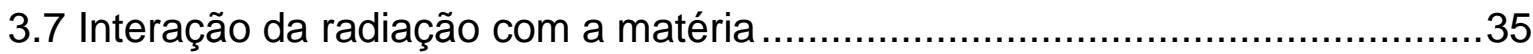

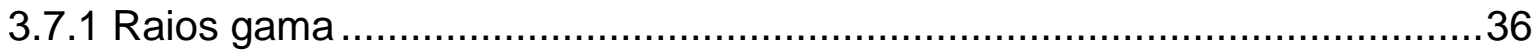

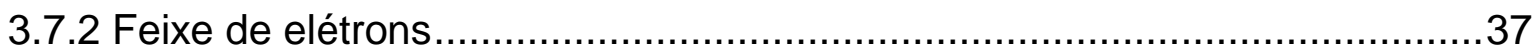

3.7.3 Química das radiações em sistemas aquosos .........................................39

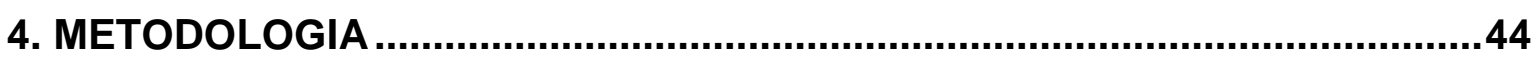

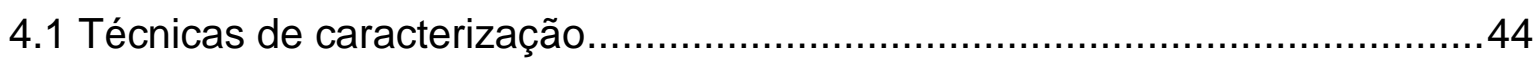

4.1.1 Análise de textura ............................................................................

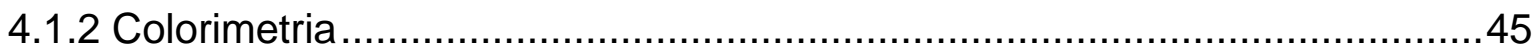

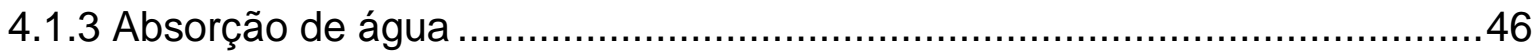

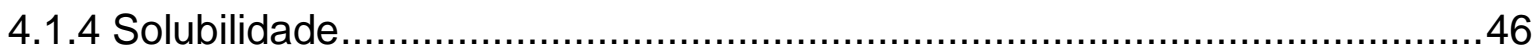

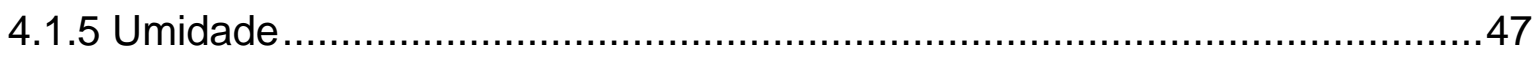

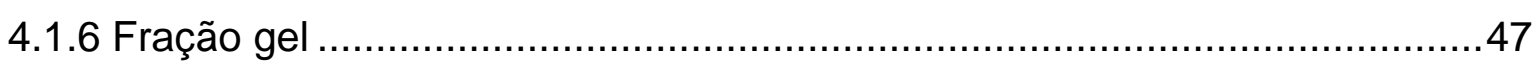

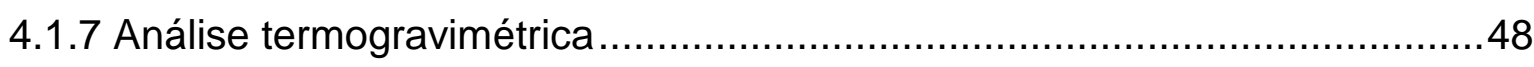




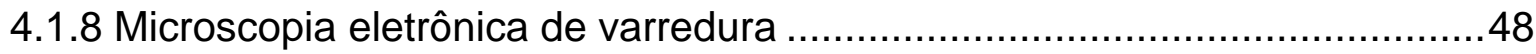

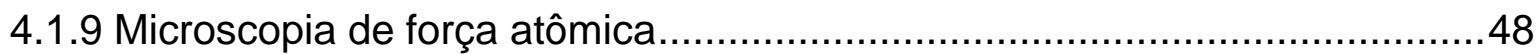

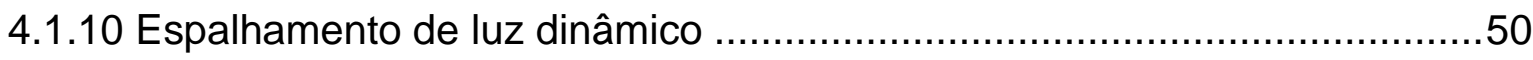

4.1.11 Asymmetrical Flow Field-Flow Fractionation ...........................................54

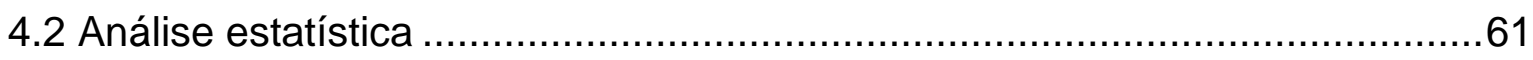

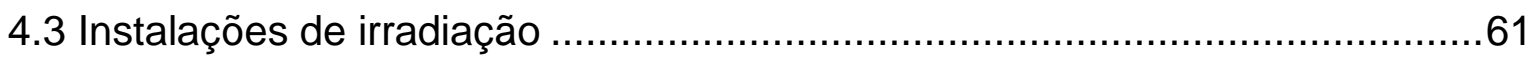

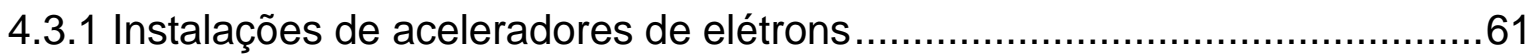

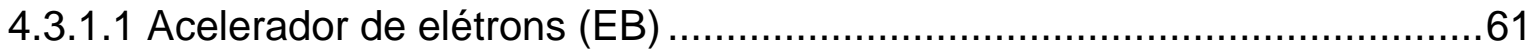

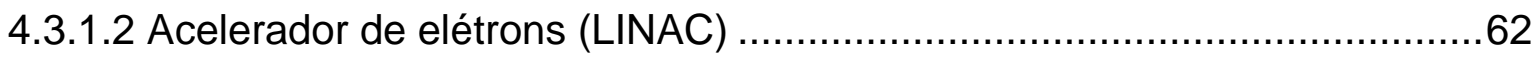

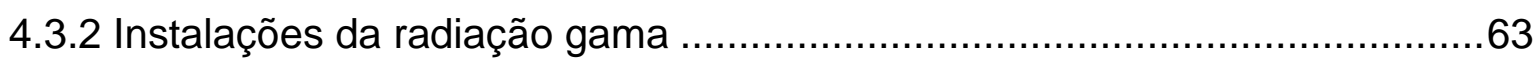

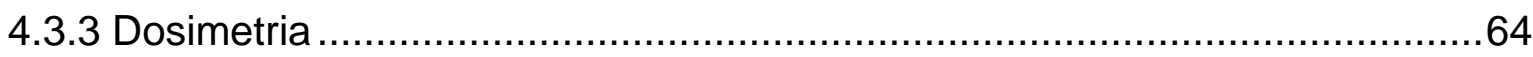

5. FILMES A BASE DE GELATINA OBTIDOS POR RADIAÇÃO IONIZANTE...65

5.1 Preparação de compósitos de gelatina e fibra do ouriço da castanha do

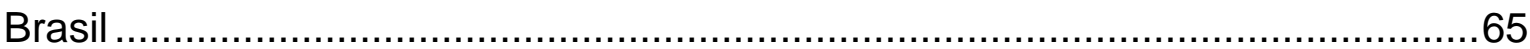

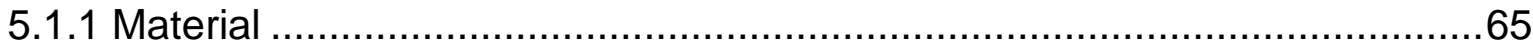

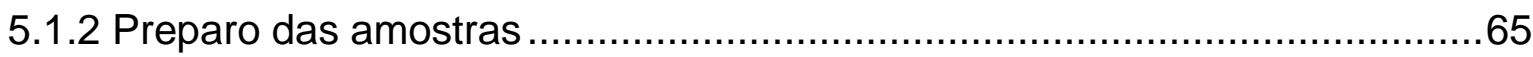

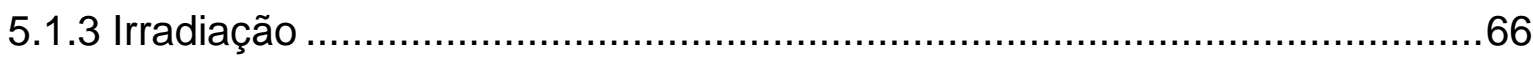

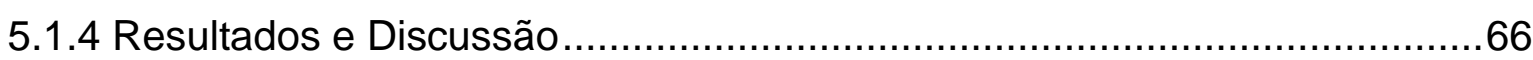

5.2 Preparação de filmes a base de gelatina com PVA ou BHT ...........................71

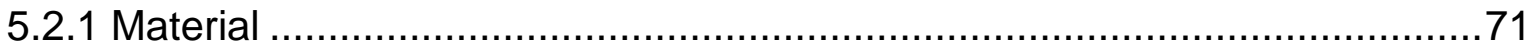

5.2.2.1 Preparação de filme a base de GEL/PVA ……….................................

5.2.2.2 Preparação de filme a base de GEL/BHT ............................................72

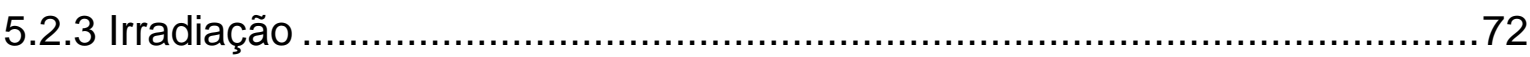

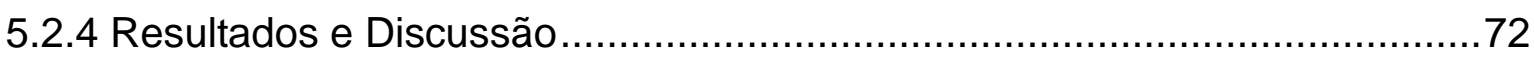

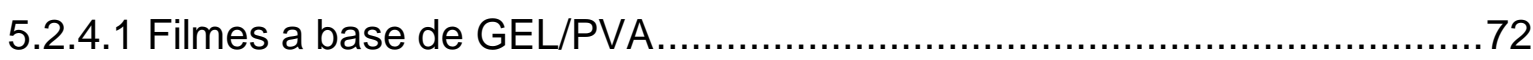

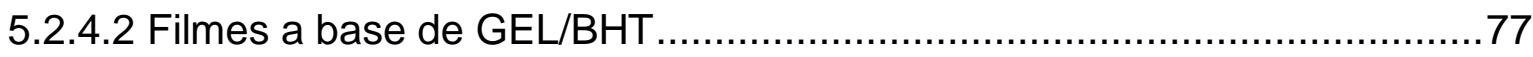

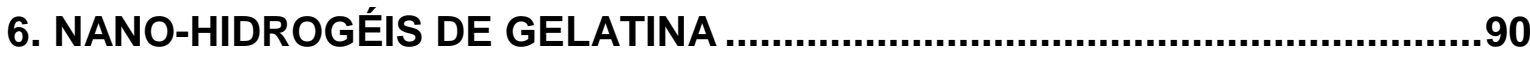

6.1 Síntese de nano-hidrogéis por radiação ionizante .........................................9

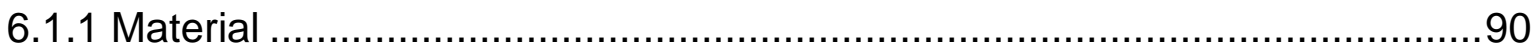

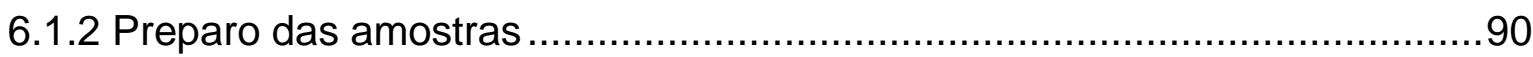

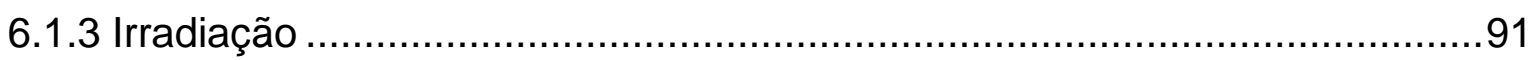

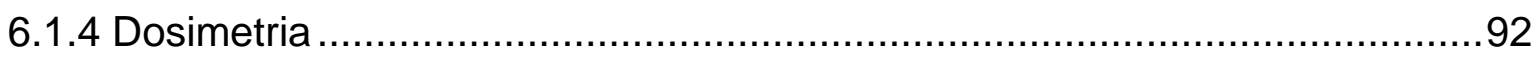

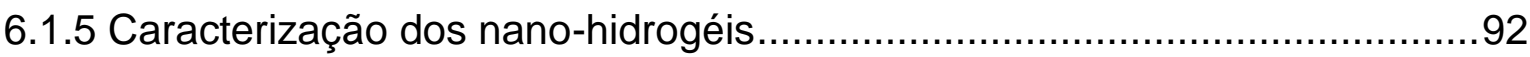

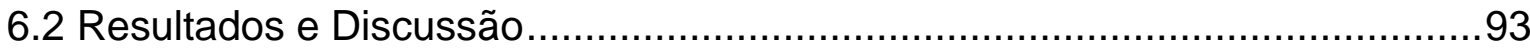


7. CONSIDERAÇÕES FINAIS

106 REFERÊNCIAS BIBLIOGRÁFICAS 


\section{LISTA DE FIGURAS}

Página

FIGURA 1 - Estrutura química da gelatina. .22 FIGURA 2 - Ouriço e casca da castanha do Brasil (Bertholletia excelsa Humb. \& Bonpl. Lecythidaceae) 26

FIGURA 3 - Espalhamento Compton (Spinks \& Woods, 1990); A energia e o momento do fóton incidente são divididos entre o fóton espalhado e o elétron de recuo

FIGURA 4 - Efeito de irradiação em proteína mostrando possível despolimerização (fragmentação) e polimerização (reticulação) das cadeias de proteínas (Kuan et al., 2013).

FIGURA 5 - Desenvolvimento esquemático espaço-tempo num sistema aquoso diluído (Magee \& Chatterjee, 1987).

FIGURA 6 - Reação de reticulação inter vs intramolecular (Al-Sheikhly, 2010)...43 FIGURA 7 - Texturômetro para medições das propriedades mecânicas dos filmes a base de gelatina. .44

FIGURA 8 - Diagrama de coordenadas do espaço de cor CIELAB 45

FIGURA 9 - Esquema de funcionamento da microscopia de força atômica 49

FIGURA 10 - AFM dentro da câmara de isolamento acústico da Asylum Research. .50

FIGURA 11 - Equipamento de DLS: ZetaPALS Particle Sizing .54

FIGURA 12 - Esquema do mecanismo de separação de cromatografia AF4 ......56 FIGURA 13 - Configuração do AF4 (Wyatt Technology Corp.) para as medições de $R_{h}$ e massa molar 60

FIGURA 14 - Acelerador de elétrons Dynamitron II, CTR (IPEN-CNEN/SP). ......61 FIGURA 15 - Instalação do LINAC da University of Maryland, College Park (UMCP). 62

FIGURA 16 - Esquema da fonte gama de ${ }^{60} \mathrm{Co}$ e armazenamento da UMCP. ....63

FIGURA 17 - Instalação da fonte gama de ${ }^{60} \mathrm{Co}$ da UMCP. .64 
FIGURA 18 - Imagens de MEV de compósitos de gelatina e fibra do ouriço da castanha do Brasil irradiados em diferentes doses de radiação: (a) não irradiado (3000x); (b) 20 kGy (3000x); (c) 40 kGy (3000x); (d) não-irradiado (500x); (e) 20 kGy (500x); (f) 40 kGy (500x).

FIGURA 19 - Cinética de absorção de água em amostras de filmes a base de gelatina contendo BHT e não contendo (BHTf) analisadas 7 dias após a irradiação no EB a 20, 40 e 60 kGy 85

FIGURA 20 - Cinética de absorção de água em amostras de filmes a base de gelatina contendo BHT e não contendo (BHTf) analisadas 14 dias após a irradiação no EB a 20, 40 e 60 kGy. 86 FIGURA 21 - Cinética de absorção de água em amostras de filmes a base de gelatina contendo BHT e não contendo (BHTf) analisadas 60 dias após a irradiação no EB a 20, 40 e 60 kGy.

FIGURA 22 - Posição das amostras, $10 \mathrm{~cm}$ e $55 \mathrm{~cm}$, em relação à distância da janela do feixe de elétrons pulsado a uma taxa de dose de 70,5 Gy/pulso e $16,5 \mathrm{~Gy} /$ pulso, respectivamente.

FIGURA 23 - Amostra depositada na mica recém clivada e mantida sob temperatura ambiente para secagem.

FIGURA 24 - Micrografias de AFM em meio líquido de nano-hidrogéis de gelatina (GEL) controle (a) e irradiados no EB pulsado a 15 kGy (b) e nano-hidrogéis de MIX a 15 kGy (c).

FIGURA 25 - Diâmetro hidrodinâmico $\left(D_{h}, n m\right)$ dos nano-hidrogéis de GEL, PEG e MIX sintetizados e irradiados no EB pulsado em uma taxa de dose de $16,5 \mathrm{~Gy} /$ pulso a $77 \stackrel{\circ}{\mathrm{C}}$ analisados no DLS. .95 FIGURA 26 - Diâmetro hidrodinâmico $\left(D_{h}, n m\right)$ dos nano-hidrogéis de GEL, PEG e MIX sintetizados e irradiados no EB pulsado em uma taxa de dose de $70,5 \mathrm{~Gy} /$ pulso a $77 \stackrel{\circ}{\mathrm{C}}$ analisados no DLS. 96 FIGURA 27 - Diâmetro hidrodinâmico $\left(D_{h}, n m\right)$ dos nano-hidrogéis de GEL, PEG e MIX sintetizados e irradiados em fonte de ${ }^{60} \mathrm{Co}$ a $70 \mathrm{kGy} \mathrm{h}^{-1}$ em diferentes doses a $77 \stackrel{\circ}{\circ}$ analisados no DLS.

FIGURA 28 - Massa molar médio $\left(\mathrm{Mn}, \mathrm{g} \mathrm{mol}^{-1}\right)$ dos nano-hidrogéis de GEL, PEG e MIX sintetizados e irradiados em fonte de ${ }^{60} \mathrm{Co}$ a $70 \mathrm{kGy} \mathrm{h}^{-1}$ em diferentes doses a $77^{\circ} \mathrm{C}$ analisados no AF4. 100 
FIGURA 29 - Massa molar médio $\left(\mathrm{Mn}, \mathrm{g} \mathrm{mol}^{-1}\right.$ ) dos nano-hidrogéis de GEL, PEG e MIX sintetizados e irradiados no EB pulsado em diferentes doses em uma taxa de dose de $70,5 \mathrm{~Gy} /$ pulso a $77^{\circ} \mathrm{C}$ analisados no AF4 .................................... 100 FIGURA 30 - Amostras irradiadas a $15 \mathrm{kGy}$ por raios- $\gamma$ e sintetizadas a $20 \stackrel{\circ}{\circ} \mathrm{em}$ diferentes concentrações de soluções de $\operatorname{MIX}(B$ a E) e amostra $A$ irradiada a 15 kGy no EB pulsado sintetizada a $77 \stackrel{\circ}{\circ} \mathrm{C}$ 102 FIGURA 31 - Esquema sugerido para dependência da concentração com duas vias para dobramento de cadeia Tm (temperatura de fusão) em polipeptídeos de cadeia única derivada de colágeno (Harrington \& Rao, 1970) 103 


\section{LISTA DE TABELAS}

Página

TABELA 1 - Fração sol (Fs), fração gel (Fg) e absorção de água de compósitos de gelatina e fibra do ouriço da castanha do Brasil irradiados em diferentes doses de radiação no EB

TABELA 2 - Análise termogravimétrica de compósitos de gelatina e fibra do ouriço da castanha do Brasil não irradiados e irradiados em EB a 20 e 40 kGy...69 TABELA 3 - Resistência à perfuração e deformação de amostras de filmes de gelatina com adição de 0 (PVAf), 5 e 10\% de PVA não irradiadas e irradiadas no EB a 10 e 20 kGy. 73

TABELA 4 - Absorção de água, umidade e solubilidade dos filmes a base de gelatina com adição de 0 (PVAf), 5 e 10\% de PVA não irradiadas e irradiadas no EB a 10 e 20 kGy.

TABELA 5 - Parâmetros de cor de amostras de filmes de gelatina com adição de 0 (PVAf), 5 e 10\% de PVA não irradiadas e irradiadas no EB a 10 e 20 kGy.......76 TABELA 6 - Umidade e solubilidade de amostras de filmes a base de gelatina (BHTf) e contendo BHT analisados 7, 14 e 60 dias após a irradiação no EB a 20, 40 e 60 kGy .78

TABELA 7 - Resistência e deformação a perfuração em amostras de filmes a base de gelatina (BHTf) e contendo BHT analisados 7, 14 e 60 dias após a irradiação no EB a 20, 40 e 60 kGy. .79 TABELA 8 - Medidas de cor em amostras de filmes a base de gelatina (BHTf) e contendo BHT analisados 7, 14 e 60 dias após a irradiação no EB a 20, 40 e 60 kGy. .83

TABELA 9 - Raio hidrodinâmico $\left(R_{h}, n m\right)$ dos nano-hidrogéis de GEL, PEG e MIX sintetizados e irradiados em fonte de ${ }^{60} \mathrm{Co}$ a $70 \mathrm{kGy} \mathrm{h}^{-1}$ em diferentes doses a $77^{\circ} \mathrm{C}$ analisados no AF4. 
TABELA 10 - Raio hidrodinâmico $\left(R_{h}, n m\right)$ dos nano-hidrogéis de GEL, PEG e MIX sintetizados e irradiados no EB pulsado em diferentes doses em uma taxa de

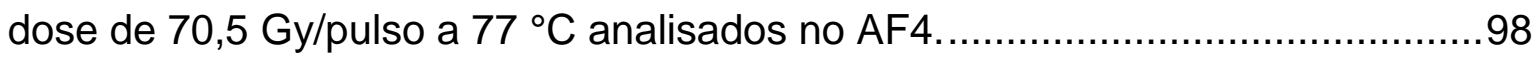




\section{INTRODUÇÃO}

Uma das formas de enfrentar o desafio de encontrar técnicas limpas, que gerem pouco resíduo, possibilite a reciclagem e sejam amigáveis com o meio ambiente está no desenvolvimento de biopolímeros, como substituintes de polímeros sintéticos (Tharanathan, 2003; Bergo \& Sobral, 2007; MMA, 2013; Embrapa, 2013). Esses compostos biodegradáveis, tais como proteínas (gelatina, proteína do trigo, colágeno) e polissacarídeos (amido, xantana, quitosana), provêm de fontes naturais e renováveis (Sobral et al., 2001; Fontes et al., 2011), de modo que os produtos a base desses componentes tornam-se um grande benefício para 0 meio ambiente. Esses materiais possuem bioatividade, biocompatibilidade (Ki et al., 2005) e novas propriedades para aplicações específicas (Lin \& Metters, 2006).

Entre os biopolímeros, a gelatina foi um dos primeiros materiais utilizados na obtenção de filmes; constitui uma classe versátil, de fácil produção e manuseio durante o preparo, abundância, baixo custo de produção, disponibilidade no mercado brasileiro e mundial (Vanin et al., 2005; Ma et al., 2012; Kanmani \& Rhim, 2014). Esta proteína possui baixa citotoxicidade, biodegradabilidade, biocompatibilidade (Gómez-Guillén et al., 2011) e é conhecida por sua capacidade de formar hidrogéis (Zegota, 1999; Naidu \& Paulson, 2011). A gelatina é um dos ingredientes alimentares mais empregados como gelificante, espessante, emulsificante e estabilizante (Strauss \& Gibson, 2004) em revestimentos para produtos alimentícios (Antoniewski et al., 2007). Na indústria farmacêutica, é utilizada para a produção de lentes de contato e medicamentos de ingestão oral (Hoffman et al., 2002), em aplicações biomédicas (Ki et al., 2005), na engenharia de tecidos (Khademhosseini \& Langer, 2007), na regeneração de órgãos (Skotak et al., 2008), em sistemas de liberação controlada de drogas (Curcio et al., 2010), na confecção de bioadesivos para curativos (Ong et al., 2008); biomateriais em blendas com outros materiais, formam compósitos para embalagens (Inamura et al., 2010), hidrogéis (Al-Sheikhly, 2010), biofilmes (Gómez-Estaca et al., 2011), entre outras aplicações. 
Novos processos e aplicações da gelatina são baseados na reticulação induzida do material, formação de blendas com outros biopolímeros ou hidrólise enzimática (Sobral et al., 2011; Gómez-Guillén, 2011).

Estruturas nanométricas estão ganhando cada vez mais atenção devido ao seu desempenho e suas propriedades únicas (Cascone et al., 2002; Imran et al., 2010; Malik et al., 2014). Assim, o crescimento e desenvolvimento nessa área têm desafiado as técnicas analíticas existentes (Williams \& Lee, 2006). Há inúmeros nanomateriais rígidos, incluindo os metais e materiais cerâmicos, que têm sido amplamente explorados e caracterizados (Li et al., 2013; Siddique \& Mehta, 2014). Por outro lado, materiais não rígidos, tais como géis de polímeros que exibem mutabilidade e capacidade de resposta a estímulos mecânicos em seu ambiente, podem ser projetados de modo a formar produtos nanoestruturados (An et al., 2011; Ko et al., 2013).

A irradiação é uma das tecnologias bem estabelecidas na área de esterilização, reticulação de polímeros, conservação de alimentos e objetos de arte, sendo aplicada comercialmente em países desenvolvidos e em desenvolvimento (IAEA, 2004a, 2004b). O uso da síntese induzida por radiação ionizante como um método para produção de materiais com melhores propriedades mecânicas (Güven, 2005; Inamura et al., 2010) e nanogéis (Ulański \& Rosiak, 2004; An et al., 2011) apresenta-se uma abordagem com múltiplas vantagens: não há necessidade de um agente de reticulação, o processo é fácil de controlar, os produtos podem ser adaptados às características físicas e químicas específicas e a esterilização é realizada simultaneamente à síntese do material (Czvikovzky, 1985; Terao et al., 2003; Azzam et al., 2011). No entanto, a síntese induzida por radiação de polímeros, que se baseia em um processo de reticulação intramolecular, é menos explorada. Uma compreensão do mecanismo de formação de reticulação é muito importante, a fim de controlar as propriedades físicas finais (por exemplo o tamanho, a conformação, o peso molecular) dos materiais produzidos.

Neste trabalho, a preparação de filmes a base de gelatina (GEL) pela adição de álcool polivinílico (PVA), hidroxitolueno butilado (BHT) ou fibra da biodiversidade brasileira e irradiados utilizando o acelerador de elétrons são apresentados no capítulo 5. A síntese de nano-hidrogéis de GEL, polietileno glicol 
(PEG) e da mistura de GEL e PEG (MIX) irradiados em fonte de ${ }^{60} \mathrm{Co}$ e feixe de elétrons pulsado são apresentados no capítulo 6 .

O capítulo 7 contém considerações finais baseados nos resultados da pesquisa apresentados nesta tese. 


\section{OBJETIVO}

A proposta do presente trabalho de tese foi explorar a contribuição da radiação ionizante no desenvolvimento de biopolímeros de gelatina: obtenção e estudo de blendas de polímeros a base de gelatina e síntese de nanopartículas induzidas por radiação por meio de processo de reticulação intramolecular. 


\section{REVISÃO DA LITERATURA}

\subsection{Biopolímeros e suas aplicações}

Os biopolímeros são macromoléculas provenientes de fontes renováveis que ocorrem na natureza. Celulose, amido, quitina, proteínas, peptídeos, DNA e RNA são exemplos de biopolímeros nos quais as unidades monoméricas são, respectivamente, açúcares, aminoácidos e nucleotídeos (Djabourov et al., 1988; Pradella, 2006; Brito et al., 2011), em que foi possível observar resultados promissores (Bigi et al., 2001; Garcia et al., 2006; Ma et al., 2012; Harper et al., 2013; Cui et al., 2014; Ortiz-Zarama et al., 2014). Muitos biopolímeros são produzidos comercialmente em escala industrial, sendo que as matérias-primas principais para a sua manufatura são fontes de carbono renováveis provenientes de carboidratos derivados de plantios comerciais de larga escala como cana-de-açúcar, milho (Brito et al., 2011) e de proteínas como colágeno, gelatina e proteína de soro (Patel \& Mikos, 2004).

O desenvolvimento de produtos a base de polímeros naturais, biopolímeros e/ou biodegradáveis estão oferecendo diversas alternativas em busca de um processo de desenvolvimento mais sustentável (Abd El-Rehim, 2006; Ma et al., 2012). Desse modo, os biopolímeros estão se firmando como uma categoria de materiais de destaque na redução do impacto ambiental perante as embalagens plásticas sintéticas provenientes de combustíveis fósseis (Mariniello et al., 2003) e o uso de diferentes matérias-primas no preparo de materiais biodegradáveis vem sendo desenvolvidos (Tharanathan et al., 2003; Kechichian et al., 2010; Nobrega et al., 2012; Liu et al., 2012; Souza et al., 2013).

O uso de embalagens biodegradáveis torna acessível potenciais benefícios econômicos para produtos de origem agrícola (Tharanathan, 2003; Abd El-Rehim, 2006). As características de filmes a base de biopolímeros podem ser determinadas pela natureza química do biopolímero (Ma et al., 2012), pois sua estrutura química e a conformação da macromolécula influenciam nas interações da matriz polimérica envolvidas na formação da rede (Miller \& Krochta, 1997). 
Além disso, pode determinar a biodegradabilidade, bioatividade, biocompatibilidade (Ki et al., 2005) e propriedades para aplicações específicas (Lin \& Metters, 2006). No entanto, a intensidade das interações proteína-proteína e proteína-solvente podem ser determinadas pelas propriedades do material, ser controladas pelas condições de formação do filme e/ou pela presença de um plastificante (Sanchéz et al., 1998).

A necessidade da utilização de vários componentes, entre eles, biomoléculas naturais para a obtenção de materiais poliméricos com características semelhantes aos polímeros sintéticos com excelentes propriedades mecânicas e de barreira está mais frequente (Tharanathan, 2003; Sobral et al., 2001; Ki et al., 2005; Lin \& Metters, 2006; Garcia et al., 2006; Amin \& Ustunol, 2007; Bergo \& Sobral, 2007; Harper et al., 2013).

\subsection{Gelatina}

A gelatina é um polipeptídeo de alto peso molecular, produto da desnaturação e degradação estrutural do colágeno. Ela é constituída por uma mistura de proteínas de origem animal solúvel em água, produzida por desnaturação térmica e ação hidrolítica do colágeno, que é a substância constituinte das fibras do tecido conjuntivo (Veis, 1964; Rose, 1985; Kozlov \& Burdygina, 1983; Windholz et al., 1983).

A gelatina é uma substância translúcida, insípida, incolor e inodora (Schrieber \& Gareis, 2007), que comercialmente é obtida de ossos, peles, chifres, tecidos conectivos de bovinos ou suínos. A gelatina tipo "A" é produzida pelo tratamento ácido da matéria-prima; o tipo "B", utilizado no presente trabalho, é produzido pelo processo alcalino (Rose, 1985; Keenan, 1998; Chaplin, 2007; Park et al., 2008).

Como toda proteína, a gelatina é um copolímero formado por aproximadamente 20 aminoácidos. Em virtude dessa diversidade molecular, as proteínas apresentam considerável potencial para a formação de diferentes ligações químicas, dependendo da posição, natureza e energia aplicada. A gelatina é rica em resíduos de glicina (quase 1 em 3 resíduos), prolina e de 4-hidroxiprolina (Ross, 1987; Lazarev et al., 1992; Veis, 1964) mas, nutricionalmente, é deficiente em isoleucina, metionina, treonina e triptofano. A deficiência desses aminoácidos pode ocasionar um desequilíbrio das funções no 
organismo humano (Fennema, 2010). A estrutura típica é: -Ala-Gly-Pro-Arg-Gly-Glu-4Hyp-Gly-Pro- (Chaplin, 2007), como é mostrado na FIG. 1.<smiles>CC(C)NC(=O)NCC(=O)N1CCCC1C(=O)NCCCCNC(N)(N)NC(=O)C(=O)NCC(=O)NCCCC(=O)NCC(=O)N1CC(O)CC1C(=O)NC=CC(=O)[O-]</smiles>

FIGURA 1 - Estrutura química da gelatina.

Uma longa história de uso seguro da gelatina em produtos farmacêuticos e cosméticos, bem como em produtos alimentícios, foi desenvolvida. Ela é considerada um material "Generally Recognized As Safe" (GRAS) pelo órgão do governo americano Food and Drug Administration (FDA) (Veis, 1964; FDA, 1975).

A gelatina é solúvel em água quente, glicerol e ácido acético, insolúvel em solventes orgânicos e incompatível com tanino e formaldeído (Windholz et al., 1983).

As propriedades da gelatina são determinadas por sua estrutura, as quais dependem não apenas da sequência de proteínas, mas também do conteúdo relativo aos vários componentes interruptos de colágeno e seu estado de agregação (Yang et al., 2007). A conversão do colágeno em gelatina por desnaturação térmica ocasiona apenas o rompimento das ligações não covalentes, tais como pontes de hidrogênio, ligações coulômbicas ou hidrofóbicas e forças de Van der Waals (Rose, 1985).

A gelatina apresenta, basicamente, as mesmas propriedades comuns típicas de substâncias poliméricas, que não é o caso do colágeno nativo. Assim, em um sistema análogo ao dos polímeros sintéticos de cadeia não ramificada, as 
macromoléculas da gelatina assumem, em soluções aquosas e temperaturas elevadas, a conformação de uma bobina (Veis, 1964).

Macromoléculas ou biopolímeros quando em suspensão aquosa formam coloides de maior ou menor fluidez dependendo da concentração da macromolécula bem como de sua natureza. Esses coloides, tanto nas células vivas como nos alimentos, podem se transformar em géis de maior rigidez e de grande importância para as propriedades funcionais desses sistemas. A formação de gel ocorre em diferentes concentrações para diferentes proteínas. A gelatina forma gel em água a uma concentração de 1\%. Muitos géis quando submetidos a um repouso prolongado manifestam perda de solvente e contração, processo conhecido como sinerese (Veis, 1964; Rose, 1985).

A gelificação é uma propriedade funcional muito importante na preparação de inúmeros alimentos que é utilizada não apenas para formar géis sólidos viscoelásticos, mas também para melhorar a absorção de água, de efeitos espessantes, de fixação de partículas, além de estabilizar emulsões e espumas (Araújo, 2006).

Pode ser considerada como a principal propriedade da gelatina, a sua capacidade de formar géis termorreversíveis em soluções aquosas durante o resfriamento em temperatura de $40^{\circ} \mathrm{C}$ (Rose, 1985; Ross-Murphy, 1992), porém essa propriedade se perde com a fervura contínua. Quando a solução aquosa de gelatina é resfriada, as regiões ricas em determinados aminoácidos proporcionam zonas de união para o estabelecimento de uma rede tridimensional do gel (Wong, 1995; Giraudier et al., 2004). Formação de hidrogel, acompanhado por um rearranjo desordem-ordem em que as cadeias de gelatina recuperam parcialmente a estrutura de tripla hélice do colágeno, leva à formação de gelatina renaturada com as principais regiões amorfas de cadeias de gelatina aleatoriamente enroladas interligadas com domínios de microcristalitos espacialmente ordenados, estabilizados por meio de pontes de hidrogênio entre $\mathrm{N}-\mathrm{H}$ das glicinas (Gly) e $\mathrm{C}=\mathrm{O}$ das prolinas (Pro) (Gorgieva \& Kokol, 2011).

A diversidade estrutural das unidades da cadeia de gelatina determina as características específicas de suas propriedades em contraponto aos polímeros sintéticos (Kozlov \& Burdygina, 1983).

Uma das peculiaridades da gelatina comum, se comparada a todos os outros biopolímeros, é sua propriedade anfotérica, que provem da presença de 
ambos os grupos funcionais dos aminoácidos, dos grupos terminais amino e carboxila da macromolécula da gelatina. Outra particularidade é a sua capacidade para formar uma estrutura helicoidal de cadeia tripla específica não observada em polímeros sintéticos; esta estrutura é formada em soluções a baixa temperatura (Kozlov \& Burdygina, 1983). A taxa de formação de uma estrutura helicoidal depende de muitos fatores, tais como a presença de ligações covalentes nas regiões reticuladas (Veis, 1964; Courts \& Stainsby, 1958), o peso molecular da gelatina, a presença de grupos amino secundários contidos na Pro (Harrington \& Hippel, 1961) e a concentração de gelatina na solução (Boedtker \& Doty, 1954). Uma terceira particularidade da gelatina é a interação específica proteína-água, diferente do observado em polímeros hidrofílicos sintéticos. Essas peculiaridades regulam as propriedades estruturais e físico-mecânicas da gelatina no estado sólido (Kozlov \& Burdygina, 1983).

A gelatina tem a habilidade de estabilizar coloides, fato exemplificado pelo seu alto número de Zygmondy (medição da estabilidade de soluções coloidais de ouro), que é o maior apresentado entre os biopolímeros. As longas cadeias de gelatina possuem sítios de adsorção anfifílicos e anfolíticos (Rose, 1985).

\subsection{Importância dos biomateriais}

Diversos autores estudaram a fabricação e caracterização de filmes de gelatina com o intuito de melhorar suas propriedades mecânicas, adicionando aditivos apropriados (Jongjareonrak et al., 2008; Mendieta-Taboada et al., 2008; Diop, 2009). Gioffre et al. (2012) determinaram a importância do pH na estabilidade de filmes de gelatina. Este mesmo grupo (Bigi et al., 1998) tinha obtido um material anisotrópico utilizando filmes de gelatina reticulado com glutaraldeído, levando à melhoria das propriedades mecânicas no sentido da deformação e à aplicação de forma útil na preparação de biomateriais.

Os filmes de gelatina geralmente têm boas propriedades de barreira ao oxigênio (Scherzer, 1997; Park et al., 2008). No entanto, a barreira à umidade e propriedades mecânicas que apresentam limitam suas aplicações. Essas questões representam um desafio para o desenvolvimento de novos materiais com propriedades adequadas às aplicações requeridas (Gómez-Guillén et al., 2011; Krochta \& De Mulder-Johnston, 1997). Filmes a base gelatina são 
altamente susceptíveis a absorção de água à temperatura ambiente e em condições relativas de umidade devido à natureza hidrofílica da gelatina. Assim, um aumento da temperatura ambiente e/ou da umidade relativa podem reduzir a resistência mecânica e aumentar a extensibilidade do material, por exemplo. Esse comportamento mostra a complexidade de aplicações em embalagens de alimentos. Várias alternativas têm sido estudadas para minimizar este problema, tais como modificações químicas ou enzimáticas da gelatina, a utilização de misturas de plastificantes ou plastificantes diferentes com diferente hidrofobicidade e a incorporação de lipídeos, entre outros. No entanto, estes resultados não têm sido satisfatórios. Por outro lado, o uso de radiação ionizante parece ser uma das ferramentas mais promissoras nesta questão (Inamura et al., 2009). A gelatina mostrou-se melhor barreira à água do que o colágeno, mas o colágeno encontrou sucesso comercial como uma proteína de revestimento por ser uma barreira excelente ao oxigênio, embora não seja uma boa barreira à umidade (Gennadios et al., 1994; Sobral et al., 2001; Thomazine et al., 2005).

Os materiais compósitos reforçados com fibras naturais têm sido 0 objeto de muitos trabalhos, seja por interesses técnicos, econômicos ou ambientais (Satyanarayana et al., 2009). O uso de fibras naturais como reforço em materiais compósitos é uma das alternativas, além do uso de fibra de vidro, nanoargilas e fibras de carbono (Ramesh et al., 2013; Zahedi et al., 2013; Dong et al., 2014). Mas, a vantagem do uso de materiais de fontes renováveis na matriz polimérica é que é possível reduzir o uso de polímeros de origem sintética (Paukszta \& Borysiak, 2013).

As fibras lignocelulósicas, além de ser biodegradáveis, são leves, de baixo custo, amigáveis ao meio ambiente e apresentam boas propriedades mecânicas (Dintcheva et al., 1997; Joshi et al., 2004; Bonelli et al., 2005; Guimarães et al., 2006; Monteiro et al., 2006; Choi et al., 2008; Żenkiewicz \& Kurcok, 2008; Ramesh et al., 2013; Santulli et al., 2013).

As fibras vegetais têm celulose em sua composição, ao passo que as fibras de origem animal, consistem basicamente de proteínas (Saheb \& Jog, 1999, Askarieh et al., 2010).

Uma grande variedade de plantas de biodiversidade brasileira oferecem propriedades desejáveis, como resistência mecânica, estabilidade química e biológica, resistência à chama, leveza, resistência à abrasão e ao 
cisalhamento, despertam grande interesse no desenvolvimento de novos compósitos poliméricos com fibras vegetais naturais (John, 1996; Marinelli et al., 2008). Os compostos lignocelulósicos podem ser constituídos e produzidos pela combinação de um ou mais materiais lignocelulósicos, tais como madeira, bambu, resíduos agrícolas, e outras substâncias de plantas, unidas por um agente de ligação (Zhou et al., 2013).

A castanheira do Brasil (Bertholletia excelsa Humb. \& Bonpl. Lecythidaceae) pode ser encontrada em matas da região amazônica continental, com destaque para o Brasil, e abrangendo também partes da Bolívia e Peru (Amazonas, 2005). A castanha do Brasil, também conhecida como castanha do Pará ou castanha da Amazônia, é comercialmente conhecida pelas nozes comestíveis, um produto muito apreciado, que são colhidas da floresta ainda intacta (Souza \& Menezes, 2004; Souza \& Menezes, 2008; Felberg et al., 2009). A castanha do Brasil é formada dentro de um ouriço espesso do fruto, que pode conter entre 14 e 24 sementes dentro (FIG. 2).

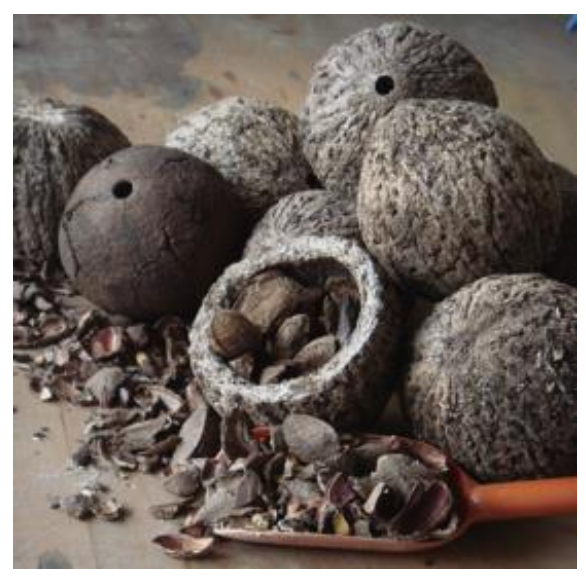

FIGURA 2 - Ouriço e casca da castanha do Brasil (Bertholletia excelsa Humb. \& Bonpl. Lecythidaceae)

Apesar do contínuo crescimento do mercado de nozes da castanha do Brasil, os resíduos da fibra da casca não tem qualquer aplicação. A busca por tecnologias alternativas que tornem possível a utilização dos subprodutos do beneficiamento da castanha do Brasil com o objetivo de desenvolver novos 
produtos com alto valor agregado é crucial. Componentes orgânicos primários de qualquer casca são constituídos por celulose, hemicelulose e lignina. Esse tipo de material pode ser usado como reforço para melhorar as propriedades mecânicas de polímeros (Aquino et al., 2000; Boneli et al., 2003; Ramires et al., 2013).

\subsection{Modificação de polímeros por ação da radiação ionizante}

A radiação ionizante interage com a matéria induzindo a formação de radicais livres que reagem quimicamente com diferentes velocidades de reação. Os radicais livres se recombinam formando retículos. O grau de reticulação vai depender do tipo de polímero e da dose de radiação. Um dos benefícios do uso da radiação para induzir reticulação é que o processo pode ser facilmente controlado pela dose aplicada. Outras influências incluem o uso de aditivos e o tipo de radiação empregado (Farhataziz \& Rodgers, 1987).

A melhoria das propriedades dos materiais induzidos por radiação ionizante é atribuída a processos de reticulação e de cisão envolvendo os radicais formados aleatoriamente ao longo das cadeias poliméricas. $O$ processo de reticulação geralmente traz uma melhoria das propriedades mecânicas, resistência química, estabilidade térmica e outras propriedades importantes (Dorschner et al., 1998; Khan et al., 1999; Machi, 1996; Rouif, 2005; Nagasawa et al., 2005; Jo et al., 2005; Ciesla et al., 2006; Choi et al., 2008). Assim, muitas pesquisas estão sendo realizadas para o desenvolvimento de compósitos de polímeros sintéticos e naturais reforçados com fibras vegetais utilizando a radiação ionizante (Czvikovszky, 1996; Tsang et al., 2000; Mortain et al., 2004; Behr et al., 2006; Khan et al., 2008).

As aplicações emergentes como a modificação de polímeros naturais pelo processamento por radiação para a obtenção de propriedades específicas suscitam considerável interesse. Já foi mostrado que o processamento de polímeros naturais por radiação é uma técnica simples, eficaz e comercialmente atraente (Haji-Saeid et al., 2007). Além disso, a tecnologia da radiação é baseada na utilização de radiação gama, feixe de elétrons e íons, que pode ser utilizada efetivamente na síntese de vários biomateriais, bem como para a esterilização (Tabata et al., 1995). Desse modo, diversas pesquisas bem sucedida têm promovido o desenvolvimento comercial nas áreas da saúde, agricultura e meio 
ambiente (Clough, 2001; Chmielewski \& Haji-Saeid, 2005; Raafat et al., 2012; Tissot et al., 2013).

A vantagem da utilização de raios-y ou feixes de elétrons em relação aos métodos convencionais de preparação de biomateriais está em sua capacidade de modificar macromoléculas, sem a adição de qualquer aditivo químico e também na possibilidade de limitar o tratamento de uma área geométrica bem definida (da superfície) do objeto. Assim, a síntese de hidrogéis reticulado por radiação e a enxertia em vários substratos estão entre as possibilidades dessa metodologia (Chapiro, 1995; Rosiak et al., 1995). Além disso, o processamento por radiação é um processo comercialmente viável que pode ser parte integrante da linha de produção de materiais hospitalares (Burns et al., 1996), curativos de hidrogéis (Ajji et al., 2005), fios e cabos resistentes à chama (Tabata, 1979), filmes termoencolhíveis para embalagens, luvas (Ratnam \& Zaman, 1998), materiais compósitos (Czvikovszky, 1985; Jipa et al., 2012), produtos moldados, entre outros (Dahlan, 2004).

Cao et al. (2007) estudaram a adição de agentes químicos de reticulação para a melhoria de propriedades mecânicas de filmes de gelatina. Por outro lado, Ressouany et al. (1998) utilizaram a radiação gama para indução da reticulação entre cadeias de proteínas e obtiveram resultados semelhantes.

Zaman et al. (2012) estudaram as propriedades termomecânicas de filmes de gelatina contendo 2-hidroximetil meta acrilato. Esse mesmo grupo (Zaman et al., 2013) comparou o efeito da radiação gama e ultravioleta em filmes de gelatina contendo 2-etil acrilato e mostrou que aqueles expostos à radiação ionizante apresentaram melhoria pronunciada nas propriedades mecânicas e na biodegradação.

O uso da radiação ionizante, ao eliminar a utilização de agentes químicos, torna o sistema livre de impurezas e resíduos potencialmente tóxicos (Ratnam et al., 2007), sendo esta uma vantagem crítica para aplicações biomédicas e na indústria de alimentos. Para muitos materiais tratados por processos de irradiação, a melhoria das propriedades é superior àquela obtida por processos convencionais (Khan et al., 2008).

A variação da viscosidade da gelatina com uso da radiação ionizante foi estudada por Vieira \& Mastro (2002). Estudos realizados por Kojima et al. (2004) utilizando doses entre 15 e 60 kGy mostraram que parte da 
gelatina irradiada dissolveu após a incubação a $40{ }^{\circ} \mathrm{C}$ por 20 minutos. Esses resultados mostraram que o hidrogel irradiado manteve um estado de gel mesmo em temperatura corporal, a qual é superior à temperatura de transição sol-gel da gelatina. Foi relatada também uma melhoria da propriedade de dureza do gel de gelatina com 0 aumento da dose de irradiação. Essas alterações nas propriedades podem ser atribuídas à reticulação das moléculas de gelatina.

A indústria de embalagens de alimentos tem um interesse particular no uso de compostos que sejam inicialmente biodegradáveis e biocompatíveis com os mais diversos tipos de produtos alimentícios (Qiu et al., 2004; Gómez-Guillén et al., 2011). Além disso, a reticulação induzida por irradiação de feixe de elétrons está se tornando aceitável para o uso em embalagens comestíveis (Al-Assaf et al., 2007).

\subsection{Hidrogéis poliméricos e suas aplicações}

Os hidrogéis podem ser definidos como polímeros de redes tridimensionais compostos por cadeias macromoleculares hidrofílicas reticuladas, que possuem um alto poder de absorção de líquido sem dissolver ou perder a sua integridade estrutural (Rosiak et al., 1995; Byrne \& Salian, 2008). Eles são considerados altamente promissores para o desenvolvimento de novos materiais (Pal et al., 2007).

O uso de hidrogéis em aplicação tópica como curativos foi desenvolvido pela técnica de radiação por Rosiak (1991). Os hidrogéis também podem ser utilizados na forma de pulverizações, emulsões, pomadas e cremes, com ou sem a adição de compostos ativos. Além disso, eles podem ser aplicados na área médica em sistema de liberação controlada de drogas, implantes, sistemas injetáveis e outros (Rosiak et al., 1995).

Os hidrogéis preparados com base em polímeros naturais, tais como gelatina, celulose e quitosana possuem diversas aplicações em biomateriais devido à sua natureza hidrofílica reticulada a cadeias macromoleculares por pontes de hidrogênio, interação de van der Waals, interações hidrofóbicas, cadeias reticuladas ou complexação iônica (Peppas et al., 2006; Tanaka et al., 2005), e ao seu alto teor de água, que é semelhante ao de uma variedade de tecidos vivos naturais (Dragan et al., 2012; Cui et al., 2014). 
Os hidrogéis de gelatina são facilmente formados e podem incorporar diversos outros compostos químicos. Dependendo do tamanho das cadeias de gelatina, a interação se faz via ligações covalentes entre os ligantes e amino grupos da proteína (Coradin et al., 2004). Esses géis podem ser modificados por agentes de reticulação, os quais melhoram a estabilidade térmica e propriedades mecânicas. Tabata \& Ikada (1998) desenvolveram hidrogéis de gelatina reticulados com glutaraldeído para sistemas de liberação controlada de drogas. Porém, eles notaram que os hidrogéis obtidos com glutaraldeído não são adequados para todos os medicamentos, pois apresentaram uma toxicidade $\mathrm{e}$ oncogenicidade significativa (Ballantyne \& Jordan, 2001). Portanto, é desejável desenvolver processos de produção de hidrogéis de gelatina por um método livre de reagentes (Terao et al., 2003).

A síntese de nanogéis de gelatina induzida por radiação em solução aquosa diluída gera espécies intermediárias nas cadeias poliméricas, pelo efeito indireto da radiação absorvida pela água, tais como elétrons hidratados $\left(\mathrm{e}_{\mathrm{aq}}^{-}\right)$, radicais hidroxila $\left({ }^{\circ} \mathrm{OH}\right)$ e os átomos de hidrogênio $(\mathrm{H})$. $\mathrm{O}$ radical ${ }^{\bullet} \mathrm{OH}$ abstrai um átomo de $\mathrm{H}$ a partir da cadeia de polímero, produzindo radicais livres de carbono ao longo da cadeia. Estes podem então recombinar-se gerando reticulação inter ou intramolecular (Al-Sheikhly, 2010). A reticulação intermolecular resulta na formação de espécies de alta massa molar, mas que não contribui para uma estrutura de ligação tridimensional 3D, enquanto a reticulação intramolecular (ciclização) induz à rede de estruturas 3D, mas sem aumento da massa molar (Poly et al., 2008). Dependendo da morfologia de superfície do nano-hidrogel, temperatura, taxa de repetição pulsada e da dose de irradiação, pode ser induzida uma maior ou menor reticulação intramolecular (Al-Sheikhly, 2010).

O processo de reticulação pode ser resumido da seguinte forma: (i) existem dois tipos de processos de reticulação: intermolecular e intramolecular; (ii) a primeira permite o aumento do peso molecular de um polímero reticulado pelo acoplamento de dois ou mais radicais do polímero; (iii) $\mathrm{O}$ último não altera massa molecular, mas afeta as quantidades relativas à dimensão da cadeia polimérica, por exemplo raio hidrodinâmico $\left(R_{h}\right)$, porque a reação de acoplamento deve ocorrer dentro da mesma cadeia polimérica (von Sonntag, 1995a; von Sonntag et al., 1995b; Ulański et al., 1994). Assim, a irradiação com raios-y 
ou feixe de elétrons de soluções diluídas de polímeros forma hidrogéis sem adição de agentes químicos de reticulação.

Rosiak et al. (1995) estabeleceram que se o polímero é irradiado em solução, só uma pequena fração da energia é absorvida pelo polímero, sendo que a maioria dos processos que ocorrem são ocasionados pela radiólise da água. Nas condições de soluções diluídas, as moléculas podem se movimentar livremente e mudar sua posição, sendo também simples a remoção de oxigênio pela saturação da solução com gases inertes ou nitrogênio. Segundo von Sonntag (1995a), pela saturação da solução com $\mathrm{N}_{2} \mathrm{O}$ (solubilidade $10^{-2} \mathrm{~mol} \mathrm{~L}^{-1}$ a $20^{\circ} \mathrm{C}$ ) o elétron solvatado será convertido no radical ${ }^{\bullet} \mathrm{OH}$ (reação 3.1, $\left.\mathrm{k}=9,1 \times 10^{9} \mathrm{~L} \mathrm{~mol}^{-1} \mathrm{~s}^{-1}\right)$, resultando em uma fonte de radicais ${ }^{\bullet} \mathrm{OH}\left(90 \%{ }^{\bullet} \mathrm{OH}\right.$, $10 \% \cdot \mathrm{H})$.

$$
e_{a q}^{-}+\mathrm{N}_{2} \mathrm{O} \rightarrow \bullet \mathrm{OH}+\mathrm{OH}^{-}+\mathrm{N}_{2}
$$

\subsection{Plastificantes e aditivos utilizados nos filmes a base de gelatina}

Para diminuir a fragilidade de filmes a base de gelatina é necessária a adição de plastificante na preparação, que atua reduzindo as forças intermoleculares e promovendo um aumento da mobilidade das cadeias poliméricas constitutivas, melhorando a flexibilidade, resistência e estabilidade do produto (Arvanitoyannis et al., 1997; Garcia et al., 2000a; Park et al., 2008; Liang et al., 2009; Ortiz-Zarama et al., 2014).

\subsubsection{Glicerol}

O glicerol (GLY), quimicamente o 1,2,3-propanotriol, conhecido também como glicerina, é um dos compostos químicos mais versáteis e valiosos conhecidos pelo homem (Pagliaro \& Rossi, 2008); e talvez o mais utilizado como plastificante de proteína (Ortiz-Zarama et al., 2014). Ele é incolor, atóxico, um líquido viscoso e higroscópico, solúvel em água (Beatriz et al., 2011) e insolúvel em éter e clorofórmio. Os grupos hidroxilas presentes na estrutura do glicerol são responsáveis pela solubilidade em água e sua natureza higroscópica (Beatriz et al., 2011). O glicerol, que pode ser usado como emoliente, umectante, 
espessante, agente de corpo, solvente, plastificante (FAO, 1976), está presente na natureza em vegetais e em animais combinados aos ácidos graxos. Suas características físico-químicas e inocuidade oferecem ao glicerol diferentes aplicações na indústria farmacêutica, na produção de cosméticos, detergentes, resinas, aditivos e na indústria alimentícia (Sanchéz et al., 1998; Rivaldi et al., 2007).

\subsection{2 Álcool polivinílico}

O álcool polivinílico (PVA), cuja fórmula é $\left[-\mathrm{CH}_{2} \mathrm{CHOH}-\right] n$, é um polímero sintético biodegradável, solúvel em água (Finch, 1992), com alta estabilidade química, preparado, diferentemente de outros polímeros vinílicos, não a partir do correspondente monômero, mas pela hidrólise do polivinil acetato (Tokiwa et al., 2001; FAO, 2004). É um polímero com habilidade de formar filmes e cujas propriedades são influenciadas por seu peso molecular e grau de hidrólise. Por apresentar alta hidrofilicidade, o PVA exibe boas propriedades de retenção de água (Pal et al., 2006); pode ser usado em um amplo escopo de aplicações comerciais, industriais, médicas e alimentares. O PVA é o único polímero de cadeia carbônica que é biodegradável sob condições aeróbicas (Suzuki et al., 1973) e anaeróbicas (Matsumura et al., 1993). Ele também tem sido muito empregado como base de polímero biodegradável solúvel em água, assim como no segmento biodegradável da cadeia polimérica (Matsumura et al., 1999), em açúcar e polímeros ramificados de ácidos graxos (Tokiwa et al., 2000).

$\mathrm{Na}$ área industrial, pode ser usado como adesivo e agente de gomagem em produtos têxteis (Tokiwa et al., 2001); também tem sido utilizado para a imobilização de células (Pattanapipitpaisal et al., 2001); na área farmacêutica, o PVA pode ser utilizado como agente de revestimento de produtos farmacêuticos e suplementos dietéticos (DeMerlis \& Schoneker, 2003); na área biomédica, como hidrogéis com boa biocompatibilidade, pele artificial, membranas de hemodiálise, sistemas de liberação controladas de drogas (Wang et al., 1997); na área alimentícia, como filme de barreira à umidade para comprimidos de suplementos alimentares ou alimentos secos que necessitam de proteção contra a absorção de umidade (FAO, 2004).

O comitê conjunto da Organização das Nações Unidas para a Alimentação e Agricultura e a Organização Mundial da Saúde sobre aditivos 
- Joint FAO/WHO Expert Committee on Food Additives (JECFA) - concluiu em sua avaliação que o PVA, quando administrado por via oral, é relativamente inofensivo, pois é muito pouco absorvido por essa via: possui a toxicidade oral aguda muito baixa, não se acumula no organismo, não é mutagênico ou clastogênico e, por uma visão geral, os resultados foram consistentes com sua toxicidade muito baixa e não mostraram nenhuma evidência de carcinogenicidade (WHO, 2004). Assim, o PVA foi incluído no guia de ingredientes inativos do FDA para uso em alimentos e comprimidos orais, notificado como um aditivo GRAS (FDA, 2003), e avaliado quanto à sua utilização na alimentação humana pelo JECFA, conforme descrito acima em 2003.

\subsubsection{Hidroxitolueno butilado}

Hidroxitolueno butilado (BHT) é um composto químico insolúvel em água, branco, inodoro, sólido cristalino e apresenta-se em flocos. É muito utilizado na indústria de alimentos como antioxidante ( $F A O, 1990)$ em óleos e gorduras vegetais e animais, produtos cárneos processados, entre outros (GSFA, 2013). Seu uso é permitido, segundo a legislação, em nível máximo de $200 \mathrm{mg} \mathrm{kg}^{-1}$ de BHT para produtos acabados (GSFA, 2013).

\subsubsection{Acrilamida}

A acrilamida é um importante produto químico industrial que tem sido usado desde meados dos anos 1950 como um intermediário químico na produção de poliacrilamidas, que são usados como floculantes para clarificar água potável, espessantes solúveis em água e em outras aplicações industriais (IFST, 2012). É possível desenvolver filmes ou hidrogéis com o uso da poliacrilamida, um polímero sintético, em diferentes proporções induzidos por irradiação (Bardajee et al., 2008). Está estabelecido que a acrilamida apresenta neurotoxicidade em humanos, como revelado por consequências ocupacionais e exposições acidentais. Estudos toxicológicos mostraram que os efeitos tóxicos agudos via dose oral foram observados em doses de até $100 \mathrm{mg} \mathrm{kg}^{-1}$ de peso corporal e foram reportados doses letais média $\left(L_{50} \mathrm{~S}\right)$ geralmente acima de $150 \mathrm{mg} \mathrm{kg}^{-1}$ de peso corporal (Dearfield et al., 1995; Doerge et al., 2008). 


\subsubsection{Polietileno glicol}

Polietileno glicol (PEG), um polímero cuja estrutura básica é $\mathrm{HO}-\left(\mathrm{CH}_{2} \mathrm{CH}_{2} \mathrm{O}\right)_{n}-\mathrm{H}$, é solúvel em água e na maioria dos solventes orgânicos. O PEG é um composto químico de importância significativa para as áreas biomédicas e de biomateriais (Kong et al., 2011), pois é biocompatível e de toxicidade muito baixa. Sendo uma substância atóxica (apresenta absorção sistêmica inferior a 0,5\%), hidrofílica e biocompatível, é aprovada pelo Food and Drug Administration (FDA) para o uso como excipiente ou como um veículo em diferentes formulações farmacêuticas, para alimentos e cosméticos (Fuertges \& Abuchowski, 1990). Por isso, é utilizado amplamente como aditivo (agente emulsificante, umectante, lubrificante, plastificante e detergente) em diversos setores (alimentício, farmacêutico, médico, odontológico, cosmético, têxtil, industrial), como citado anteriormente.

Além disso, o PEG é um biopolímero muito utilizado na síntese de hidrogéis (Sirpal et al., 2007); não prejudica proteínas ativas ou células embora interaja com as células da membrana. O PEG está sujeito à modificação química imediata e ligação a outras moléculas e superfícies, mas quando ligado a outras moléculas, o efeito causado sobre a química dessa molécula é irrelevante, porém controla sua solubilidade e pode aumentar sua dimensão (Harris, 1992).

Os sítios reativos mais comuns em polipeptídeos para ligar aos polímeros de PEG são os amino grupos de lisina ou os grupos de aminoácidos $\mathrm{N}$-terminais de outros aminoácidos (Zalipsky \& Lee, 1992).

A modificação de proteínas com PEG confere uma série de características únicas e vantajosas. Elas incluem o aumento da vida em circulação, diminuição da imunogenicidade e/ou antigenicidade, aumento da resistência à proteólise, maior solubilidade e estabilidade (Abuchowski \& Davis, 1981). Destas propriedades, a redução da imunogenicidade e aumento da vida em circulação têm o maior impacto clínico (Fuertges \& Abuchowski, 1990).

Abuchowski (1975) observou que a ligação covalente de PEG às proteínas origina conjugados ativos que são não imunogênicos e não antigênicos e aumentaram significativamente a vida útil do soro. Nagaoka et al. (1984) constataram que a ligação covalente de PEG às superfícies retardam significativamente a adsorção de proteína a estas superfícies. 
Os grupos hidroxila terminais da molécula de PEG fornecem um sítio de ligação covalente pronto às outras moléculas ou superfícies. As moléculas as quais o PEG é ligado, geralmente, permanecem ativas mostrando que PEG ligado não desnatura proteínas nem impede a aproximação de outras moléculas de dimensões menores (Harris, 1992).

\subsection{Interação da radiação com a matéria}

Nesta seção, os princípios básicos da química e também da física das radiações são apresentados e adaptados para explicar o sistema experimental investigado neste trabalho, incluindo as características de diferentes tipos de fontes de radiação ionizante e reações de radicais livres induzidos pela radiação ionizante. Radiação gama de cobalto-60 ( $\left.{ }^{60} \mathrm{Co}\right)$ e aceleradores de elétrons são frequentemente usados como fontes de radiação ionizante.

A energia depositada em um meio homogêneo complexo é proporcional à fração de elétrons de cada componente. As proporções relativas aos produtos químicos induzidos por radiação ionizante podem variar de acordo com a transferência linear de energia (TLE) e a composição do meio absorvido. A TLE $\left(k e V \mu \mathrm{m}^{-1}\right)$ está associada à natureza e a energia da radiação incidente e pode ser definida como a taxa linear de perda de energia das partículas ionizantes (carregadas), que estão presentes nos raios da radiação ou surgem a partir deles, enquanto atravessa um meio. A radiação de baixa TLE gera íons (ânions, íons positivos, elétrons secundários) e espécies eletronicamente excitadas na forma de pequenos aglomerados (spurs). Essas espécies reativas podem induzir as alterações químicas de um material. Conforme a energia é transferida das partículas carregadas para matéria, as partículas perdem energia cinética e deixam um rastro de espécies ionizadas e excitadas em seu caminho. Os elétrons de alta energia percorrem o meio aquoso e perdem discretamente cerca de $100 \mathrm{eV}$ para produzir espécies ionizadas primárias da interação, especialmente radicais hidroxilas e elétrons hidratados (Spinks \& Woods, 1990; Woods \& Pikaev, 1994). O volume de material no qual a energia é depositada em cada etapa é conhecido como "spur". Na água, o raio médio do spur é de cerca de $1 \mathrm{~nm}$ e a separação média entre os sucessivos spurs é de aproximadamente 200 nm (Spinks \& Woods, 1990; Chatterjee, 1987). 
As espécies químicas primárias são geradas após a deposição física de energia em menos de $10^{-12} \mathrm{~s}$.

$A$ radiação de baixa TLE (tal como elétrons de alta energia ou raios $\mathrm{Y}$ ) induz espécies ionizadas e excitadas mais amplamente separadas no spurs, ao passo que a radiação de alta TLE, tal como partículas pesadas carregadas (por exemplo partículas $\alpha$ ), produz um rastro de partículas, que é densamente preenchido por spurs. Fótons gama do ${ }^{60} \mathrm{Co}$ e elétrons de alta energia dos aceleradores de elétrons produzem elétrons secundários quando interagem com a matéria. A TLE de 1,25 MeV dos fótons gama e de $7 \mathrm{MeV}$ dos elétrons são aproximadamente $0,2 \mathrm{eV} \mathrm{nm}^{-1} \mathrm{em}$ meio aquoso (Henglein et al., 1969).

\subsubsection{Raios gama}

A radiação gama é uma forma de radiação eletromagnética produzida pelo decaimento radioativo com energias na ordem de keV a MeV. O radioisótopo ${ }^{60} \mathrm{Co}\left(\mathrm{T}^{1} 1 / 2: 5,263\right.$ anos; $\beta$ : 0,314 MeV; $\gamma: 1,173$ e 1,332 MeV) por decaimento beta transforma-se em níquel-60 ( $\left({ }^{60} \mathrm{Ni}\right)$. Em seguida, ele decai ao seu estado fundamental pela emissão de raios gama (Woods \& Pikaev, 1994).

O conceito de dose de radiação é dado pela quantidade de energia absorvida pelo material quando passa através do campo de radiação durante 0 processamento. Pode ser medida utilizando-se uma unidade chamada de "Gray" (Gy). Em trabalhos antigos, a unidade utilizada era o rad (1 Gy = 100 rads, 1 kGy = 1000 Gy). Em termos de relações de energia, um Gy é igual a um joule de energia absorvida por kg de material sendo irradiado.

Os principais mecanismos de interação da radiação de raios gama incluem o efeito fotoelétrico, espalhamento Compton e a produção de pares. Nesse experimento, a energia (média) dos raios gama de ${ }^{60} \mathrm{Co}$ de 1,25 MeV perdeu a maior parte de sua energia por meio do espalhamento Compton. O espalhamento Compton é uma interação elástica em que um fóton incidente transfere energia suficiente para ejetar um elétron livre ou fracamente ligado de dentro do material, de forma que o elétron é acelerado e o fóton sofre deflexão de direção incidente com energia reduzida (Spinks \& Wood, 1990). A probabilidade de espalhamento Compton diminui conforme ocorre um aumento da energia do fóton. Um diagrama esquemático de espalhamento Compton é mostrado na FIG.3 e a equação descritiva correspondente é dada pela 
equação (3.2) (Spinks \& Wood, 1990). A excitação e ionização geradas pelo espalhamento de fótons tornam-se insignificantes após várias interações, ao passo que os elétrons produzidos pelo espalhamento Compton possuem energia mais elevada e contribuem mais para as alterações químicas que eventualmente ocorrem no material. Alguns elétrons Compton podem produzir eventos ionizantes na ordem de dez mil, enquanto que um único fóton gama de 1,25 MeV pode apenas produzir vários eventos de ionização antes que ele desapareça.

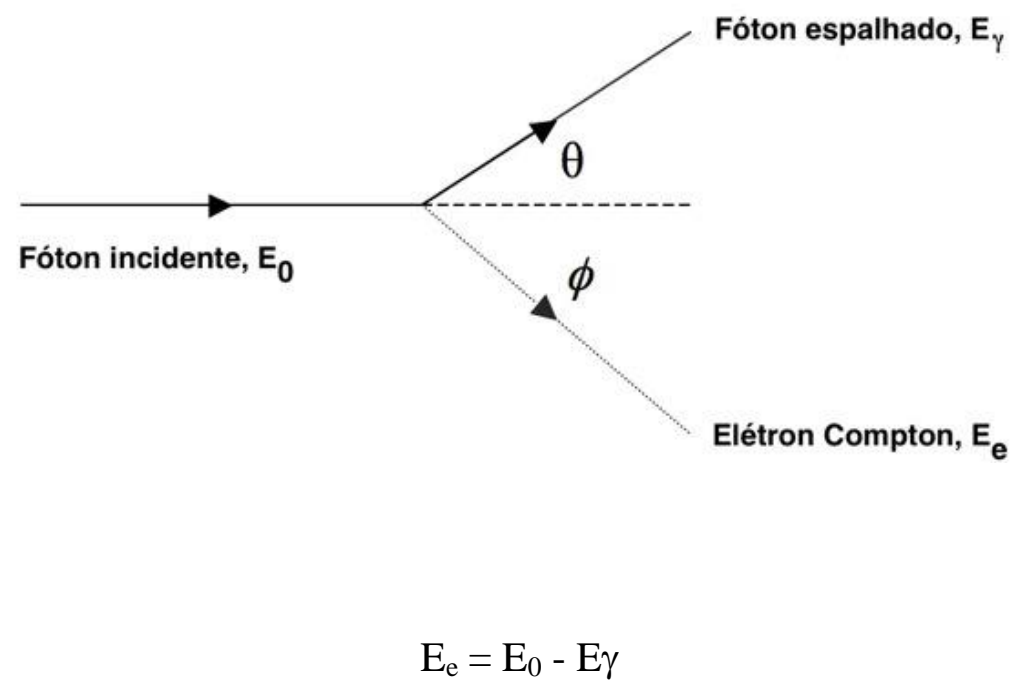

FIGURA 3 - Espalhamento Compton (Spinks \& Woods, 1990); A energia e o momento do fóton incidente são divididos entre 0 fóton espalhado e o elétron de recuo.

$$
\frac{E_{\gamma}}{E_{0}} \cong \frac{1}{1-2 E(1-\cos \theta)}
$$

\subsubsection{Feixe de elétrons}

A radiação ionizante por feixe de elétrons envolve a interação de elétrons com a matéria por diversos processos, incluindo a emissão de radiação ionizante, colisões elásticas e inelásticas. O tipo de interação é determinado principalmente pela energia dos elétrons incidentes. Os elétrons produzidos pelo 
acelerador linear de elétrons da University of Maryland, College Park (LINAC UMCP) têm energia de $7 \mathrm{MeV}$ que se perde predominantemente por meio de colisões inelásticas. Conforme os elétrons primários são desacelerados, uma grande quantidade de elétrons secundários, terciários e elétrons consecutivos são produzidos. A perda de energia do elétron por ionização e excitação é descrito pela seguinte equação de Bethe (3.3) (Spinks \& Woods, 1990):

$$
\begin{array}{r}
-\left(\frac{d E}{d l}\right)_{c o l}=\frac{2 \pi N e^{4} Z}{m_{e} v^{2}}\left[\ln \frac{m_{e} v^{2} E}{2 I^{2}\left(1-\beta^{2}\right)}-\left(2 \sqrt{1-\beta^{2}}-1+\beta^{2}\right) \ln 2+1-\beta^{2}+\frac{1}{8}\left(1-\sqrt{1-\beta^{2}}\right)^{2}\right] \\
\mathrm{J} \mathrm{m}^{-1}(3.3)
\end{array}
$$

Nesta equação, $(d E / d l)_{c o l}$ é a perda de energia específica ou poder de freamento $S ; N$ é o número de átomos por unidade de volume; $e$ representa a carga do elétron; $Z$ representa o número atômico do material de barreira; $m_{e}$ é a massa em repouso do elétron; $\nu$ é a velocidade dos elétrons; $\beta$ é $\nu / c$; $c$ é a velocidade da luz; e $I$ é o potencial médio de excitação para os átomos do material de barreira. $O$ poder de freamento da colisão em massa, $(S / \rho)_{c o l}$, em que $\rho$ é a densidade do material, é definido a seguir:

$$
\left(\frac{S}{\rho}\right)_{c o l}=-\left(\frac{d E}{d l}\right)_{c o l} \times \frac{1}{\rho}
$$

Para calcular o alcance máximo de penetração dos elétrons produzidos pelo LINAC UMCP, pode-se utilizar a seguinte equação empírica (Sheien et al., 1998):

$$
R=530 E-106
$$


Em que $R$ é alcance do elétron $\left(\mathrm{mg} \mathrm{cm}^{-2}\right)$ e $E$ representa a energia máxima dos elétrons (7 MeV para o UMCP LINAC). $R$ é dado como $3,6 \mathrm{~g} \mathrm{~cm}^{-2}$ para $7 \mathrm{MeV}$. Assim, sabendo a densidade da solução, pode-se calcular o alcance máximo $(\mathrm{cm})$ dos elétrons na solução.

\subsubsection{Química das radiações em sistemas aquosos}

As interações da radiação com a matéria estão distribuídas proporcionalmente à fração de elétrons de cada componente. Assim, no caso de uma solução diluída de polímero, que é de interesse no presente trabalho, espécies reativas primárias são predominantemente formadas no solvente (água) e, em seguida, são induzidos os efeitos químicos secundários em solutos em menores proporções (Spinks \& Woods, 1990).

O efeito direto predomina nos sistemas em que os radicais reativos não podem se deslocar livremente ou quando uma espécie particular compreende uma fração de maior massa da matriz total, conduzindo a uma degradação radio induzida. O efeito direto normalmente produz produtos primários, tais como elétrons de alta energia e na sequência um cátion ou interações dos elétrons de alta energia, que seriam termalizados (Spinks \& Woods, 1990).

O efeito indireto é ocasionado pela interação da radiação com as moléculas de água (radiólise), gerando radicais livres, que irão interagir com outros constituintes do material tratado com radiação (Tritsch, 2000).

A química das radiações da água e de soluções aquosas tem sido amplamente estudada por sua importância biológica. A irradiação de sistemas aquosos com raios y ou elétrons de alta energia (baixa TLE) gera os seguintes produtos primários: elétrons hidratados $\left(\mathrm{e}_{\mathrm{aq}}{ }^{-}\right)$, átomos de hidrogênio $(\mathrm{H})$ e radicais hidroxila $\left(\mathrm{HO}^{\bullet}\right)$, que reagem com o material biológico, por exemplo proteínas provocando polimerização (dimerização) e fragmentação (FIG. 4). Estas reações têm sido amplamente estudadas, especialmente aquelas que envolvem radicais livres $\mathrm{HO}^{\bullet}$, devido à sua importância em distúrbios oxidativos biológicos (Lee et al., 1996; Audette-Stuart et al., 2005; El-Din et al., 2013). 
Radiólise da água

Radiação $+\underset{H}{\mathrm{O}^{\prime}} \longrightarrow \stackrel{\mathrm{HO}^{\circ}}{\mathrm{e}_{\mathrm{aq}}^{-}}+\mathrm{H}^{\cdot}+\mathrm{H}_{2}+\mathrm{HO}-\mathrm{OH}+\mathrm{H}_{3} \mathrm{O}^{+}$

Redução por elétron hidratado

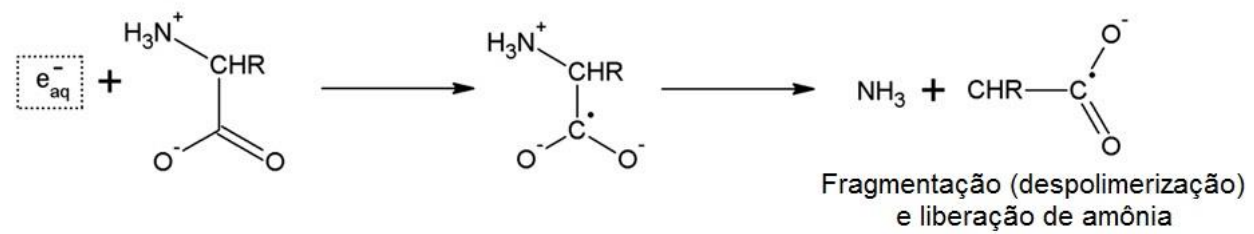

Oxidação por radical hidroxila e átomos de hidrogênio

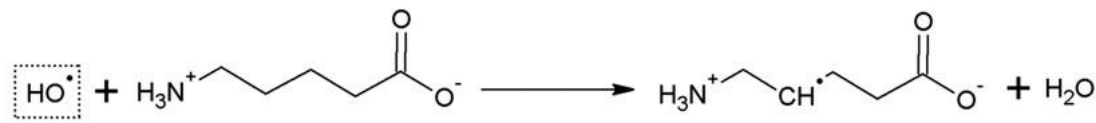

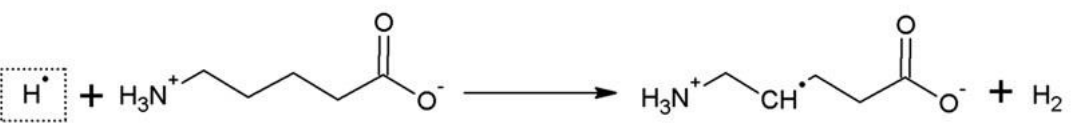<smiles>CC(C)CCCC(C[NH3+])C(CCC(=O)[O-])CCC(=O)[O-]</smiles>

FIGURA 4 - Efeito de irradiação em proteína mostrando possível despolimerização (fragmentação) e polimerização (reticulação) das cadeias de proteínas (Kuan et al., 2013).

Os elétrons com energias térmicas tornam-se hidratados $\left(e_{a q}{ }^{-}\right)$, conforme são cercados pelas moléculas de água polar em um curto período de tempo (cerca de $10^{-12} \mathrm{~s}$ ). Partículas carregadas (íons) também se transformam em uma forma hidratada, conforme os íons são rodeados por moléculas de água com a atração eletrostática entre os íons e dipolos da água mantendo-os unidos (Sheien et al., 1998).

A FIG. 5 representa o desenvolvimento espaço-tempo da transformação de espécies intermediárias e a sua difusão de expansão dirigida. 
Nos produtos da radiólise da água, espécies geradas em torno de $10^{-7} \mathrm{~s}$ após a deposição de energia são: ${ }^{\bullet} \mathrm{OH}, \mathrm{e}_{\mathrm{aq}}^{-}, \mathrm{H}, \mathrm{H}_{3} \mathrm{O}^{+}, \mathrm{H}_{2} \mathrm{O}_{2}$ e $\mathrm{H}_{2}$.

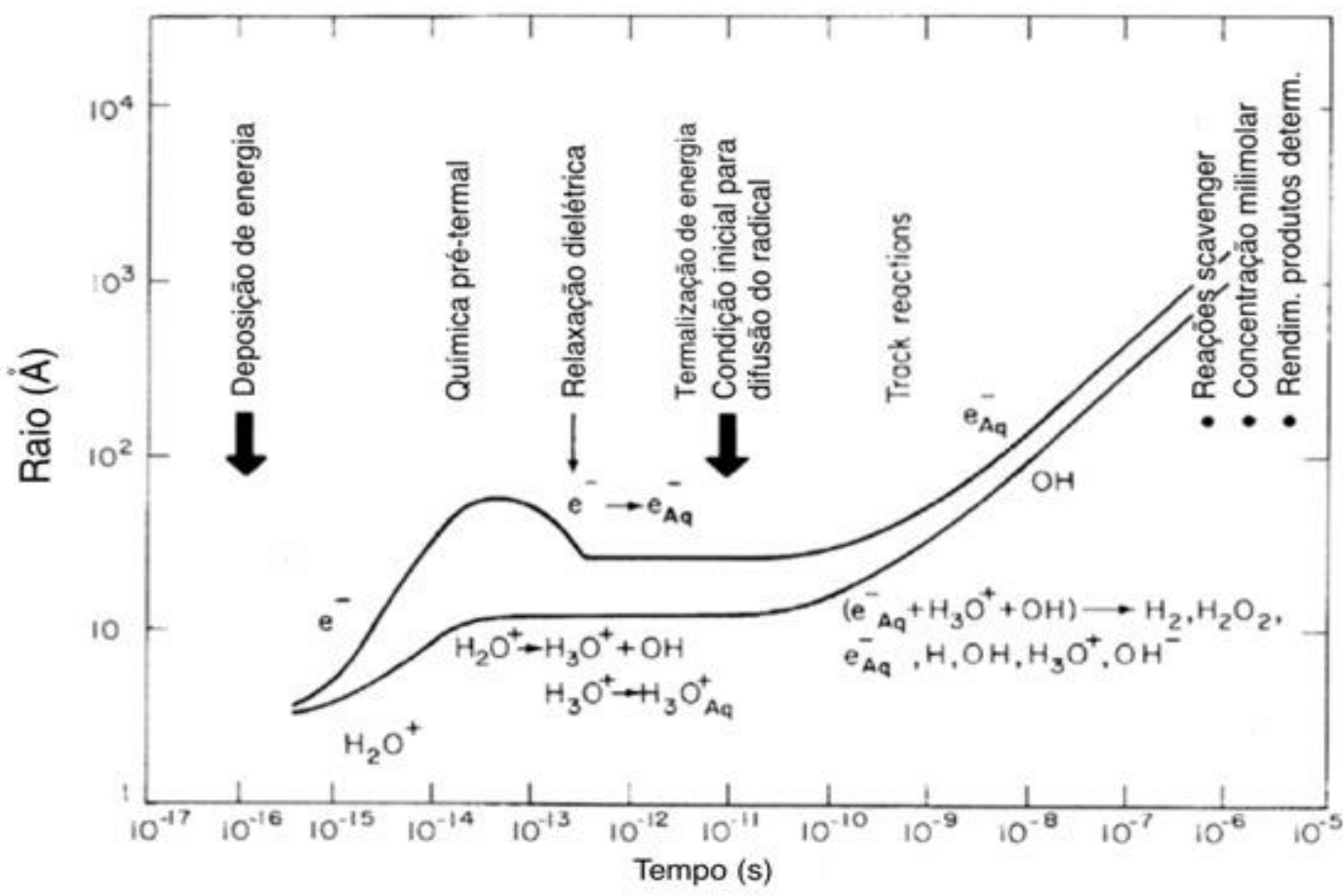

FIGURA 5 - Desenvolvimento esquemático espaço-tempo num sistema aquoso diluído (Magee \& Chatterjee, 1987).

Os radicais hidroxila $(\bullet \mathrm{OH})$ são muito reativos; reagem sobre as ligações insaturadas com constante de velocidade próxima da velocidade de difusão e imediatamente abstraem $\mathrm{O}$ H das ligações $\mathrm{C}-\mathrm{H}$ das cadeias macromoleculares para produzir radicais carbonilas. Como a energia de ligação O-H na água é muito elevada $\left(\Delta H(\mathrm{H}-\mathrm{OH})=495 \mathrm{~kJ} \mathrm{~mol}^{-1}\right)$, abstrações de $\mathrm{H}$ ligados a átomos de carbono $\left(\Delta H(\mathrm{C}-\mathrm{H})=385-410 \mathrm{~kJ} \mathrm{~mol}^{-1}\right)$ são sempre reações exotérmicas. Por causa da alta reatividade, a abstração de $\mathrm{H}$ por ${ }^{\bullet} \mathrm{OH}$ é um processo não seletivo (Schuchmann \& von Sonntag, 1977). Os átomos de H também podem contribuir para esta captação de $H$, como é mostrado a seguir: 


$$
\mathrm{RH}+\mathrm{H} / \bullet \mathrm{OH} \rightarrow \mathrm{R} \bullet+\mathrm{H}_{2} / \mathrm{H}_{2} \mathrm{O}
$$

Em que $R$ representa o grupo alquil ou aril e $R^{\bullet}$ representa cada radical.

Além da abstração do $\mathrm{H},{ }^{\bullet} \mathrm{OH}$ está envolvido com as ligações duplas:

$$
\text { - } \mathrm{OH}+\mathrm{CH}_{2}=\mathrm{CH}_{2} \rightarrow \mathrm{HO}-\mathrm{CH}_{2}-\mathrm{CH}_{2} \cdot\left(k=4,8 \times 10^{9} \mathrm{~L} \mathrm{~mol}^{-1} \mathrm{~s}^{-1}\right)(3.7)
$$

$\mathrm{O}^{\bullet} \mathrm{OH}$ reage predominantemente com ligações duplas polarizadas no centro rico em elétrons (Steenken \& O'Neill, 1978), devido à sua eletrofilicidade (Anbar et al., 1966).

O elétron hidratado $\left(e_{\mathrm{aq}}{ }^{-}\right)$, um elétron localizado rodeado por moléculas de água orientadas, é um agente redutor forte. A reação de transferência de um elétron pode ser expressa como descrito abaixo (Farhataziz \& Rodgers, 1987):

$$
e_{a q}{ }^{-}+S^{n} \rightarrow S^{n-1}
$$

Em que $n$ é a carga do soluto $S$. Ele reage preferencialmente com um orbital vazio de um sistema e é altamente reativo com moléculas orgânicas com orbitais vazios (tais como a maioria dos compostos aromáticos: compostos carbonila, haletos, dissulfetos, tióis, e nitro compostos).

$O e_{a q}$ reage com o oxigênio para produzir o íon do radical superóxido $\left(\mathrm{O}_{2}^{\bullet}\right.$ ) (reação de 3.9). $\mathrm{O} \mathrm{O}_{2}^{\bullet-}$ é então convertido em $\mathrm{OH}_{2}{ }^{\bullet-}$ dependendo do $\mathrm{pH}$ do soluto, como é descrito na reação de 3.10 a seguir (von Sonntag, 1987).

$$
\begin{aligned}
& e_{a q}^{-}+\mathrm{O}_{2} \rightarrow \mathrm{O}_{2}^{-} \cdot \quad\left(\mathrm{k}=1,9 \times 10^{10} \mathrm{~L} \mathrm{~mol}^{-1} \mathrm{~s}^{-1}\right) \\
& \mathrm{O}_{2}^{--}+\mathrm{H}_{3} \mathrm{O}^{+} \rightleftarrows \mathrm{OH}_{2}^{--}+\mathrm{H}_{2} \mathrm{O} \quad(\mathrm{pKa}=4.7)
\end{aligned}
$$


A reação de recombinação dos radicais é o tipo de reação mais importante para formação do gel, e pode ocorrer entre as cadeias adjacentes do polímero (reticulação intermolecular) ou dentro da mesma cadeia polimérica (reticulação intramolecular). A FIG. 6 mostra o esquema dos dois tipos de reação de reticulação. $O$ aumento da dimensão média e da massa molar da cadeia de polimérica é esperado pela reticulação intermolecular, enquanto que pela reticulação intramolecular a massa molar é mantida com uma redução da dimensão (Wang et al., 1997; Kadlubowski et al., 2003).

\section{Gel Macroscópico}

- Radical polímero

- Ligação reticulada
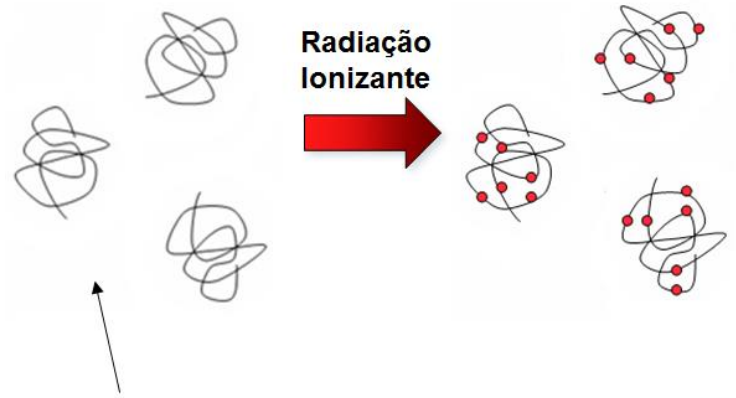

Reticulação Intermolecular
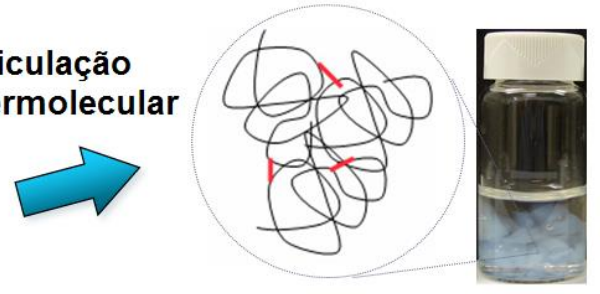

Nanogel

Cadeia polimérica na água
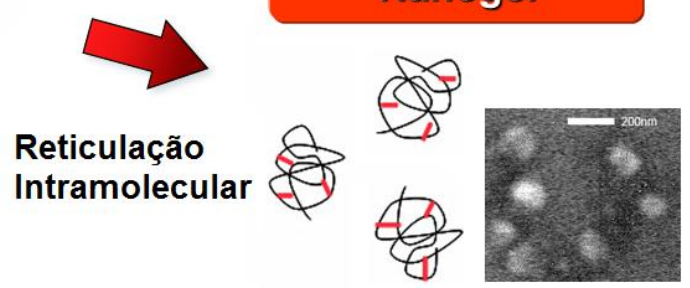

FIGURA 6 - Reação de reticulação inter vs intramolecular (Al-Sheikhly, 2010). 


\section{METODOLOGIA}

\subsection{Técnicas de caracterização}

\subsubsection{Análise de textura}

O analisador de textura, ou texturômetro, do laboratório de análises físico-químicas do CTR (IPEN-CNEN/SP) foi utilizado para avaliar a qualidade dos filmes à base de gelatina. A análise foi realizada pelo estudo das propriedades mecânicas dos filmes pelo princípio de perfuração. Entre os testes de resistência mecânica conhecidos, foi estudado o teste de resistência à perfuração (força de ruptura) e à deformação na ruptura dos filmes. $O$ analisador de textura Texture Analyser, modelo TA-XTPlus da Stable Micro Systems, UK utilizado é mostrado na FIG. 7. O equipamento foi conectado a uma célula de carga de $50 \mathrm{~kg}$; o software utilizado foi o Exponent e os acessórios acoplados para realizar os experimentos foram suporte para filme (HDP/FSR) e probe esférico de aço inoxidável de $5 \mathrm{~mm}$ de diâmetro $(\mathrm{P} / 5 \mathrm{~S})$. Os ensaios foram realizados em uma velocidade constante de $0,5 \mathrm{~mm} \mathrm{~s}^{-1}$ e a distância de $15 \mathrm{~mm}$.. Para cada ensaio foram utilizados 10 corpos de prova de $30 \mathrm{~mm}^{2}$ para todas as doses estudadas.

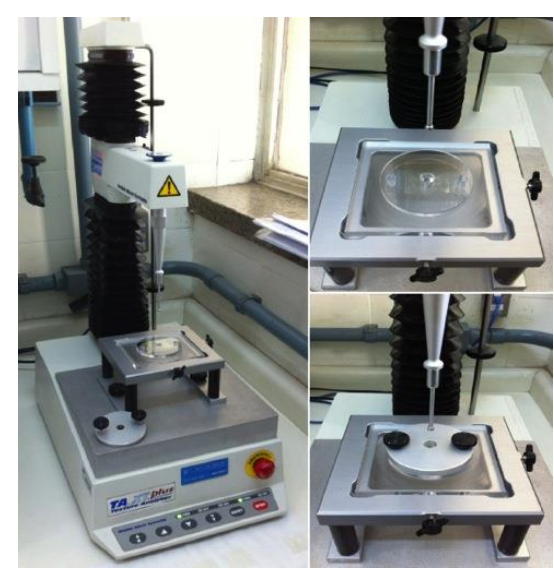

FIGURA 7 - Texturômetro para medições das propriedades mecânicas dos filmes a base de gelatina. 


\subsubsection{Colorimetria}

O colorímetro do laboratório de análises físico-químicas do CTR (IPEN-CNEN/SP) foi utilizado para determinar as coordenadas colorimétricas dos filmes à base de GEL.

O sistema de coordenadas CIE $1976\left(L^{*}, a^{*}, b^{*}\right)$ ou CIELAB possui um espaço de cor tridimensional, aproximadamente uniforme, produzido pela representação gráfica em coordenadas retangulares, $L^{*}, a^{*}, b^{*}$, definido em 1976 pela CIE (Commission Internationale de l'Eclairage). Esse sistema foi introduzido e tornou-se bem aceito e amplamente utilizado (CIE, 2007), pois representa mais fielmente a sensibilidade humana à cor (Bernardin \& Riella, 1999).

A análise de cor foi realizada segundo o espaço de cor CIE 1976 $\left(L^{*}, a^{*}, b^{*}\right)$ em que o coeficiente de luminosidade, $L^{*}$, varia do preto $=0$ para 0 branco $=100$. Para qualquer medida de luminosidade, $L^{*}$, as coordenadas $\left(a^{*}, b^{*}\right)$ localizam a cor na rede perpendicular ao eixo $L^{*}$. No eixo horizontal a coordenada $+\mathrm{a}^{*}$ indica uma tonalidade de vermelho-roxo; $-a^{*}$, o verde-azulado. No eixo vertical, $+b^{*}$ indica o amarelo e $-b^{*}$ o azul. Chroma é a intensidade ou pureza da cor em relação ao cinza (McGuire, 1992). O ângulo Hue quantifica cor, em que vermelho-arroxeado $=0^{\circ}$, amarelo $=90^{\circ}$, verde-azulado $=180^{\circ}$ e azul $=270^{\circ}$ (Voss, 1992). O diagrama abaixo representa as coordenadas do espaço de cor CIELAB (FIG. 8):

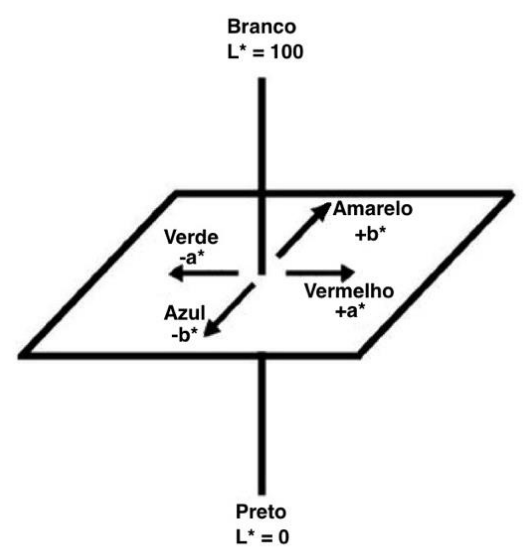

Fonte: https://sites.google.com/site/sachidanandabs/colorspace

FIGURA 8 - Diagrama de coordenadas do espaço de cor CIELAB. 
Para os experimentos, foi utilizado o colorímetro Chroma meter, modelo CR-400 (Konica Minolta Camera Co., Osaka, Japão) e a placa de calibração branco padrão CR-A43. Três leituras de valores de cor $\left(L^{*}, a^{*}, b^{*}\right)$ foram medidas para cada filme e foram utilizadas 10 filmes para cada ensaio para todas as doses estudadas. O Croma e o ângulo Hue foram calculados usando as seguintes equações:

$$
\begin{aligned}
& C=\sqrt{\left(a^{*}\right)^{2}+\left(b^{*}\right)^{2}} \\
& H=180^{\circ}+\tan ^{-1}\left(b^{*} / a^{*}\right), \text { para } a^{*}<0
\end{aligned}
$$

\subsubsection{Absorção de água}

A avaliação da resistência à absorção de água ou intumescimento dos filmes a base de GEL foi realizado com base no método descrito por Chiono et al. (2008). Amostras dos filmes a base de gelatina $(10 \times 10 \mathrm{~mm})$ foram pesadas (Mi), colocadas em água destilada e armazenadas em temperatura ambiente durante $24 \mathrm{~h}$. Após $24 \mathrm{~h}$, os géis inchados foram removidos da água, secos com papel absorvente e pesados (Mf). Cada ensaio foi realizado em triplicata. Assim, a cinética de absorção dos géis (S) foi obtida pela seguinte equação:

$$
S(\%)=\frac{M f-M i}{M i} \times 100
$$

\subsubsection{Solubilidade}

A solubilidade dos filmes a base de gelatina foram determinados com base na metodologia descrita por Colla et al. (2006). As amostras de filmes a base de GEL (10 x $10 \mathrm{~mm})$ foram pesadas e secas em estufa com circulação de ar a $105 \pm 1^{\circ} \mathrm{C}$ por $24 \mathrm{~h}$. Em seguida, as amostras foram colocadas em béqueres com $50 \mathrm{~mL}$ de água destilada e armazenadas em temperatura ambiente 
durante 24 h, com agitação suave ocasional. Após 24 h, os filmes não dissolvidos foram secos em estufa de ar circulante a $105 \pm 1 \stackrel{\circ}{ } \mathrm{C}$ durante $24 \mathrm{~h}$ e pesados. Cada ensaio foi realizado em triplicata. Assim, a solubilidade dos filmes foi calculada pela equação:

$$
F S(\%)=\frac{W i-W f}{W i} \times 100
$$

Nesta equação, Wi representa o peso inicial do filme e Wf representa o peso do resíduo do filme seco não dissolvido.

\subsubsection{Umidade}

O teor de umidade de filmes a base de GEL foi determinado com base no método descrito por Guerrero et al. (2011) medindo a perda de peso das amostras $(10 \times 10 \mathrm{~mm})$ após secagem sob estufa com circulação de ar a $105 \pm 1^{\circ} \mathrm{C}$ até atingir o peso constante. Cada ensaio foi realizado em triplicata.

\subsubsection{Fração gel}

A análise de fração gel de compósitos de gelatina foram determinadas com base na metodologia descrita por Darwis et al. (1993). A fração gel oferece o teor de gel do material reticulado. Essa técnica utiliza o método gravimétrico para realizar o experimento no extrator Soxhlet. Assim, o ensaio foi realizado pesandose amostras de $300 \pm 10 \mathrm{mg}$, sendo que cada ensaio foi realizado em triplicata. A fração gel (conteúdo reticulado) das amostras foi estimada removendo a fração solúvel das amostras irradiadas pela extração em água destilada durante 24 horas em temperatura de ebulição $\left(100^{\circ} \mathrm{C}\right)$. Após $24 \mathrm{~h}$, o gel obtido foi seco até atingir peso constate. A fração gel foi calculada conforme a equação abaixo:

$$
\text { Fração gel }(\%)=\frac{W_{s}}{W_{i}} \times 100 \%
$$


Em que Wi é massa inicial da amostra seca e Ws é a massa da parte insolúvel da amostra seca após extração com água destilada.

\subsubsection{Análise termogravimétrica}

O analisador termogravimétrico do laboratório de análises térmicas do CTR (IPEN-CNEN/SP) foi empregado para avaliar a estabilidade térmica dos materiais compósitos. A análise termogravimétrica (TGA) é uma técnica que permite medir a variação da massa em função da temperatura e do tempo. Deste modo, a estabilidade térmica dos materiais compósitos foi avaliada utilizando o analisador termogravimétrico modelo TGA-50 (Shimadzu, Japão). Amostras pesando 5,0 $\pm 1,0 \mathrm{mg}$ foram colocadas em cadinhos de platina, utilizando 0 ar como atmosfera e uma taxa de fluxo de $50 \mathrm{~mL} \mathrm{~min}^{-1}$. Os experimentos foram conduzidos de temperatura ambiente $\left(25^{\circ} \mathrm{C}\right)$ a $600^{\circ} \mathrm{C}$ em uma taxa de aquecimento de $10^{\circ} \mathrm{C} \mathrm{min}^{-1}$.

\subsubsection{Microscopia eletrônica de varredura}

A caracterização morfológica do material compósito foi realizada empregando a microscopia eletrônica de varredura (MEV) do laboratório de Microscopia \& Microanálise do CCTM, IPEN-CNEN/SP. Os ensaios foram realizados no MEV da Philips, modelo XL 30. Para realizar os experimentos no MEV foi necessário preparar as amostras adequadamente para a análise. Então, as amostras foram submetidas à fratura após terem sido submetidas ao congelamento rápido criogênico (nitrogênio líquido). A superfície de fratura foi fixada com carbono em um suporte apropriado (stubs) e em seguida as amostras foram introduzidas em uma câmara metalizadora a vácuo até atingir o ponto crítico de secagem; então foram revestidos com ouro por pulverização catódica. As análises foram realizadas utilizando elétrons secundários (SE) e retroespalhados.

\subsubsection{Microscopia de força atômica}

O equipamento de Microscopia de Força Atômica (AFM) do Molecular Mechanics and Self-Assembly Laboratory da UMCP é uma importante ferramenta analítica nanoscópica que fornece informações relativas à morfologia da superfície pela produção de um mapa em 3D da superfície da amostra com alta 
resolução (isto é, $1 \times 10^{-10} \mathrm{~m}$ ) (Blanchard \& Campbell, 1995). É um instrumento que pode ser explorado em um nível de sensibilidade de força de $10^{-18} \mathrm{~N}$. Esse nível de sensibilidade transpõe o regime de forças interatômicas entre átomos isolados e amplia as oportunidades para diversas aplicações (Binning et al., 1986): em ciência dos materiais, que pode variar de polímeros (Yuan et al., 2011) a energia fotovoltaica (Li et al., 2005) e da física (Klein et al., 2013) à química (Lin et al., 2007; Schwartz, 2002); abrangendo também a área biológica e bioengenharia (Takeda et al., 2003; Wu et al., 2011).

$O$ instrumento de AFM baseia-se na detecção das forças entre uma agulha (ponta) ultrafina e a superfície de interesse (Meyer \& Amer, 1988). Uma ilustração esquemática da AFM pode ser observada na FIG. 9. Uma haste extremamente fina (cantilever) composta por uma agulha (ponta) ultrafina foi montada perpendicularmente à direção longitudinal da haste e colocada sobre a amostra. Essa agulha percorre a amostra, realizando uma varredura da superfície. Um laser é refletido pela parte traseira da haste para um sensor de fotodiodo quadrante sensível à posição, que registra qualquer deflexão da haste induzida pela força de Van der Waals entre a ponta e a amostra (Ratner \& Tsukruk, 1996). Assim, esses sinais são processados para obter as informações topográficas da superfície.

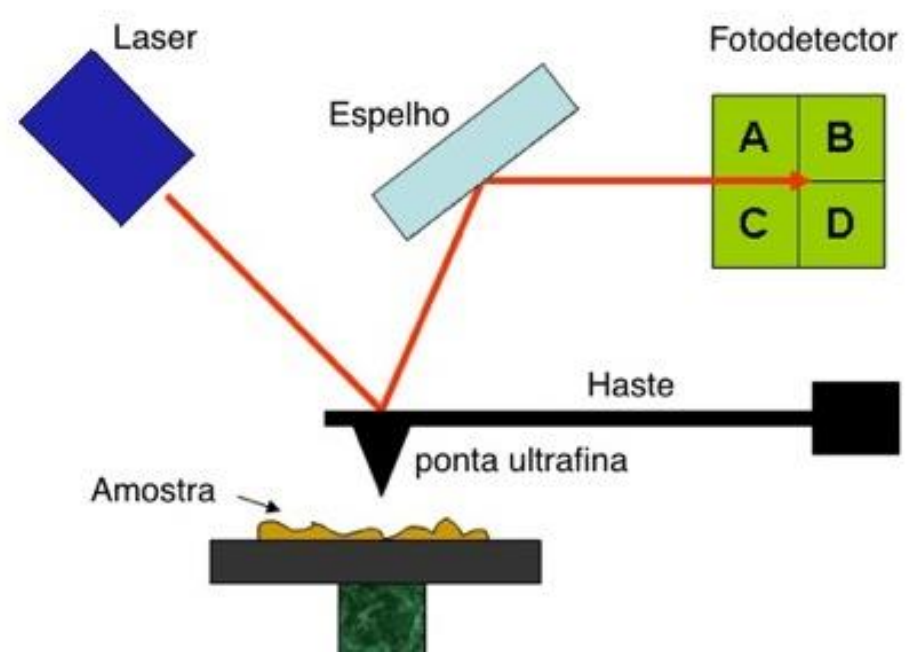

FIGURA 9 - Esquema de funcionamento da microscopia de força atômica 
A visualização da superfície das nanopartículas de GEL, PEG e MIX foi realizada utilizando a ferramenta de AFM da Asylum Research - Atomic Force Microscopes (CA, USA), modelo MFP-3D, software Igor Pro 6.21, em modo de contato (C) e intermitente (AC), com a ponta para amostras macias (FIG. 10). A haste oscila com uma frequência de ressonância específica dada por um pequeno acionador piezoelétrico montado na agulha do modo C e AC. A amplitude de oscilação da haste é reduzida conforme a agulha se aproxima da superfície da amostra. O mecanismo auxiliar eletrônico ajusta a altura da haste acima da amostra para manter a amplitude de oscilação da haste enquanto faz a varredura sobre a amostra. A análise tomográfica da superfície das amostras de GEL, PEG e MIX foi realizada depositando a amostra sobre o disco de substrato de mica clivada com 9,9 mm de diâmetro, em meio líquido e seco e em temperatura ambiente.

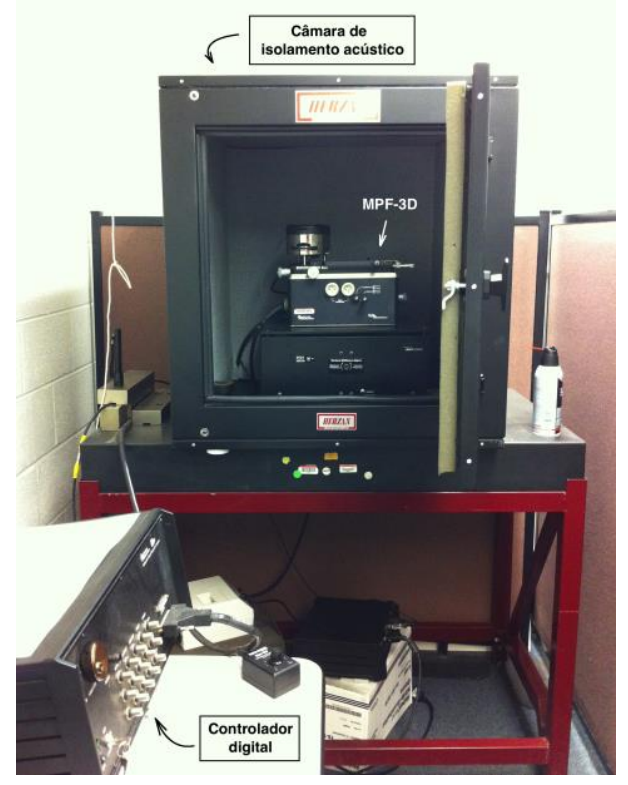

FIGURA 10 - AFM dentro da câmara de isolamento acústico da Asylum Research.

\subsubsection{Espalhamento de luz dinâmico}

O equipamento de espalhamento de luz dinâmico (Dynamic Light Scattering - DLS) do National Institute of Standards and Technology (NIST) foi 
utilizado para avaliar a distribuição de tamanho das partículas. O DLS também é conhecido como espectroscopia de correlação de fótons (photon correlation spectroscopy - PCS). Essa técnica é um dos métodos mais populares utilizados na determinação da dimensão das partículas.

A técnica de DLS mede o tamanho das partículas com base no grau de amplitude espectral induzido em um feixe de laser incidente por espalhamento de partículas do movimento Browniano, ou seja, essa identificação é feita pela iluminação das partículas com o laser e analisando-se as flutuações de intensidade de luz espalhada com o tempo devido à interferência construtiva e destrutiva. (Berne \& Pecora, 1976; Schmitz, 1990; Choi et al., 2010). O movimento Browniano é o movimento aleatório de partículas coloidais devido às colisões múltiplas com as moléculas do líquido que as rodeia. A intensidade da luz dispersa a partir dessas partículas difusoras oscilará no tempo, carregando, assim, a informação sobre o coeficiente de difusão das partículas (Tscharnuter, 2000).

A característica principal do movimento browniano para o DLS é que pequenas partículas se movem rapidamente enquanto partículas grandes movem-se vagarosamente. A relação entre $o$ tamanho da partícula e sua velocidade devido ao movimento Browniano é definida na equação de Stokes-Einstein. E a velocidade da partícula no meio resultado do movimento Browniano da macromolécula em solução é definida pelo coeficiente de difusão (Berne \& Pecora, 1976).

Quando a luz incide sobre a matéria, o campo elétrico da luz induz uma polarização de oscilação de elétrons nas moléculas. Assim, as moléculas fornecem uma fonte secundária de luz e subsequentemente espalhamento de luz. Os deslocamentos de frequência, a distribuição angular, a polarização e a intensidade do espalhamento de luz são determinados pelo tamanho, forma e interações moleculares no material (Berne \& Pecora, 1976).

Esse método determina o coeficiente de difusão translacional (D ou Dt) e o raio hidrodinâmico $\left(R_{h}\right)$ medindo as flutuações dependentes do tempo na intensidade de espalhamento em um determinado ângulo $\theta$ (Pecora, 1985; Schmitz, 1990; Phillies, 1990). As flutuações na intensidade de espalhamento são correlacionadas para obter uma função de intensidade de autocorrelação $g(\tau)$, 
como uma função de correlação (decaimento) de tempo $\tau$. As médias autocorrelatadas são produtos de duas intensidades de luz espalhadas $\mathrm{I}(\mathrm{t})$ e $\mathrm{I}(\mathrm{t}+\tau)$ medidas em tempos diferentes. $\mathrm{I}(\mathrm{t})$ é convertido para $<\mathrm{l}(\mathrm{t}) \mathrm{I}(\mathrm{t}+\tau)>$ pelo autocorrelatador. A função de correlação $g(\tau)$ é definida a seguir.

$$
g(\tau)=\lim _{T_{A} \rightarrow \infty} \frac{1}{T_{A}} \int_{0}^{T_{A}} I(t) I(t+\tau) d t=\langle I(t) I(t+\tau)\rangle
$$

A equação 3.16 mostra que $I(t)$ e $I(t+\tau)$ são a média calculada durante um longo período de tempo $\mathrm{T}_{\mathrm{A}}$ para obter a média geral, como é conhecida: média de todas as configurações possíveis das moléculas na solução. Se o sistema está em equilíbrio, a média geral é constante ao longo do tempo, de modo que $<\mathrm{l}(\mathrm{t}) \mathrm{I}(\mathrm{t}+\tau)>=<\mathrm{l}(0) \mathrm{I}(\tau)>$.

A intensidade de espalhamento $\mathrm{I}(\mathrm{t})$ oscila em torno de uma média $<\mathrm{l}>$, de modo que $\mathrm{I}(\mathrm{t})$ também possa ser descrita em termos de um componente de flutuação $\Delta \mathrm{l}(\mathrm{t})$ como:

$$
I(t)=<I>+\Delta I(t)
$$

Uma vez que, por definição, $\langle\Delta \mathrm{l}(\mathrm{t})>=0$, a função de autocorrelação pode ser representada como:

$$
g(\tau)=<I(t) I(t+\tau)>=<I>^{2}+<\Delta I(t) \Delta I(t+\tau)>
$$

Este pode, então, ser dividido por $<1>^{2}$ para obter:

$$
\frac{<I(t) I(t+\tau)>}{<I>^{2}}=1+\frac{<\Delta I(t) \Delta I(t+\tau)>}{<I>^{2}}=1+f_{c} g_{2}(\tau)
$$


Em que $f_{c}$ é um fator de coerência que depende da geometria do instrumento, que é definida pela equação 3.20:

$$
f_{c} \equiv<\Delta I^{2}>/<I>^{2}
$$

$g_{2}(\tau)$ é a função de autocorrelação normalizada de intensidade, que é definida como:

$$
g_{2}(\tau) \equiv<\Delta I(t) \Delta I(t+\tau)>/<I>^{2}
$$

A função de autocorrelação da intensidade de espalhamento medida, $g_{2}(\tau)$, pode ser convertida na função de autocorrelação, $g_{1}(\tau)$, de campo elétrico, $E_{s}(t)$, pela relação Sieger.

$$
\begin{aligned}
& g_{2}(\tau) \equiv\left|g_{1}(\tau)\right|^{2} \\
& g_{1}(\tau) \equiv \frac{<E_{S}^{*}(t) \cdot E_{S}(t+\tau)>}{<E_{S}^{*}(t) \cdot E_{S}(t)>}
\end{aligned}
$$

Em que $\mathrm{E}_{\mathrm{s}}(\mathrm{t})$ é o campo elétrico no tempo $t$, $\mathrm{e}^{*}$ indica o complexo conjugado. Se considerarmos a espécie espalhada como uma partícula esférica monodispersa diluída, então a função de correlação de campo elétrico forma um simples decaimento exponencial de tempo $(\tau)$, que é dada por:

$$
g_{1}(\tau)=\exp \left(-D q^{2} \tau\right)
$$

Em que $D$ é o coeficiente de difusão translacional da partícula e $q$ é o vetor de onda. Assim, como $D$ está diretamente relacionado ao raio hidrodinâmico 
$\left(R_{h}\right)$ ou diâmetro hidrodinâmico $\left(D_{h}\right)$ pode ser calculado pela relação de Stokes-Einstein:

$$
R_{h}=\frac{k_{B} T}{6 \pi \eta D} \quad \text { ou } \quad D_{h}=\frac{k_{B} T}{3 \pi \eta D}
$$

Em que $k_{B}$ é a constante de Boltzmann, $T$ é a temperatura absoluta, e $\eta$ é a viscosidade do solvente.

O diâmetro hidrodinâmico médio $\left(D_{h}\right)$ das amostras não irradiadas e irradiadas foi medido pelo DLS modelo ZetaPALS Particle Sizing (Brookhaven Instruments Corporation, NY, USA), que possui um ângulo de espalhamento de $90^{\circ}$, laser de fotodiodo vermelho com potência de $35 \mathrm{~mW}$ e comprimento de onda de $660 \mathrm{~nm}$, utilizando o software ver. 3.93. Cubetas de poliestireno descartáveis de 1 a $3 \mathrm{~mL}$ foram utilizadas nos ensaios. A imagem do equipamento de DLS está apresentada na FIG. 11.

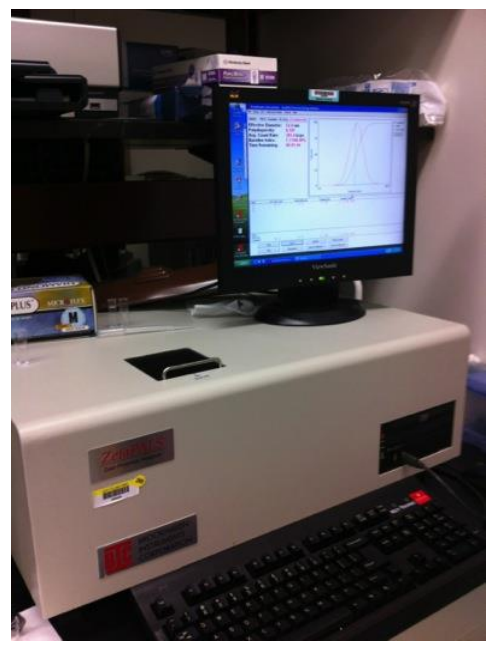

FIGURA 11 - Equipamento de DLS: ZetaPALS Particle Sizing

\subsubsection{Asymmetrical Flow Field-Flow Fractionation}

O Asymmetrical Flow Field-Flow Fractionation (AF4) vem se destacando devido ao rápido avanço na área de biotecnologia, acompanhado por 
uma demanda crescente por potentes métodos analíticos de alta eficiência (Fraunhofer \& Winter, 2004). Esse método permite atingir vários sistemas de amostragem, pois é uma técnica capaz de separar partículas coloidais em uma faixa de 1-1000 nm com alta resolução (Schimpf et al., 2000). Essa técnica abrange os compostos supramoleculares (Kowalkowski, et al., 2006) pela habilidade de separar e caracterizar materiais como: polímeros (Giddings, et al., 1977a; Messaud et al., 2009), coloides (Runyon et al., 2013), proteínas (Giddings et al., 1977b; Arfvidsson \& Wahlund, 2003) e partículas em geral (Wyatt, 1993; Luykx et al., 2008) de dimensões que variam de 0,01-100 $\mu \mathrm{m}$ (Giddings, 1976, 1993; Giddings et al., 1977b; Fraunhofer \& Winter, 2004; Kowalkowski et al., 2006).

A técnica de separação no AF4 é realizada dentro de um canal de fluxo em que é estabelecido um perfil de fluxo laminar parabólico (newtoniano) como em um tubo capilar, onde os analitos são impulsionados em direção à camada limite do canal. A posição de cada uma das espécies no perfil de fluxo laminar corresponde ao seu coeficiente de difusão. É essa distinção dos coeficientes que possibilita a análise de distribuição de tamanho. A aplicação de um fluxo de fase móvel secundária que conduz os componentes da amostra em direção à superfície do canal de acúmulo é gerada por causa de um campo hidrodinâmico não específico através do canal. Esta parede de acumulação é a membrana permeável.

A seleção de uma membrana apropriada depende das macromoléculas ou partículas a serem separadas, sendo que o tamanho do poro deve ser suficientemente pequeno para reter os analitos, mas suficientemente grande para permitir que a solução de transporte passe através dele (Kowalkowski et al., 2006). Em outras palavras, é um campo de força perpendicular à direção do fluxo do solvente, que impulsiona os componentes da amostra a acumularem-se na parede do canal, criando um gradiente de concentração. Devido ao estabelecimento do gradiente de concentração, a difusão por movimento browniano gera um fluxo no sentido inverso. As partículas menores, com maior difusividade, atingem uma posição de equilíbrio na parte superior do canal, onde a taxa de fluxo longitudinal é mais elevada e são transportadas mais rapidamente ao longo do canal (Schimpf et al., 2000). No entanto, as partículas maiores e com menor difusividade estão posicionadas na parte inferior do canal, e movem-se 
mais lentamente ao longo dele. As partículas de tamanhos diferentes podem ser separadas por este gradiente de velocidade fluindo no interior do canal (Giddings, 1976). As partículas menores eluem primeiro e depois as maiores; o oposto do que ocorre no método de separação de cromatografia de permeação em gel (GPC), em que as moléculas maiores eluem primeiro (Pasch \& Trathnigg, 1999). Assim, as partículas menores difundem a uma taxa mais rápida do que as de maiores dimensões, e consequentemente, a eluição a partir do canal de saída provém da espécie menor para a maior (Giddings, 1973; Fraunhofer \& Winter, 2004; Moquin et al., 2013).

O processo de separação é executado em três fases (Schimpf et al., 2000): injeção, concentração e eluição. Durante os primeiros dois passos, o fluxo de entrada principal é dividido, introduzido no canal de ambas as extremidades, e equilibrado para reunir-se na entrada da injeção. O fluxo que se move para baixo e permeia através da membrana é então concentrado em uma banda delgada e permeia através da membrana. Após a transferência da amostra, o fluxo de injeção é interrompido e o fluxo padrão é substituído para o modo de eluição. A amostra separada é eluída do canal de saída e, em seguida, transportada para uma matriz de detectores para ser analisada. Um esquema de AF4 é mostrado na seguinte FIG. 12.
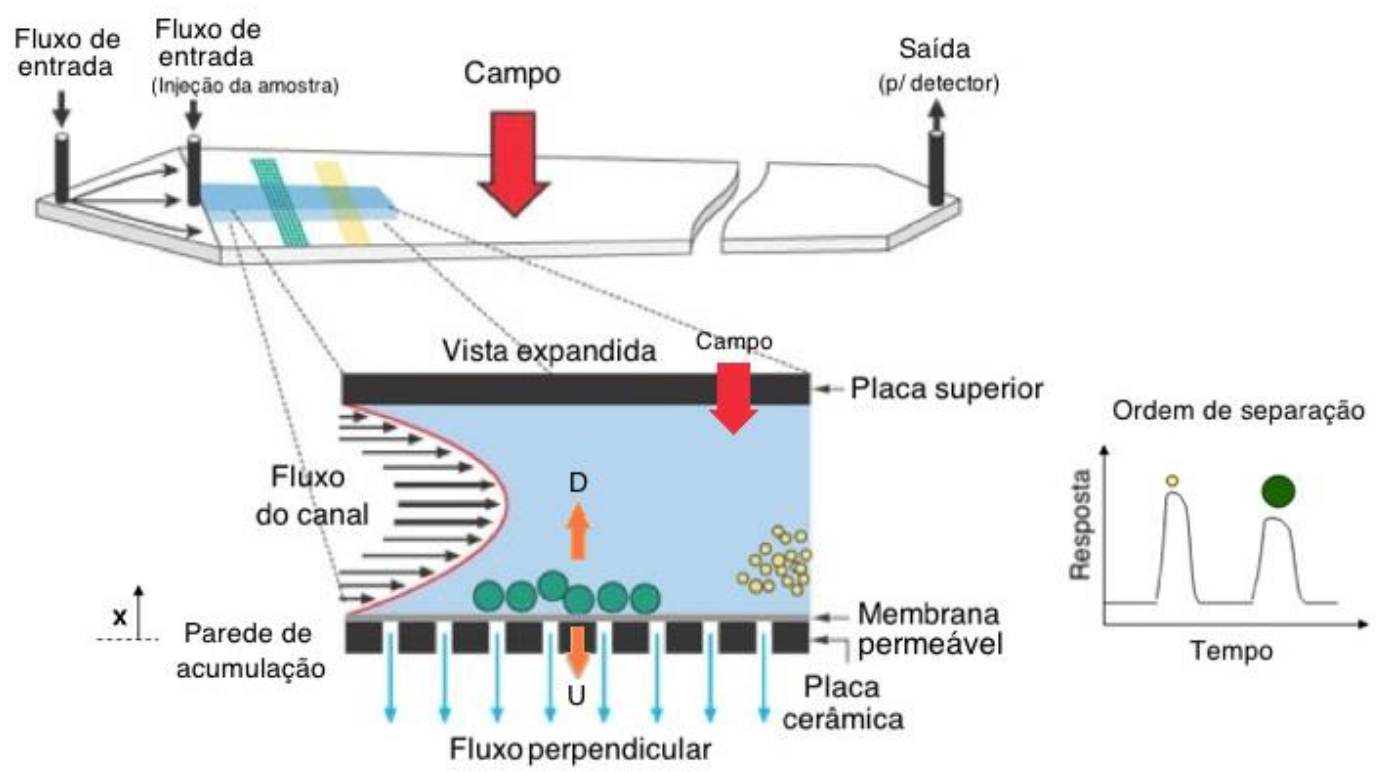

Fonte: Wyatt technology

FIGURA 12 - Esquema do mecanismo de separação de cromatografia AF4. 
O equipamento de cromatografia AF4 do National Institute of Standards and Technology (NIST) foi empregado na determinação do tamanho e da massa molar das partículas estudadas. A cromatografia AF4 é um método de cromatografia líquida de fase única, em que a separação de alta resolução ocorre em um campo de força aplicado de fluxo laminar (Giddings, 1973). Essa técnica não exige qualquer suporte de coluna, de modo que o processo é rápido e sem uma fase estacionária, que pode interagir com, ou alterar a amostra.

Uma equação de retenção é utilizada para descrever a distribuição da concentração (isto é, altura da molécula sobre a parede de acumulação) e perfil de fluxo parabólico (isto é, a taxa de fluxo do transportador na altura específica sobre a parede de acumulação). A distribuição de concentração é uma função de velocidade baixa $U$ e de velocidade alta $D$, e é descrita abaixo (Giddings, 1973):

$$
c(x)=c_{0} e^{-\frac{x U}{D}}=c_{0} e^{-\frac{x}{L}} \text { onde, } L=\frac{D}{U}
$$

Nesta equação, $c$ é a concentração de soluto, $c_{0}$ é a concentração à altura zero, $x$ é a distância da parede de acumulação, $U$ é a velocidade de arraste, $D$ é o coeficiente de difusão e $L$ é a espessura média da camada.

A média de espessura da camada $L$ do soluto sobre a parede de acumulação é estabelecida pelo equilíbrio entre a velocidade de arraste $U$ e a difusividade $D$. A velocidade de arraste $U$ é definida como a força $F$ sobre o soluto dividido pelo coeficiente de atrito $f: U=F / f$. O coeficiente de atrito é descrito pela equação de Nernst-Einstein: $f=k T / D$, em que $k$ é a constante de Boltzmann e $T$ é a temperatura. As espécies com diferentes médias de espessura da camada $L$ sobre a parede de acumulação apresentam diferentes zonas de velocidades, que conduzem a separação ao longo do canal ou a separação na sequência de eluição (Giddings, 1973).

O perfil do fluxo parabólico no fluxo de transporte pode ser modelado pela seguinte equação pressupondo que: (1) velocidade $=0$ na parede de acumulação $(x=0)$, (2) o perfil de fluxo é constante ao longo do eixo a separação (Giddings, 1973). 


$$
v(x)=6 \cdot\langle v\rangle \cdot\left(\frac{x}{w}-\frac{x^{2}}{w^{2}}\right)
$$

Em que $v$ é a velocidade do fluxo do líquido transportador, <v> é a velocidade média do líquido transportador, $x$ é a distância da parede de acumulação e $w$ é a espessura do canal.

O parâmetro de retenção $R$ é definido como a velocidade média de uma espécie em particular em relação à velocidade média do transportador $<v>$. $A$ velocidade média $V$ é a soma do produto de todas as diferentes taxas de fluxo no canal e a concentração da amostra correspondente $c(x)^{*} v(x)$ dividido pela soma de todas as concentrações $c(x)$.

$$
R=\frac{V}{\langle v\rangle}=\frac{t_{0}}{t_{r}}=\frac{V_{0}}{V_{r}}=\frac{\langle c(x) \cdot v(x)\rangle /\langle c(x)\rangle}{\langle v\rangle}
$$

A partir das três equações acima, o parâmetro de retenção $R$ pode ser expresso como descrito abaixo (Giddings et al., 1976):

$$
\begin{aligned}
& R=6 \cdot \lambda \cdot\left[\operatorname{coth}\left(\frac{1}{2 \cdot \lambda}\right)-2 \cdot \lambda\right] \\
& \lambda=\frac{L}{w}=\frac{1}{w} \cdot \frac{D}{U}=\frac{1}{w} \cdot \frac{k_{B} T}{F}
\end{aligned}
$$

Em que $\lambda$ é a espessura adimensional ou a espessura da camada reduzida, $L$ representa a média de espessura da camada, $w$ é a espessura do canal, $U$ é a velocidade de arraste, $D$ é o coeficiente de difusão, $T$ é a 
temperatura, $k_{B}$ representa a constante de Boltzmann e $F$ é a força que age sobre o soluto.

No Flow Field-Flow Fractionation (FFFF), solutos são transportados contra a parede de acumulação com velocidade $U$ pelo fluxo vertical $V_{x}$. A velocidade $\dot{U}$ pode ser expressa conforme a seguir:

$$
\dot{U}=\frac{\dot{V_{x}}}{A}=\frac{\dot{V}_{x} w}{V_{0}}
$$

Em que $\dot{V}_{x}$ é a taxa de fluxo perpendicular volumétrico, $A$ é a área de superfície da parede de acumulação, $V_{0}$ é o volume do canal e $w$ é a espessura do canal.

A força $F$ que atua sobre o soluto é definido abaixo (Schimpf et al., 2000):

$$
F=\frac{\dot{V_{x}} \cdot w}{V_{0}} \cdot f
$$

O parâmetro de retenção $R$ para o AF4 é descrito pela equação a seguir:

$$
R=\frac{t_{0}}{t_{r}} \approx 6 \lambda \operatorname{com} \lambda=\frac{k_{B} \cdot T}{w \cdot F}
$$

Em que to é o tempo de vácuo, $t_{r}$ é o tempo de retenção, $\lambda$ é a espessura da camada reduzida, $w$ é a espessura do canal, $T$ é a temperatura, $k_{B}$ representa a constante de Boltzmann e $F$ é a força que age sobre o soluto.

O raio hidrodinâmico $R_{h}$ é calculado a partir da relação de Stokes-Einstein e o coeficiente de difusão $D$; neste experimento foi calculado a partir da equação de retenção conforme a seguir (Roessner, 2006): 


$$
\begin{aligned}
& R_{h}=\frac{k_{B} \cdot T}{6 \cdot \pi \cdot \eta \cdot D} \\
& D=\frac{t_{0} \cdot w^{2} \cdot \dot{V}_{x}}{6 \cdot t_{r} \cdot V_{0}}
\end{aligned}
$$

Nestes experimentos a distribuição de tamanho das partículas $\left(R_{h}\right)$ e a massa molar $\left(\mathrm{g} \mathrm{mol}^{-1}\right)$ dos nano-hidrogéis de GEL, PEG e MIX foram obtidos utilizando o AF4 acoplado ao detector de espalhamento de luz de laser multiangular (MALLS). O equipamento é constituído pelo sistema de separação Eclipse ${ }^{\circledR}$ acoplado ao detector de espalhamento de luz de laser multiangular DAWN EOS, Wyatt Technology, Santa Barbara, CA. A configuração do equipamento está apresentada na FIG. 13. A coleta e o processamento de dados das amostras foram realizados pelo software ASTRA V.

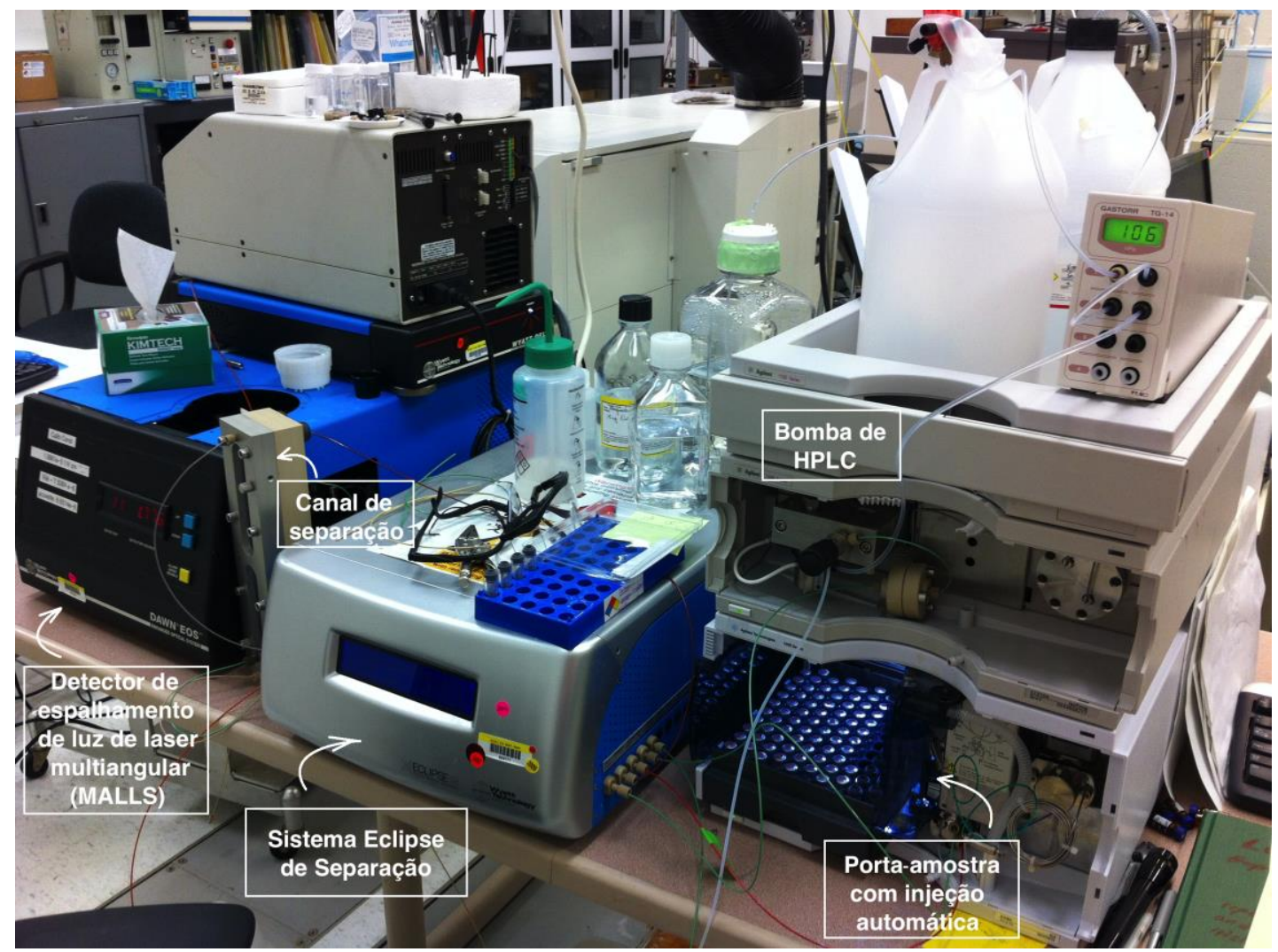

FIGURA 13 - Configuração do AF4 (Wyatt Technology Corp.) para as medições de $R_{h}$ e massa molar. 


\subsection{Análise estatística}

A análise estatística dos resultados foi realizada aplicando-se a análise de variância (ANOVA) por meio de um software Statgraphics Plus 3.1 (Statistical Graphics Corp). E quando detectada uma diferença significativa entre as médias dos grupos $(p \leq 0,05)$, elas foram comparadas e analisadas pelo teste de Fisher. Para todos os testes estatísticos o nível de significância utilizado foi $p \leq 0,05$. Os dados foram apresentados como: média \pm desvio padrão.

\subsection{Instalações de irradiação}

\subsubsection{Instalações de aceleradores de elétrons}

\subsubsection{Acelerador de elétrons (EB)}

No acelerador, os elétrons são produzidos em um cátodo de tungstênio aquecido mantido em uma região de potência mais elevada. A potência máxima do feixe está diretamente relacionada com a voltagem de aceleração e a corrente de elétrons. Esses elétrons são acelerados por uma diferença de potencial aplicada entre o cátodo e o ânodo. Com a aceleração os elétrons adquirem energia suficiente para atravessar a janela de saída, constituída por uma folha de titânio que apresenta resistência mecânica suficiente para suportar a pressão atmosférica do exterior (Bly, 1988; Singh \& Silverman, 1992). A FIG 14 mostra um acelerador Dymamitron II utilizado para aplicações industriais.

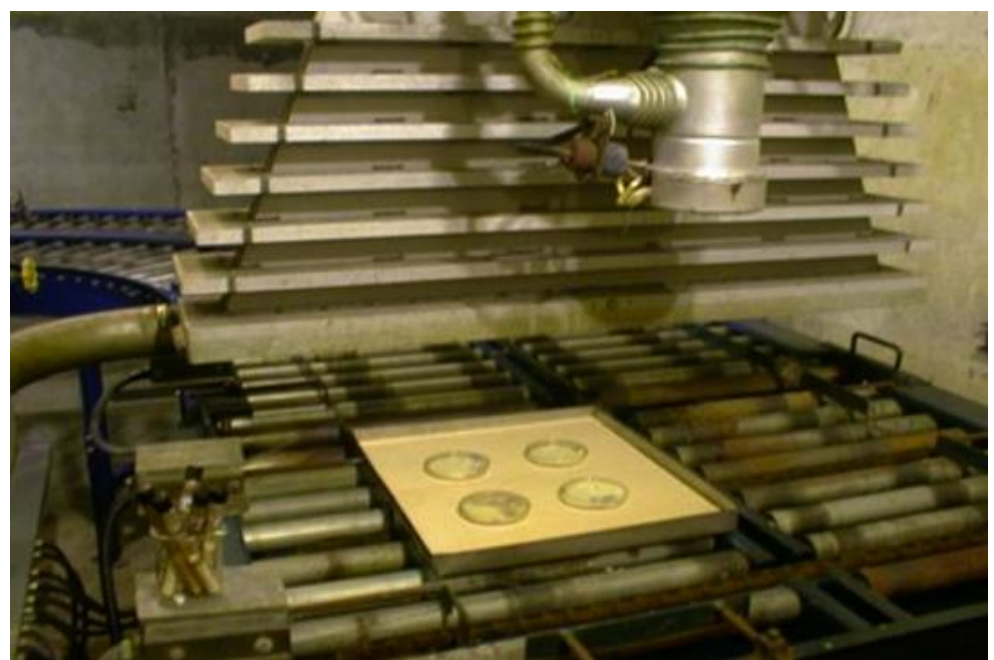

FIGURA 14 - Acelerador de elétrons Dynamitron II, CTR (IPEN-CNEN/SP). 


\subsubsection{Acelerador de elétrons (LINAC)}

O acelerador linear de feixe de elétrons (LINAC) pulsado (FIG. 15) consiste de um transformador de pulso, um canhão de elétrons, alojamento do canhão (que consiste da direção canhão, ânodo e colimador), bobinas magnéticas, guia do acelerador, fonte de alimentação, bomba de vácuo e o chassi do regulador de corrente. Os pulsos de elétrons são emitidos por um filamento aquecido para a cavidade da estrutura do guia de onda do acelerador (cerca de 1,5 m de comprimento) com uma largura de pulso de 3 microssegundos ( $\mu \mathrm{s})$, a uma contínua taxa de repetição variável de até cerca de 550 pulsos por segundo em um nível de pulso de cerca de $80 \mathrm{kV}$. O filamento é composto por aluminato de bário $\left(\mathrm{BaAl}_{2} \mathrm{O}_{4}\right)$, que é um material termiônico. Quando aquecidos, os elétrons são evaporados e quebrados livremente a partir dos átomos da superfície. Os elétrons emitidos são acelerados para o cátodo por um potencial controle de 3 kV DC, focados, e, em seguida, passados por uma abertura de colimação. Uma fina lente magnética colocada entre o cátodo e o colimador provoca a variação de corrente injetada por causar a mudança na distância focal e diâmetro do colimador do feixe (Jones, 2001).

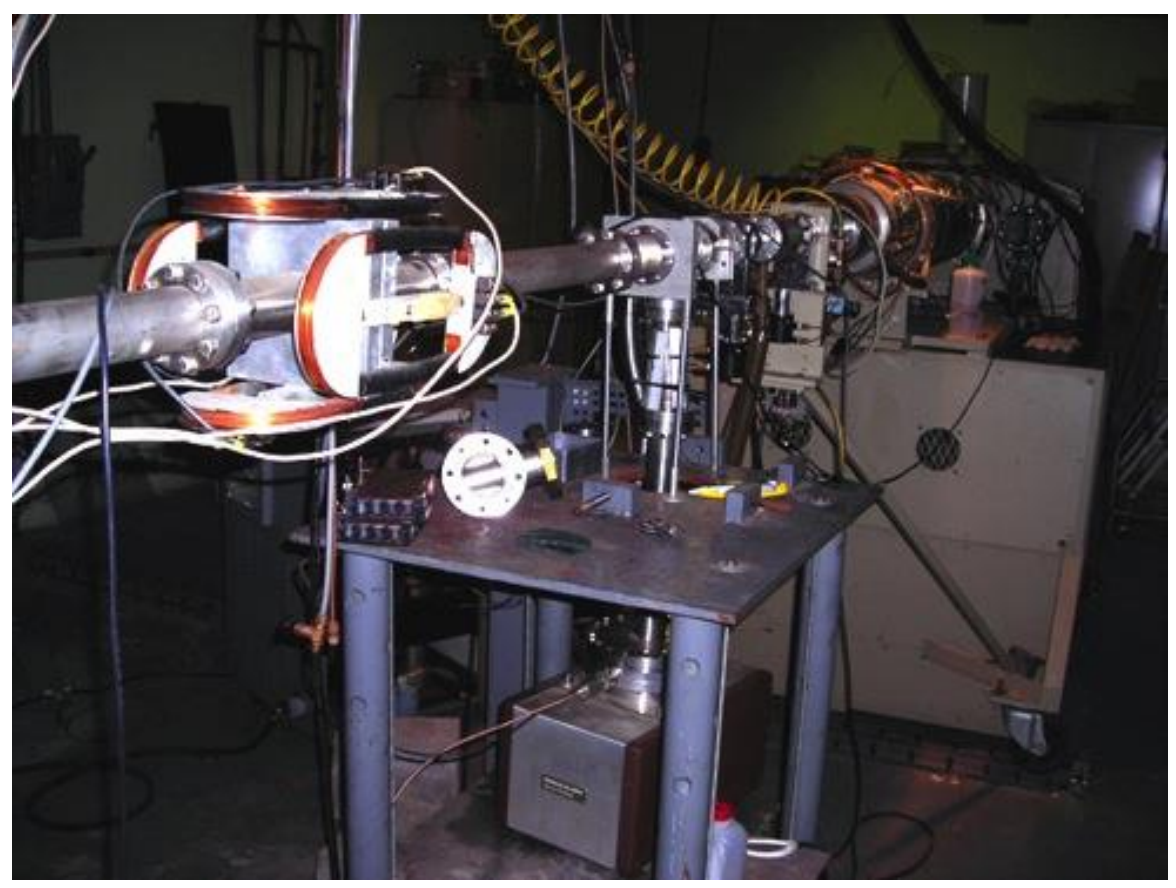

FIGURA 15 - Instalação do LINAC da University of Maryland, College Park (UMCP). 


\subsubsection{Instalações da radiação gama}

Em toda fonte de radiação gama de ${ }^{60} \mathrm{Co}\left(\mathrm{T}_{1 / 2}: 5,263\right.$ anos; $\beta^{-}: 0,314 \mathrm{MeV} ; \quad \gamma: 1,173$ e 1,332 MeV) a energia de decaimento beta é completamente absorvida pelo revestimento de aço inoxidável onde o material do radioisótopo ${ }^{60} \mathrm{Co}$ é colocado, fazendo com que o efeito da radiação beta se torne insignificante. Exemplo de fonte de ${ }^{60} \mathrm{Co}$ é mostrado na FIG 16 e 17.

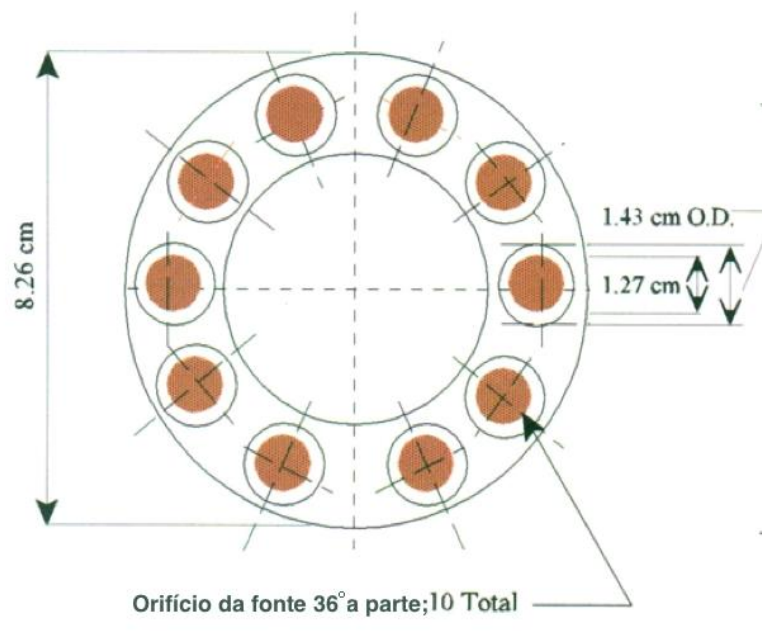

(A) Vista de cima

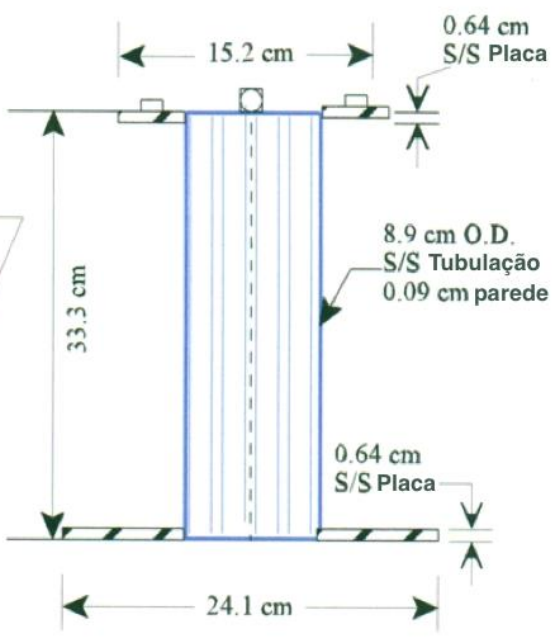

(B) Vista lateral

FIGURA 16 - Esquema da fonte gama de ${ }^{60}$ Co e armazenamento da UMCP.

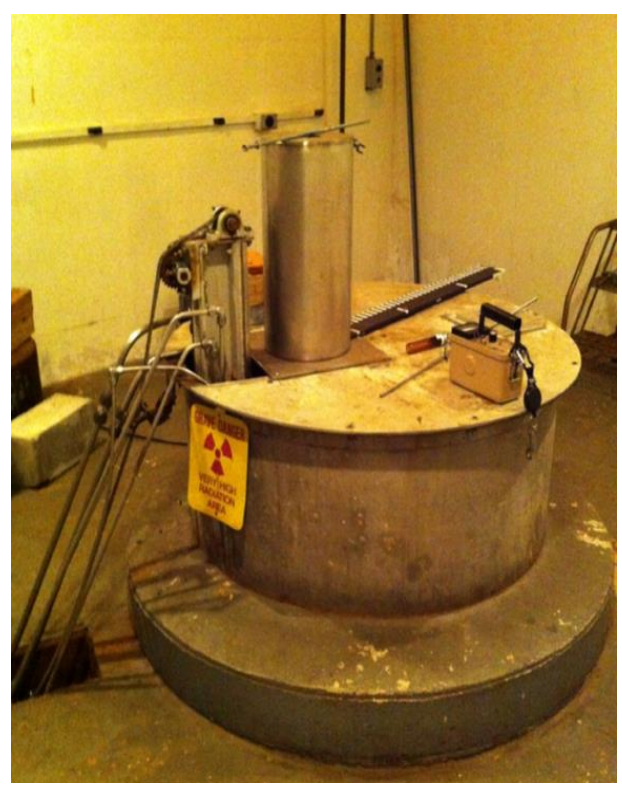


FIGURA 17 - Instalação da fonte gama de ${ }^{60} \mathrm{Co}$ da UMCP.

\subsubsection{Dosimetria}

A dosimetria é importante para validar o processo e estabelecer a distribuição de dose no produto. Para determinar a dose depositada num sistema, podem ser utilizados filmes radiocrômicos (Spinks \& Woods, 1990). 


\section{FILMES A BASE DE GELATINA OBTIDOS POR RADIAÇÃO IONIZANTE}

Este capítulo é dedicado ao estudo de filmes a base de gelatina envolvendo GLY, PVA, BHT, acrilamida e/ou fibra vegetal, irradiados no acelerador de elétrons Dynamitron II. As propriedades dos materiais desenvolvidos serão analisadas e discutidas neste capítulo.

Este capítulo foi subdividido em dois subcapítulos: 5.1 Compósitos de gelatina (GEL) envolvendo a glicerol (GLY), acrilamida e fibra, irradiados no acelerador de elétrons e 5.2 Filmes a base de GEL envolvendo o GLY, PVA ou BHT e irradiados no acelerador de elétrons.

\subsection{Preparação de compósitos de gelatina e fibra do ouriço da castanha do Brasil}

\subsubsection{Material}

Amostras de gelatina (GEL) tipo B de origem bovina, grau alimentício, da Gelita do Brasil Ltda (240Bloom/10mesh) foram utilizadas no desenvolvimento de filmes com diferentes características. Outros produtos foram empregados para compor os filmes: glicerina (GLY) PA ACS, cod. 15375 da Casa Americana de Art. Lab. Ltda (CAAL), Art Mono Acrilamida $\mathrm{H}$ foi cedida pela Aratorp Industrial. A fibra lignocelulósica utilizada foi proveniente dos resíduos descartados pelas indústrias de processamento de castanha do Brasil fornecida pela Amazon Brazil Nuts.

\subsubsection{Preparo das amostras}

Inicialmente as fibras do ouriço da castanha do Brasil foram lavadas em água destilada para remover as impurezas. As fibras foram secas em estufa a $80 \pm 2{ }^{\circ} \mathrm{C}$. Em seguida, as fibras secas foram reduzidas a um pó fino, com dimensões de partículas iguais ou menores do que $250 \mu \mathrm{m}$, utilizando moinho de 
bolas. Após testes preliminares, chegou-se a estabelecer os percentuais utilizados a seguir. Os espécimes de gelatina, de 3,2 $\mathrm{mm}$ de espessura, reforçados com $10 \%$ do ouriço da castanha do Brasil, foram preparados pela dissolução da GLY como plastificante (20\% p/p), adição de acrilamida ( $25 \%$ p/p) e GEL $(25 \% \mathrm{p} / \mathrm{p})$ em água destilada em banho de água a $70^{\circ} \mathrm{C}$. Após homogeneização, as fibras foram adicionadas, permanecendo sob agitação por 30 minutos. O sistema GEL/acrilamida/fibra vegetal foi moldado em placas de vidro, forradas com filme de polietileno e mantidos a temperatura ambiente até o momento da irradiação.

\subsubsection{Irradiação}

Para desenvolver os filmes a base de gelatina foi utilizado o acelerador de elétrons Dynamitron II, Radiation Dynamics Inc. localizado no Centro de Tecnologia das Radiações (CTR), IPEN-CNEN/SP. Amostras de GEL reforçadas com fibra vegetal de ouriço da castanha do Brasil foram tratadas com doses de 20 e 40 kGy, empregando os seguintes parâmetros: energia 1,202 MeV, corrente de feixe 0,62 $\mathrm{mA}$, taxa de dose 2,81 $\mathrm{kGy} \mathrm{s}^{-1}$, velocidade da bandeja de 6,72 $\mathrm{m} \mathrm{min}^{-1}$, uso de temperatura ambiente, na presença de ar em todas as amostras. Após a irradiação, as amostras foram colocadas em sacos plásticos e armazenadas em ambiente seco e no abrigo de luz por sete dias. Após a estocagem, foram realizados a análise da fração gel, o teste de absorção de água, a TGA e a caracterização morfológica dos materiais compósitos no MEV.

\subsubsection{Resultados e Discussão}

A melhoria das propriedades mecânicas pelo tratamento por EB já foi observado em diferentes sistemas poliméricos que incluem adição de fibras polissacarídicas (Czvikovzky, 1985; Ramires et al., 2013).

No sistema GEL/acrilamida/fibra vegetal as amostras não irradiadas apresentaram aspecto visual de um material elástico, opaco e adesivo (Inamura et al., 2010).

As amostras submetidas à irradiação apresentaram uma diminuição do aspecto de consistência elástica e adesiva, e o brilho foi intensificado. A eficiência de reticulação induzida pela irradiação foi estimada pela determinação da fração gel por extração com água (TAB. 1). O aumento significativo $(p \leq 0,05)$ da absorção 
de água e da fração gel com a dose de radiação por EB evidencia a reticulação e, consequentemente, a formação de um hidrogel como resultado dessa absorção de água, que é um resultado obtido por Vijayabaskar et al. (2008). Uma observação semelhante a da extensão de reticulação dada pelo aumento da fração gel com o aumento da dose de radiação foi notado em um sistema PVC reforçado com OPEFB (fibras de palma) (Ratnam et al., 2007). Outros pesquisadores obtiveram resultados análogos em outros sistemas (Lee et al., 2013; Liu et al., 2012; Sengupta et al., 2006; Wang et al., 2007).

TABELA 1 - Fração sol (Fs), fração gel (Fg) e absorção de água de compósitos de gelatina e fibra do ouriço da castanha do Brasil irradiados em diferentes doses de radiação no EB.

\begin{tabular}{cccc}
\hline Dose (kGy) & Fs (\%) & Fg (\%) & Absorção de água (\%) \\
\hline $\mathbf{0}$ & $94,3 \pm 0,7^{\mathrm{a}}$ & $5,7 \pm 0,7^{\mathrm{a}}$ & $93,1 \pm 10,6^{\mathrm{a}}$ \\
$\mathbf{2 0}$ & $72,3 \pm 0,9^{\mathrm{b}}$ & $27,7 \pm 0,9^{\mathrm{b}}$ & $213,9 \pm 9,3^{\mathrm{b}}$ \\
$\mathbf{4 0}$ & $66,1 \pm 1,6^{\mathrm{c}}$ & $33,9 \pm 1,6^{\mathrm{c}}$ & $283,9 \pm 3,2^{\mathrm{c}}$
\end{tabular}

Médias na mesma coluna com diferentes letras minúsculas são significativamente diferentes $(p \leq 0,05)$ de acordo com o teste LSD.

Segundo a literatura, as alterações nas propriedades de sorção estão relacionadas à cristalinidade do material (Chapiro, 1988). Jones et al. (1999) mencionaram que houve uma boa concordância entre os vários métodos utilizados na análise da fração gel de polietileno linear de baixa densidade (LLDPE) irradiados, confirmando a presença de reações em cadeia mediadas por radicais livres, mesmo sob condições significativas de vácuo. Eles propuseram que as reações em cadeia explicam a maior parte do desvio de comportamento ideal de Charlesby-Pinner de polímeros irradiados.

A caracterização morfológica desses materiais compósitos irradiados em EB foi realizada por MEV (FIG. 18). As micrografias mostraram uma dispersão homogênea da fibra na matriz polimérica. Pelas micrografias das amostras irradiadas a 20 kGy, (b) e (e), pôde-se observar que a lacuna entre a fibra e a matriz polimérica diminuiu, o que poderia sugerir uma melhoria da aderência entre fibra e matriz. Porém, na FIG. 18 (e) é perceptível a ocorrência de pequenas 
bolhas, resultado do processo de irradiação, que pode ter comprometido alguma das propriedades do material compósito. Ismail \& Nurdin (1998) mostraram uma melhoria das propriedades mecânicas com a forte adesão entre a fibra e a matriz. Segundo Moura et al. (2010) materiais compósitos de EVOH e piaçava apresentaram uma superfície lisa e melhor adesão interfacial como consequência da irradiação. Porém, de acordo com esses pesquisadores, as doses aplicadas foram insuficientes para apresentar diferenças significativas entre as amostras irradiadas e não irradiadas.

Outros pesquisadores observaram uma superfície rugosa e irregular na MEV da gelatina pura. Esta característica domina a superfície de membrana de gelatina pura (Rahman et al., 2010).
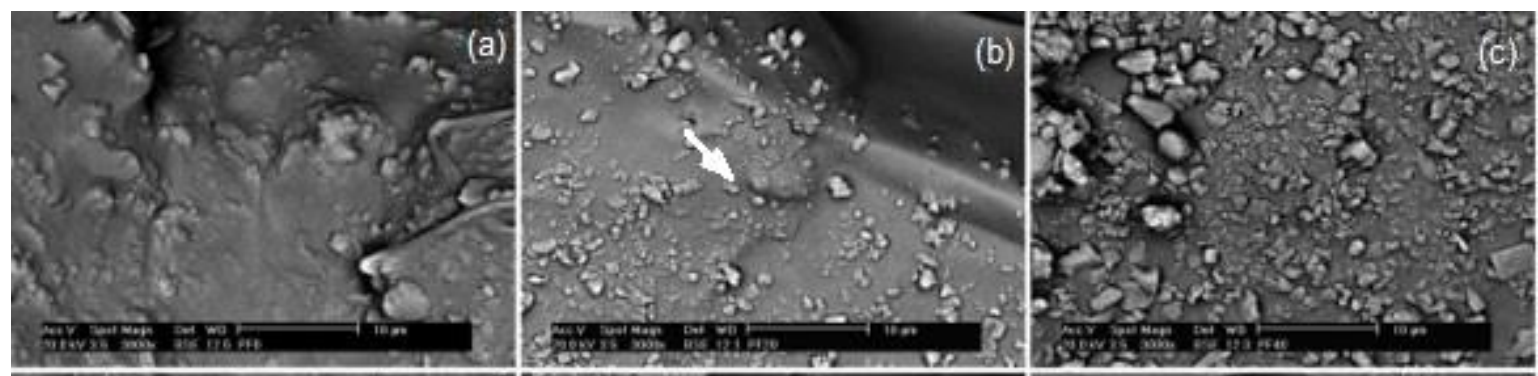

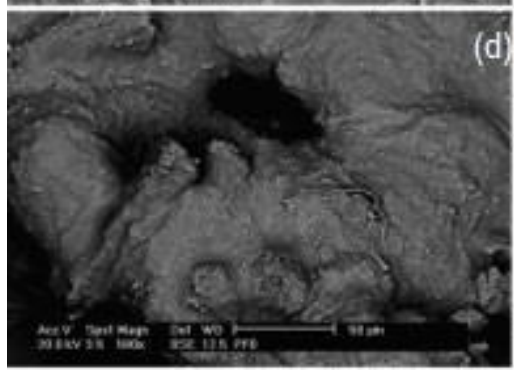

0 kGy

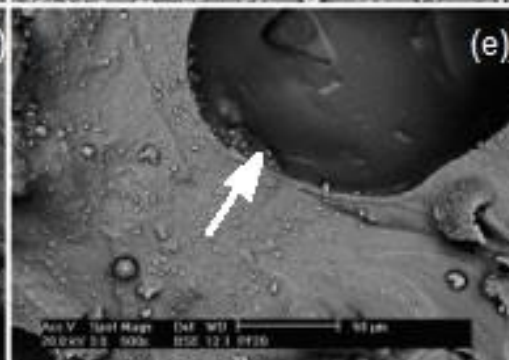

20 kGy

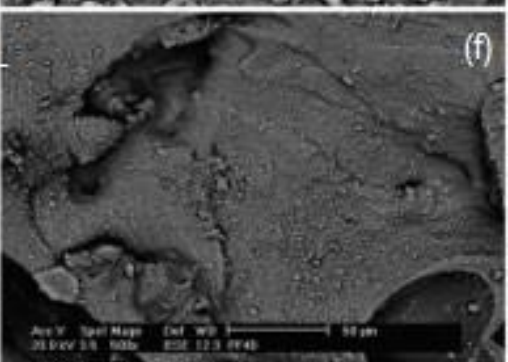

40 kGy

FIGURA 18 - Imagens de MEV de compósitos de gelatina e fibra do ouriço da castanha do Brasil irradiados em diferentes doses de radiação: (a) não irradiado (3000x); (b) 20 kGy (3000x); (c) 40 kGy (3000x); (d) não-irradiado (500x); (e) 20 kGy (500x); (f) 40 kGy (500x).

A estabilidade térmica ou degradação padrão dos produtos foram avaliadas por análise termogravimétrica (TGA). Os resultados obtidos (TAB. 2) apresentaram duas regiões de transformação de perda de massa. A primeira 
região de transformação foi atribuída à perda de água e a evaporação de voláteis. Essa perda de massa foi significativa $(p \leq 0,05)$ entre as doses estudadas, que ocorre entre a temperatura ambiente e $140^{\circ} \mathrm{C}$, correspondendo a uma perda de massa de $28,3 \pm 0,6 \%$ e $11,8 \pm 0,7 \%$ para as amostra 0 kGy e 40 kGy, respectivamente.

Resultados similares foram apresentados por Mu et al. (2013) em nanocompósitos de GEL-PEG-MMT (argila montmorillonite), em que a primeira decomposição térmica, no intervalo de $130-220^{\circ} \mathrm{C}$, foi atribuída à perda de compostos de baixa massa molecular, especialmente a água ligada. Os resultados apresentados também estão de acordo com Barreto et al. (2003), que observaram um comportamento semelhante ao de produtos de gelatina no primeiro estágio de transformação, até $200{ }^{\circ} \mathrm{C}$. Rahman et al. (2010) também observaram que o primeiro estágio de perda de massa, a cerca de $130-150{ }^{\circ} \mathrm{C}$, estava relacionado à perda de água em amostras de gelatina irradiada pura. Kaminśka \& Sionkowska (1996) também chegaram a resultados análogos no estudo do efeito da radiação UV na degradação do colágeno.
TABELA 2 - Análise termogravimétrica de compósitos de gelatina e fibra do ouriço da castanha do Brasil não irradiados e irradiados em EB a 20 e 40 kGy.

\begin{tabular}{|c|c|c|c|c|c|c|}
\hline \multirow{2}{*}{$\begin{array}{l}\text { Dose } \\
\text { (kGy) }\end{array}$} & \multicolumn{3}{|c|}{$1^{\mathrm{a}}$ região transformação } & \multicolumn{3}{|c|}{$2^{\mathrm{a}}$ região transformação } \\
\hline & 0 & 20 & 40 & 0 & 20 & 40 \\
\hline $\operatorname{Td}^{1}\left({ }^{\circ} \mathrm{C}\right)$ & $46 \pm 2^{\mathrm{B}}$ & $44 \pm 1^{B C}$ & $75 \pm 2^{A}$ & $191 \pm 3^{B}$ & $180 \pm 2^{C}$ & $206 \pm 1^{A}$ \\
\hline $\operatorname{Tm}^{2}\left({ }^{\circ} \mathrm{C}\right)$ & $91 \pm 1^{\mathrm{A}}$ & $86 \pm 2^{C}$ & $90 \pm 1^{A B}$ & $247 \pm 1^{A}$ & $240 \pm 3^{C}$ & $246 \pm 2^{A B}$ \\
\hline $\operatorname{Tf}^{3}\left({ }^{\circ} \mathrm{C}\right)$ & $141 \pm 2^{A}$ & $140 \pm 2^{A B}$ & $118 \pm 1^{C}$ & $288 \pm 2^{C}$ & $290 \pm 1^{C B}$ & $300 \pm 2^{A}$ \\
\hline$W^{4}(\%)$ & $28,3 \pm 0,6^{A}$ & $25,9 \pm 0,7^{B}$ & $11,8 \pm 0,7^{\circ}$ & $56,3 \pm 0,9^{C}$ & $64,0 \pm 0,9^{\mathrm{B}}$ & $71,3 \pm 0,9^{A}$ \\
\hline $\begin{array}{l}\text { Médias na } \\
\text { acordo com } \\
1 \text { Início da ter } \\
2 \text { Temperatur } \\
3 \text { Final da ten } \\
4{ }^{4} \text { Pico de per }\end{array}$ & $\begin{array}{l}\text { ratura de deg } \\
\text { de massa }\end{array}$ & $\begin{array}{l}\text { diferentes lett } \\
\text { dação } \\
\text { cão } \\
\text { dação }\end{array}$ & maiúsculas & o significativan & ente diferentes & $(p \leq 0,05)$ de \\
\hline
\end{tabular}

A segunda região de transformação descrita na TAB. 2 corresponde à taxa de degradação máxima que se inicia em $180^{\circ} \mathrm{C}$ e vai até $300^{\circ} \mathrm{C}$, mostrando 
que houve perda de massa significativa $(p \leq 0,05)$, entre 56,3 a $71,3 \%$. Vale ressaltar que o compósito irradiado a 40 kGy apresentou um ganho significativo $(p \leq 0,05)$, cerca de $8 \%$, no início da temperatura de degradação em comparação com o controle não irradiado. Esse ganho poderia ser atribuído à estabilidade térmica da gelatina, que apresenta uma ampla faixa de temperatura no estado vítreo, com o limite superior entre $205^{\circ} \mathrm{C}-210^{\circ} \mathrm{C}$, caracterizando-a como um material com ampla resistência ao calor (Kozlov \& Burdygina, 1983). A segunda etapa de degradação $\left(\mathrm{a} \sim 200^{\circ} \mathrm{C}\right)$ foi associada à ruptura da estrutura helicoidal da gelatina, que ocorre com a quebra dos segmentos da cadeia tripla em cadeias separadas (Kozlov \& Burdygina, 1983; Barreto et al., 2003; Peña et al., 2010). Rahman et al. (2010) analisaram blendas de óxido de polietileno (PEO)/Gelatina e observaram que a segunda perda de massa começou a cerca de $250{ }^{\circ} \mathrm{C}$, exibindo a extensão da degradação térmica da gelatina. Eles consideraram que a grande perda de massa no intervalo de $250-400{ }^{\circ} \mathrm{C}$ correspondente à blenda de PEO/GEL e deve-se à desintegração intermolecular e à quebra parcial da estrutura molecular. Eles mostraram também que a incorporação de PEO na GEL aumentou a estabilidade térmica da blenda. Kaminśka \& Sionkowska (1996) estabeleceram que a degradação pode ser possível após a ruptura de pontes de hidrogênio inter e intramoleculares, que são responsáveis pela manutenção da ordem da cadeia polimérica (alfa-hélice, betaestrutura) em filmes proteicos.

Com base nos resultados apresentados pelos compósitos de gelatina e fibra do ouriço da castanha do Brasil pôde-se concluir que:

- Após o processo de irradiação as amostras apresentaram uma diminuição do aspecto elástico, uma consistência menos adesiva e um brilho intensificado.

- A eficiência da reticulação radioinduzida foi estimada pelo aumento da fração gel: a amostra não irradiada apresentou um valor de $5,7 \pm 0,7 \%$ e a irradiada a $20 \mathrm{kGy}$ valor de $27,7 \pm 0,9 \%$.

- A estabilidade térmica e propriedades morfológicas do compósito de gelatina e ouriço da castanha do Brasil foram aprimoradas pela reticulação induzida pela radiação. 
- O aumento da absorção de água entre a amostra não irradiada $(93,1 \pm 10,6) \%$ e irradiada a $20 \mathrm{kGy}(213,9 \pm 9,3) \%$ evidenciou a reticulação e a formação de hidrogel.

- Pela análise termogravimétrica, as amostras irradiadas a 40 kGy apresentaram um ganho de $8 \%$ do início da temperatura de degradação em relação às amostras não irradiadas de $191 \pm 3^{\circ} \mathrm{C}$ para $206 \pm 1^{\circ} \mathrm{C}$ fato atribuído à estabilidade térmica da gelatina conferida pelo estado vítreo.

\subsection{Preparação de filmes a base de gelatina com PVA ou BHT}

\subsubsection{Material}

Amostras de gelatina (GEL) tipo B de origem bovina, grau alimentício, da Gelita do Brasil Ltda (240Bloom/10mesh) foram utilizadas no desenvolvimento de filmes com diferentes características. Outros produtos foram empregados na composição do filme: glicerina (GLY) PA ACS, cod. 15375 da Casa Americana de Art. Lab. Ltda (CAAL) como plastificante, PVA (Mowiol 40/88) da Clariant, hidroxitolueno butilado (BHT) da Quiminvest.

\subsubsection{Preparação de filme a base de GEL/PVA}

Após testes preliminares, chegou-se a estabelecer os percentuais descritos a seguir. A solução aquosa envolvendo GEL 10\% (p/p), GLY 5\% (p/p) foi preparada dissolvendo-as em banho-maria $60^{\circ} \mathrm{C}$ por 30 minutos. $\mathrm{O}$ PVA $12 \%(\mathrm{p} / \mathrm{v})$ foi dissolvido em água destilada em banho-maria $90^{\circ} \mathrm{C}$ até a completa dissolução. Em seguida, o PVA foi adicionado à solução a base de GEL em diferentes porcentagens: 0\% (PVAf), 5\% (5\% PVA) e 10\% (10\% PVA) e dissolvidos em banho-maria a $60^{\circ} \mathrm{C}$ por 30 minutos sob constante agitação. $\mathrm{O}$ sistema GEL/PVA foi moldado em placas de vidro forradas com filme de polietileno e levados para a estufa $25,0 \pm 0,1^{\circ} \mathrm{C}$ com convecção de ar por até $48 \mathrm{~h}$ para secagem dos filmes. Depois do período de secagem, os filmes foram irradiados seguindo os parâmetros descritos na seção 5.2.3 a seguir. Após sete dias de armazenamento foram realizados os testes de resistência mecânica, cor, absorção de água, umidade e solubilidade. 


\subsubsection{Preparação de filme a base de GEL/BHT}

Após testes preliminares, chegou-se a estabelecer os percentuais descritos a seguir. As soluções aquosas de GEL 10\% (p/p), GLY 5\% (p/p) foram preparadas em banho-maria $60^{\circ} \mathrm{C}$ por 30 minutos, sob constante agitação. Para avaliar os efeitos da incorporação de BHT em filmes a base de GEL, foram adicionados BHT 17 ppm à solução aquosa. Ambas as soluções homogêneas, sem BHT (BHTf) e contendo BHT (BHT), foram moldadas em placas de vidro com filme de polietileno e secas por $48 \mathrm{~h}$ em estufa com circulação de ar $25,0 \pm 0,1^{\circ} \mathrm{C}$. Depois do período de secagem, os filmes foram irradiados e armazenados seguindo as condições descritas na seção 5.2.3 a seguir. Para estudar a influência da adição do antioxidante, BHT, os filmes foram armazenados por 7, 14 e 60 dias e posteriormente realizados os testes de resistência mecânica, cor, absorção de água, umidade e solubilidade.

\subsubsection{Irradiação}

Para desenvolver os filmes a base de gelatina com PVA ou BHT foi empregado também o acelerador de elétrons Dynamitron II, Radiation Dynamics Inc. localizado no Centro de Tecnologia das Radiações (CTR), IPEN-CNEN/SP, utilizando os seguintes parâmetros: taxa de dose 22,41 kGy s${ }^{-1}$, energia 1,407 MeV, corrente de feixe 5,4 $\mathrm{mA}$, velocidade da esteira de 6,72 $\mathrm{m} \mathrm{min}^{-1}$, em temperatura ambiente e na presença de ar. Após a irradiação, as amostras foram mantidas no abrigo de luz, em dessecador com sílica e em temperatura ambiente.

As amostras de filmes a base de GEL adicionadas de 5\% PVA e 10\% PVA foram irradiadas a 10 e $20 \mathrm{kGy}$.

Os filmes a base de GEL com adição de BHT e BHTf foram irradiados com doses de irradiação: 20, 40 e 60 kGy.

\subsubsection{Resultados e Discussão}

\subsubsection{Filmes a base de GEL/PVA}

As propriedades mecânicas dos filmes, não irradiados e irradiados, a base de GEL/PVA estão apresentadas na TAB. 3, representadas pela resistência à perfuração e deformação. As amostras PVAf apresentaram um aumento $(p \leq 0,05)$ da resistência à perfuração e diminuição da deformação com o aumento 
da dose de radiação. Para as amostras 5\% PVA houve um decréscimo $(p \leq 0,05)$ da resistência à perfuração e da deformação dos filmes com o incremento da dose.

TABELA 3 - Resistência à perfuração e deformação de amostras de filmes de gelatina com adição de 0 (PVAf), 5 e 10\% de PVA não irradiadas e irradiadas no EB a 10 e 20 kGy.

\begin{tabular}{llccc}
\hline Propriedades & Amostra & \multicolumn{3}{c}{ Dose (kGy) } \\
\cline { 3 - 5 } & & 0 & 10 & 20 \\
\hline Resistência à & PVAf & $70 \pm 10^{\mathrm{Cc}}$ & $76 \pm 9^{\mathrm{CBa}}$ & $78 \pm 11^{\mathrm{ABb}}$ \\
Perfuração & 5\%PVA & $82 \pm 8^{\mathrm{Aa}}$ & $77 \pm 9^{\mathrm{ABa}}$ & $65 \pm 7^{\mathrm{Cc}}$ \\
$(\mathrm{N})$ & 10\%PVA & $81 \pm 7^{\mathrm{Aba}}$ & $82 \pm 8^{\mathrm{Aa}}$ & $84 \pm 9^{\mathrm{Aba}}$ \\
\hline & PVAf & $54,5 \pm 0,7^{\mathrm{Ab}}$ & $51,0 \pm 0,7^{\mathrm{Bc}}$ & $48,3 \pm 0,4^{\mathrm{Cc}}$ \\
Deformação & 5\%PVA & $58,3 \pm 0,5^{\mathrm{Aa}}$ & $58,1 \pm 0,5^{\mathrm{ABa}}$ & $52,4 \pm 0,3^{\mathrm{Cb}}$ \\
(\%) & 10\%PVA & $53,7 \pm 0,4^{\mathrm{Abc}}$ & $53,6 \pm 0,4^{\mathrm{Ab}}$ & $54,3 \pm 0,6^{\mathrm{Aab}}$ \\
\hline
\end{tabular}

Médias na mesma linha com diferentes letras maiúsculas e médias na mesma coluna com diferentes letras minúsculas são significativamente diferentes $(p \leq 0,05)$ de acordo com o teste LSD.

Pela comparação de todas as amostras, pôde-se observar que a amostra 10\% PVA irradiada a 20 kGy apresentou a maior resistência à perfuração $(84 \pm 9) \mathrm{N}$. Houve também diferença significativa $(p \leq 0,05)$ entre as amostras 10\% PVA e PVAf (sem aditivo) em relação à melhoria da resistência com o aumento da dose de radiação. A deformação diminuiu com o aumento da dose de radiação comparando PVAf e 5\% PVA (TAB. 3). O aumento da resistência à ruptura associado ao aumento da dose de radiação já tinha sido mencionado por Inamura et al. (2009) trabalhando com outros filmes de gelatina. É preciso salientar também a importância do plastificante e a sua concentração na obtenção de filmes. Galdeano (2007) destacou que os agentes plastificantes reduzem as interações entre as cadeias adjacentes do biopolímero, o que leva ao aumento da mobilidade e, assim, à flexibilidade dos filmes (Bergo \& Sobral, 2007; Mali et al., 2005; Garcia et al., 2000b).

A absorção de água, o teor de umidade e a solubilidade dos filmes a base de gelatina mostraram diferente comportamento na presença de 0, 5 e 10\% de PVA. Também, as amostras apresentaram comportamento diferente 
dependendo da dose aplicada (TAB. 4). A absorção de água diminuiu com o aumento da dose de radiação para as amostras PVAf e 5\% PVA. Contrariamente, os resultados das amostras de 10\% PVA mostraram uma situação anômala: houve um aumento com a dose de radiação $(p \leq 0,05)$. Essa singularidade pode ser resultado da influência particular na relação entre a estrutura polimérica e a sensibilidade frente à radiação de alta energia aplicada.

A umidade e solubilidade sofreram discreta variação $(p \leq 0,05)$ entre as amostras não irradiadas e irradiadas e na presença do PVA. Novamente, no caso da aplicação de dose de 10 kGy é possível observar comportamento anômalo que remeteria à natureza da reação de reticulação diferenciada para esse valor da energia absorvida.

Cataldo et al. (2008) mencionaram que obtiveram reticulação de gelatina extraída de colágeno de pele suína e a transformaram em um hidrogel estável permanentemente por y-radiação. Strauss \& Gibson (2004) induziram reticulação utilizando compostos fenólicos de plantas como agentes reticulantes no lugar da radiação ionizante. Os géis reticulados por esses meios mostraram ter maior resistência mecânica, menor grau de absorção de água e menos grupos amino livres. Estas propriedades de géis de gelatina reticuladas e coacervatos a base de gelatina têm aplicações para o desenvolvimento de novos ingredientes alimentares.

TABELA 4 - Absorção de água, umidade e solubilidade dos filmes a base de gelatina com adição de 0 (PVAf), 5 e 10\% de PVA não irradiadas e irradiadas no EB a 10 e 20 kGy.

\begin{tabular}{llccc}
\hline Propriedades & Amostra & \multicolumn{3}{c}{ Dose (kGy) } \\
\cline { 3 - 5 } & & 0 & 10 & 20 \\
\hline Absorção & PVAf & $247 \pm 2^{\mathrm{Ac}}$ & $243 \pm 24^{\mathrm{Ac}}$ & $239 \pm 14^{\mathrm{Ac}}$ \\
de água & 5\%PVA & $349 \pm 25^{\mathrm{Ab}}$ & $328 \pm 16^{\mathrm{Bb}}$ & $313 \pm 10^{\mathrm{CBb}}$ \\
$(\%)$ & 10\%PVA & $370 \pm 7^{\mathrm{Cab}}$ & $416 \pm 14^{\mathrm{Aa}}$ & $381 \pm 9^{\mathrm{Ba}}$ \\
\hline & PVAf & $19,1 \pm 0,9^{\mathrm{Aa}}$ & $17,1 \pm 0,5^{\mathrm{Cb}}$ & $17,4 \pm 1,0^{\mathrm{BCc}}$ \\
Umidade & 5\%PVA & $16,1 \pm 0,6^{\mathrm{Cc}}$ & $17,4 \pm 0,7^{\mathrm{Bba}}$ & $17,6 \pm 0,6^{\mathrm{ABc}}$ \\
$(\%)$ & 10\%PVA & $16,4 \pm 0,4^{\mathrm{Bbc}}$ & $15,9 \pm 1,0^{\mathrm{BCc}}$ & $18,5 \pm 0,2^{\mathrm{Ac}}$ \\
\hline & PVAf & $39,5 \pm 0,8^{\mathrm{Cb}}$ & $42,6 \pm 0,7^{\mathrm{Ba}}$ & $42,6 \pm 0,7^{\mathrm{ABa}}$ \\
Solubilidade & 5\%PVA & $39,7 \pm 0,6^{\mathrm{Aba}}$ & $38,6 \pm 0,4^{\mathrm{Ab}}$ & $39,5 \pm 1,0^{\mathrm{Ab}}$ \\
& 10\%PVA & $37,4 \pm 0,6^{\mathrm{Bc}}$ & $36,9 \pm 0,6^{\mathrm{BCc}}$ & $38,4 \pm 0,5^{\mathrm{Ac}}$ \\
\hline
\end{tabular}

Médias na mesma linha com diferentes letras maiúsculas e médias na mesma coluna com diferentes letras minúsculas são significativamente diferentes $(p \leq 0,05)$ de acordo com o teste LSD. 
Os mecanismos moleculares que controlam a funcionalidade em filmes de gelatina são pouco compreendidos. Segundo Audette-Stuart et al. (2005), quando as proteínas são irradiadas em fase líquida, a maioria dos danos causados nas cadeias polipeptídicas está associada à ação dos radicais hidroxilas. Vieira \& Mastro (2002) estudaram o efeito de duas diferentes fontes de radiação ionizante, a radiação gama de fonte de ${ }^{60} \mathrm{Co}$ e a irradiação por EB na fragmentação da proteína de gelatina em meio aquoso. Eles relacionaram o decréscimo da viscosidade de soluções de gelatina à fragmentação da proteína, sendo que as doses de radiação apresentaram valores próximos comparáveis para ambos os processos de irradiação.

A mobilidade molecular de filmes de gelatina em água e glicerol moldados a quente e a frio também foi estudada por outros autores (Lukasik \& Ludescher, 2005). Eles consideraram que reticulações físicas, na realidade, aumentaram a mobilidade molecular da gelatina.

Resultados dos testes colorimétricos apresentados na TAB. 5 indicam que as alterações de cor nos filmes a base de GEL estão relacionadas às doses de radiação. As amostras apresentaram pequena diminuição da luminosidade $\left(L^{*}\right)$ com a dose aplicada. O parâmetro $-a^{*}$ (cor verde-azulado) aumentou $(p \leq 0,05)$ com o aumento da dose em todas as amostras, no entanto, diminuiu conforme aumentou a porcentagem de PVA. Para o parâmetro $+b^{*}$ (cor amarela) houve uma diminuição $(p \leq 0,05)$ com o aumento da dose. No entanto, com o aumento do teor de PVA houve redução do valor de $+b^{*}$. O aumento do valor do croma como resultado de um aumento da dose se refletiu no aspecto amarelado dos filmes. Houve também um acréscimo do ângulo Hue com o aumento da dose como apresentado na TAB. 5. Esses resultados são próximos a $90^{\circ}$ mostrando que estão na região da cor amarela do diagrama CIELAB (Voss, 1992). Similarmente, Jipa et al. (2012) observaram um decréscimo na luminosidade e aumento do amarelamento das amostras irradiadas em fonte gama de ${ }^{127} \mathrm{Cs}$. 
TABELA 5 - Parâmetros de cor de amostras de filmes de gelatina com adição de 0 (PVAf), 5 e 10\% de PVA não irradiadas e irradiadas no EB a 10 e 20 kGy.

\begin{tabular}{llccc}
\hline $\begin{array}{l}\text { Parâmetro } \\
\text { de cor }\end{array}$ & Amostra & \multicolumn{3}{c}{ Dose (kGy) } \\
\cline { 3 - 5 }$L^{*}$ & PVAf & $96,64 \pm 0,39^{\mathrm{Aa}}$ & $96,36 \pm 0,43^{\mathrm{ABa}}$ & $96,22 \pm 0,38^{\mathrm{CBa}}$ \\
& PVA 5\% & $96,54 \pm 0,18^{\mathrm{Aa}}$ & $96,45 \pm 0,16^{\mathrm{ABa}}$ & $96,27 \pm 0,12^{\mathrm{Ca}}$ \\
& PVA 10\% & $96,46 \pm 0,23^{\mathrm{Aa}}$ & $96,44 \pm 0,22^{\mathrm{ABa}}$ & $96,27 \pm 0,18^{\mathrm{Ca}}$ \\
\hline \multirow{2}{*}{$a^{*}$} & PVAf & $-0,42 \pm 0,07^{\mathrm{Ac}}$ & $-0,96 \pm 0,13^{\mathrm{Bc}}$ & $-1,18 \pm 0,26^{\mathrm{Cc}}$ \\
& PVA 5\% & $-0,36 \pm 0,04^{\mathrm{Ab}}$ & $-0,59 \pm 0,12^{\mathrm{Bb}}$ & $-0,80 \pm 0,09^{\mathrm{Cb}}$ \\
& PVA 10\% & $-0,14 \pm 0,04^{\mathrm{Aa}}$ & $-0,41 \pm 0,07^{\mathrm{Ba}}$ & $-0,73 \pm 0,06^{\mathrm{Cab}}$ \\
\hline \multirow{3}{*}{$b^{*}$} & PVAf & $4,43 \pm 0,23^{\mathrm{Cc}}$ & $6,70 \pm 0,63^{\mathrm{Ba}}$ & $8,37 \pm 1,16^{\mathrm{Aa}}$ \\
& PVA 5\% & $4,74 \pm 0,18^{\mathrm{Ca}}$ & $6,06 \pm 0,59^{\mathrm{Bb}}$ & $7,30 \pm 0,57^{\mathrm{Ac}}$ \\
& PVA 10\% & $4,60 \pm 0,16^{\mathrm{Cb}}$ & $5,98 \pm 0,29^{\mathrm{Bcb}}$ & $7,72 \pm 0,52^{\mathrm{Abc}}$ \\
\hline \multirow{3}{*}{ Croma } & PVAf & $4,4 \pm 0,2^{\mathrm{Cc}}$ & $6,8 \pm 0,6^{\mathrm{Ba}}$ & $8,5 \pm 1,1^{\mathrm{Aa}}$ \\
& PVA 5\% & $4,7 \pm 0,2^{\mathrm{Ca}}$ & $6,1 \pm 0,6^{\mathrm{Bb}}$ & $7,3 \pm 0,6^{\mathrm{Ac}}$ \\
& PVA 10\% & $4,6 \pm 0,2^{\mathrm{Cb}}$ & $6,0 \pm 0,3^{\mathrm{Bcb}}$ & $7,8 \pm 0,5^{\mathrm{Abc}}$ \\
\hline \multirow{2}{*}{ Annulo } & PVAf & $95,3 \pm 0,6^{\mathrm{Ca}}$ & $98,2 \pm 0,6^{\mathrm{Aa}}$ & $98,2 \pm 0,4^{\mathrm{BAa}}$ \\
Hue & PVA 5\% & $94,4 \pm 0,3^{\mathrm{Cb}}$ & $95,5 \pm 1,0^{\mathrm{Bb}}$ & $96,2 \pm 0,3^{\mathrm{Ab}}$ \\
& PVA 10\% & $91,7 \pm 0,5^{\mathrm{Cc}}$ & $93,9 \pm 0,2^{\mathrm{Bc}}$ & $95,4 \pm 0,2^{\mathrm{Acb}}$ \\
\hline
\end{tabular}

Médias na mesma linha com diferentes letras maiúsculas e médias na mesma coluna com diferentes letras são significativamente diferentes $(p \leq 0,05)$ de acordo com o teste LSD.

Com base nos resultados apresentados pelos filmes à base de gelatina com PVA pôde-se concluir que:

- O filme contendo $10 \%$ PVA irradiado a 20 kGy apresentou a maior resistência à perfuração $(84 \pm 9) \mathrm{N}$ em relação ao filme PVAf (78 \pm 11$)$ N na mesma dose.

- A deformação dos filmes diminuiu com o aumento da dose de radiação quando se compara PVAf e 5\% PVA.

- A absorção de água diminuiu com o aumento da dose de radiação para as amostras PVAf e 5\% PVA.

- O aumento da absorção de água das amostras 10\% PVA com aumento da dose de radiação $(p \leq 0,05)$ é uma singularidade que pode ser atribuída à influência particular na relação entre a estrutura polimérica e a sensibilidade frente à radiação de alta energia aplicada. 
- A umidade e a solubilidade sofreram discreta variação $(p \leq 0,05)$ entre as amostras não irradiadas e irradiadas e na presença do PVA.

- A absorção de água, o teor de umidade e a solubilidade dos filmes à base de gelatina apresentaram diferente comportamento na presença de 0,5 e $10 \%$ de PVA. Também, as amostras apresentaram comportamento diferente dependendo da dose aplicada.

- Houve um aumento $(p \leq 0,05)$ do parâmetro $+b^{*}$ (cor amarela) com o aumento da dose. No entanto, com o aumento do teor de PVA houve redução do valor de $+b^{*}$.

\subsubsection{Filmes a base de GEL/BHT}

Revestimentos comestíveis de colágeno/gelatina propiciam aplicações promissoras por sua capacidade de transportar antioxidantes e agentes antimicrobianos (Antoniewski \& Barringer, 2010; Wu et al., 2013). Como mencionado anteriormente, os filmes a base de gelatina podem ser utilizados como barreira ao oxigênio, transporte de antioxidantes e migração de umidade (Mendis et al., 2005).

O teor de umidade em filmes fornece informações sobre a interação entre a GEL e antioxidantes, pois a presença destes pode afetar a afinidade de água (Martins et al., 2012). Na TAB. 6 são apresentadas as porcentagens de umidade e solubilidade dos filmes a base de GEL, sem adição de BHT (BHTf) e com a incorporação de BHT (BHT) irradiados em diferentes doses e analisados 7 , 14 e 60 dias após a irradiação. Em geral houve diminuição no teor de umidade em relação ao período de armazenamento. A inclusão do antioxidante diminuiu significativamente a umidade $(p \leq 0,05)$; dados de solubilidade também se mostraram inferiores nas amostras com adição do BHT. As discrepâncias encontradas não foram significativas. 
TABELA 6 - Umidade e solubilidade de amostras de filmes a base de gelatina (BHTf) e contendo BHT analisados 7, 14 e 60 dias após a irradiação no EB a 20, 40 e 60 kGy.

\begin{tabular}{|c|c|c|c|c|c|}
\hline \multirow[t]{2}{*}{ Propriedades } & \multirow[t]{2}{*}{ Amostra } & \multicolumn{4}{|c|}{ Dose (kGy) } \\
\hline & & 0 & 20 & 40 & 60 \\
\hline \multirow{6}{*}{$\begin{array}{l}\text { Umidade } \\
(\%)\end{array}$} & $\mathrm{BHTf}{ }^{7 d i a s}$ & $18,1 \pm 3,3^{\mathrm{Aa}}$ & $17,2 \pm 3,0^{\mathrm{Aa}}$ & $18,1 \pm 3,2^{\mathrm{Aa}}$ & $18,5 \pm 3,2^{\mathrm{Aa}}$ \\
\hline & $\mathrm{BHTf}{ }^{14 d i a s}$ & $15,6 \pm 2,9^{\mathrm{Aa}}$ & $14,8 \pm 3,6^{\mathrm{Ad}}$ & $14,6 \pm 4,3^{\mathrm{Aad}}$ & $14,1 \pm 3,7^{\mathrm{Ad}}$ \\
\hline & BHTf 60 dias & $14,9 \pm 2,1^{\mathrm{Ba}}$ & $15,0 \pm 0,3^{\mathrm{BAa}}$ & $13,3 \pm 0,5^{\mathrm{Ced}}$ & $12,7 \pm 0,8^{\mathrm{DCed}}$ \\
\hline & $\mathrm{BHT}^{7 \text { dias }}$ & $16,9 \pm 2,7^{\text {Aab }}$ & $16,7 \pm 3,4^{\mathrm{Aa}}$ & $17,4 \pm 3,7^{\text {Aadb }}$ & $16,6 \pm 4,1^{\text {Aadb }}$ \\
\hline & $\mathrm{BHT}^{\text {14dias }}$ & $14,2 \pm 5,6^{\mathrm{Aeb}}$ & $14,3 \pm 3,2^{\text {Aae }}$ & $14,8 \pm 4,2^{\text {Aadebc }}$ & $14,3 \pm 3,1^{\text {Acdeb }}$ \\
\hline & $\mathrm{BHT}^{60 \text { dias }}$ & $13,5 \pm 0,2^{\text {Afbe }}$ & $12,7 \pm 0,2^{\mathrm{Bfe}}$ & $12,3 \pm 0,4^{\text {CBfdec }}$ & $12,0 \pm 0,6^{\mathrm{DCfdec}}$ \\
\hline \multirow{6}{*}{$\begin{array}{l}\text { Solubilidade } \\
(\%)\end{array}$} & BHTf $^{7 \text { dias }}$ & $48,8 \pm 1,4^{\mathrm{Aa}}$ & $50,9 \pm 2,4^{\mathrm{Aa}}$ & $49,9 \pm 2,1^{\mathrm{Ac}}$ & $49,7 \pm 1,9^{\mathrm{Ac}}$ \\
\hline & BHTf ${ }^{14 d i a s}$ & $48,5 \pm 2,7^{\mathrm{Aab}}$ & $49,3 \pm 6,1^{\mathrm{Aa}}$ & $49,4 \pm 1,2^{A c}$ & $49,0 \pm 0,4^{\mathrm{Ac}}$ \\
\hline & BHTf ${ }^{60 d i a s}$ & $47,2 \pm 4,7^{\text {Dabd }}$ & $47,8 \pm 0,5^{\mathrm{DCa}}$ & $52,7 \pm 5,0^{A C}$ & $50,5 \pm 1,9^{\mathrm{DCAc}}$ \\
\hline & $\mathrm{BHT}^{7 \text { dias }}$ & $48,4 \pm 1,5^{\text {Aabdc }}$ & $49,8 \pm 1,3^{\mathrm{Aa}}$ & $49,6 \pm 3,0^{A C}$ & $50,7 \pm 1,3^{A c}$ \\
\hline & $\mathrm{BHT}^{14 \mathrm{dias}}$ & $46,4 \pm 3,6^{\text {Dabdce }}$ & $49,5 \pm 1,5^{\mathrm{Aa}}$ & $47,8 \pm 2,0^{\mathrm{Dc}}$ & $49,3 \pm 1,1^{\mathrm{BACc}}$ \\
\hline & $\mathrm{BHT}^{60 \text { dias }}$ & $43,8 \pm 0,4^{\mathrm{Dfe}}$ & $46,3 \pm 0,7^{\mathrm{DCa}}$ & $54,4 \pm 8,5^{\mathrm{Ac}}$ & $48,7 \pm 0,3^{\mathrm{DCBc}}$ \\
\hline
\end{tabular}

Médias na mesma linha com diferentes letras maiúsculas e médias na mesma coluna com diferentes letras minúsculas são significativamente diferentes $(p \leq 0,05)$ de acordo com o teste LSD.

Yakimets et al. (2007), trabalhando com filmes de gelatina, observaram que a proporção entre a estrutura de bobina da gelatina e de tripla hélice foi alterada com o aumento da umidade dos filmes. Padrões de raios- $X$ indicaram que o máximo teor relativo de estrutura de tripla hélice $(9-11 \%)$ correspondeu ao intervalo médio de teor de água estudado (11,2-15\%), o que pode ser atribuído à adsorção de moléculas de água por sítios hidrofóbicos localizados dentro das triplas hélices (Kozlov \& Burdygina, 1983; Yakimets et al., 2005).

Carvalho et al. (2006) observaram que o aumento da umidade do filme de gelatina ocasionou um aumento da mobilidade da cadeia polimérica conforme descrito por Donhowe \& Fennema (1992). E assim, a redução da resistência à perfuração e aumento da deformação.

O efeito do teor de água na estrutura de biopolímeros como a gelatina foi observado por Yakimets et al. (2007). Esse estudo verificou que os sistemas diferem consideravelmente na forma como a água adsorvida interage com estas estruturas; e estes diferentes efeitos da água sobre os filmes biopoliméricos poderiam ser utilizados para explicar a alteração de suas propriedades elásticas. 
A TAB. 7 mostra os efeitos da aplicação da irradiação EB sobre algumas propriedades mecânicas em filmes a base de gelatina com BHT e sem BHT (BHTf), analisadas 7, 14 e 60 dias após a irradiação.

As amostras BHTf analisadas após 7 dias de armazenamento $\left(\mathrm{BHTf}^{7 \text { dias }}\right)$ apresentaram uma redução significativa $(\mathrm{p} \leq 0,05)$ da resistência à perfuração entre as amostras não irradiadas $83 \pm 29 \mathrm{~N}$ e irradiadas a partir de 40 kGy $(55 \pm 21)$ N. Para as amostras avaliadas após 60 dias de armazenamento (BHTf $\left.{ }^{60 d i a s}\right)$, ao contrário da anterior, houve um aumento significativo da resistência à perfuração com o aumento da dose $(p \leq 0,05)$ entre a amostra não irradiada $(110 \pm 8) \mathrm{N}$ e as irradiadas a partir de $40 \mathrm{kGy}(123 \pm 7) \mathrm{N}$.

Para os ensaios de deformação, verificou-se que houve uma redução significativa $(p \leq 0,05)$ entre a amostra $\mathrm{BHTf}^{7 d i a s}$ não irradiada $(67,0 \pm 0,8) \%$ e as irradiadas a partir de $20 \mathrm{kGy}(55,3 \pm 0,2) \%$. As amostras $\mathrm{BHTf}^{14 \text { dias }}$ apresentaram o mesmo comportamento. E as amostras BHTf 60 dias apresentaram um comportamento irregular entre os valores e as doses aplicadas, porém houve uma diferença significativa ( $p \leq 0,05)$ entre a amostra irradiada a 20 kGy $(66,0 \pm 0,4) \%$ e as demais amostras não irradiadas $(61,8 \pm 0,3) \%$ e as irradiadas a 40 kGy $(56,7 \pm 0,4) \%$ e 60 kGy $(56,1 \pm 0,8) \%$.

TABELA 7 - Resistência e deformação a perfuração em amostras de filmes a base de gelatina (BHTf) e contendo BHT analisados 7, 14 e 60 dias após a irradiação no EB a 20, 40 e 60 kGy.

\begin{tabular}{|c|c|c|c|c|c|}
\hline \multirow[t]{2}{*}{ Propriedades } & \multirow[t]{2}{*}{ Amostra } & \multicolumn{4}{|c|}{ Dose (kGy) } \\
\hline & & 0 & 20 & 40 & 60 \\
\hline \multirow{6}{*}{$\begin{array}{l}\text { Resistência } \\
\text { à perfuração } \\
\text { (N) }\end{array}$} & BHTf7dias & $83 \pm 29^{A c}$ & $72 \pm 32^{\mathrm{ABe}}$ & $55 \pm 21^{\mathrm{CBf}}$ & $53 \pm 21^{\text {DBCf }}$ \\
\hline & $\mathrm{BHTf}{ }^{14 d i a s}$ & $69 \pm 10^{\mathrm{Bce}}$ & $73 \pm 10^{\text {BAed }}$ & $63 \pm 5^{\mathrm{BDfe}}$ & $65 \pm 10^{\text {BADfc }}$ \\
\hline & $\mathrm{BHTf}^{60 d i a s}$ & $110 \pm 8^{\mathrm{Da}}$ & $112 \pm 5^{\mathrm{DCa}}$ & $123 \pm 7^{\mathrm{Ba}}$ & $126 \pm 13^{\mathrm{ABa}}$ \\
\hline & $\mathrm{BHT}^{7 \mathrm{dias}}$ & $76 \pm 17^{\text {Bced }}$ & $81 \pm 15^{\text {BAedc }}$ & $70 \pm 19^{\mathrm{BACce}}$ & $55 \pm 19^{\text {DCfce }}$ \\
\hline & $\mathrm{BHT}^{14 d i a s}$ & $68 \pm 5^{\text {Ccefd }}$ & $71 \pm 3^{\text {CAedfc }}$ & $69 \pm 9^{\mathrm{CABdec}}$ & $62 \pm 2^{\text {Dfcde }}$ \\
\hline & $\mathrm{BHT}^{60 d i a s}$ & $90 \pm 8^{\mathrm{Dcbd}}$ & $106 \pm 6^{\mathrm{Aba}}$ & $100 \pm 11^{\mathrm{CAb}}$ & $101 \pm 3^{\mathrm{BACb}}$ \\
\hline \multirow{6}{*}{$\begin{array}{l}\text { Deformação } \\
(\%)\end{array}$} & $\mathrm{BHTf}{ }^{7 d i a s}$ & $67,0 \pm 0,8^{\mathrm{Aa}}$ & $55,3 \pm 0,2^{\mathrm{Bf}}$ & $53,2 \pm 0,4^{\mathrm{CBf}}$ & $52,0 \pm 0,6^{\mathrm{DBCd}}$ \\
\hline & $\mathrm{BHTf}{ }^{14 \mathrm{dias}}$ & $65,7 \pm 0,9^{\mathrm{Aad}}$ & $59,0 \pm 0,6^{\mathrm{Bbe}}$ & $55,2 \pm 0,6^{\mathrm{DBfc}}$ & $55,8 \pm 0,8^{\mathrm{CBDdc}}$ \\
\hline & $\mathrm{BHTf}^{60 \text { dias }}$ & $61,8 \pm 0,3^{\text {Bed }}$ & $66,0 \pm 0,4^{\mathrm{Aa}}$ & $56,7 \pm 0,4^{\mathrm{Cbc}}$ & $56,1 \pm 0,8^{\mathrm{DCbc}}$ \\
\hline & $\mathrm{BHT}^{7 \text { dias }}$ & $66,4 \pm 0,8^{\text {Aadc }}$ & $56,8 \pm 0,4^{\text {Bfed }}$ & $53,9 \pm 0,4^{\mathrm{CBfcbd}}$ & $51,6 \pm 0,5^{\text {DCde }}$ \\
\hline & $\mathrm{BHT}^{14 d i a s}$ & $66,9 \pm 0,6^{\text {Aadbe }}$ & $56,1 \pm 0,8^{\text {Dfed }}$ & $59,0 \pm 0,6^{\mathrm{CDab}}$ & $59,5 \pm 0,5^{\text {BDCacb }}$ \\
\hline & $\mathrm{BHT}^{60 d i a s}$ & $59,4 \pm 0,3^{\mathrm{Afe}}$ & $57,6 \pm 0,6^{\text {ABfecd }}$ & $53,4 \pm 0,2^{\text {Cfced }}$ & $50,0 \pm 0,2^{\text {Ddfe }}$ \\
\hline
\end{tabular}
minúsculas são significativamente diferentes $(p \leq 0,05)$ de acordo com o teste LSD. 
As amostras com adição de BHT analisadas após 7 dias de armazenamento $\left(\mathrm{BHT}^{7 \text { dias }}\right)$ apresentaram uma resistência à ruptura irregular nas doses aplicadas, apresentando uma diferença significativa $(p \leq 0,05)$ entre a amostra não irradiada $76 \pm 17 \mathrm{~N}$ e as irradiadas a $60 \mathrm{kGy}(55 \pm 19) \mathrm{N}$. As amostras avaliadas após 14 dias $\left(\mathrm{BHT}^{14 \text { dias }}\right)$ de estocagem apresentaram uma diminuição significativa $(p \leq 0,05)$ na resistência entre as amostras a 40 kGy $(69 \pm 9)$ N e 60 kGy (62 \pm 2$)$ N. Para as amostras avaliadas após 60 dias de armazenamento ( $\left.\mathrm{BHT}^{60 d i a s}\right)$ houve um aumento significativo $(\mathrm{p} \leq 0,05) \mathrm{da}$ resistência à perfuração entre a amostra não irradiada $(90 \pm 8) \mathrm{N}$ e irradiadas a partir de $20 \mathrm{kGy}(106 \pm 6) \mathrm{N}$, seguindo o mesmo comportamento das amostras BHTf ${ }^{60 d i a s}$.

Para os ensaios de deformação, verificou-se que houve uma redução significativa $(p \leq 0,05)$ entre a amostra $\mathrm{BHT}^{7 \text { dias }}$ não irradiada $(66,4 \pm 0,8) \%$ e as irradiadas a partir de $20 \mathrm{kGy}(56,8 \pm 0,4) \%$. As amostras $\mathrm{BHT}^{14 d i a s}$ apresentaram um comportamento irregular, porém houve uma diferença significativa $(p \leq 0,05)$ entre a amostra não irradiada $(66,9 \pm 0,6) \%$ e irradiada a partir de 20 kGy $(56,1 \pm 0,8) \%$. Já as amostras $\mathrm{BHT}^{60 \text { dias }}$ apresentaram uma redução significativa $(p \leq 0,05)$ entre a amostra não irradiada $(59,4 \pm 0,3) \%$ e irradiada a partir de 40 kGy $(53,4 \pm 0,2) \%$.

Os resultados em termos de resistência à perfuração para os filmes BHTf e BHT 7, 14 e 60 dias após irradiação, apresentaram uma diferença significativa $(p \leq 0,05)$ entre as amostras irradiadas e não irradiadas. Pelos

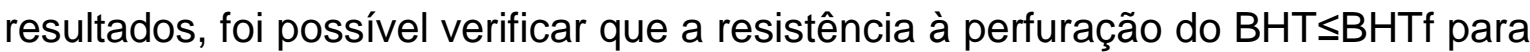
a maioria das amostras, como por exemplo entre as amostras a 20 kGy BHTf 60 dias $(112 \pm 5) \mathrm{N}$ e BHT${ }^{60 d i a s}(106 \pm 6) \mathrm{N}$, não foi significativa $(p \leq 0,05)$. No entanto, para as amostras a partir de $40 \mathrm{kGy}$, essa diferença torna-se significativa no mesmo período de armazenamento. A magnitude da resistência à perfuração é sempre maior nas amostras armazenadas por 60 dias após a irradiação quando comparadas aos outros filmes. Essa resistência à perfuração no período de armazenamento mais longo (após 60 dias), em particular para o $\mathrm{BHTf}$, sugere que ocorreu alguma interação entre as moléculas de gelatina e o antioxidante adicionado. Jongjareonrak et al. (2008) utilizaram gelatinas provenientes de pele de peixes e obtiveram alguns resultados conflitantes sobre a influência do BHT. Eles descreveram que a incorporação de BHT em geral 
aumentou a resistência à tração (TS) e alongamento na ruptura (EAB) do filme de GEL da pele do bigeye snapper, mas diminuiu EAB do filme de GEL de pele de brownstripe red snapper.

Segundo os resultados obtidos neste trabalho, exibidos na TAB. 7, verificou-se que as amostras BHTf apresentaram maior deformação do que as amostras com BHT quando comparadas no mesmo período de estocagem, como no caso da amostra não irradiada $\mathrm{BHTf}^{60 d i a s}(61,8 \pm 0,3) \%>\mathrm{BHT}^{60 d i a s}(59,4 \pm 0,3) \%$, em que houve uma diferença significativa $(p \leq 0,05)$. Uma diminuição da deformação com o aumento da dose de radiação pode ser observada para quase todas as amostras. O aumento do tempo de armazenamento diminuiu a deformação para amostras não irradiadas. No entanto, para as amostras irradiadas houve uma variação dos valores com o aumento do tempo de estocagem, mostrando que a adição do antioxidante afetou as propriedades mecânicas nas condições aplicadas. Spizzirri et al. (2009) mostram que a incorporação de aditivos é um método efetivo de melhorar as propriedades de proteínas como a gelatina.

Yakimets et al. (2007) observaram que as peculiaridades das redes poliméricas e as diferentes interações e estruturas moleculares têm forte influência nas propriedades elásticas da gelatina.

As alterações de cor entre os filmes contendo BHT ou não contendo $\mathrm{BHT}$ (BHTf) irradiados em diferentes doses foram avaliados tomando por base a distribuição espectral dos filmes em uma placa branca padrão (TAB. 8). Pelos resultados de $L^{*}$ obtidos, verificou-se que houve uma redução significativa $(p \leq 0,05)$ entre os filmes não irradiados e irradiados para todas as amostras, como por exemplo nas amostras em que a diferença apresentou-se entre 0 e 60 kGy: $\operatorname{BHTf}^{14 d i a s}(96,1 \pm 0,5)$ e $(93,8 \pm 0,5)$, e BHT $^{60 d i a s}(95,4 \pm 0,4)$ e $(93,1 \pm 0,4)$, respectivamente. Esse comportamento uniforme de redução da $L^{*}$ ocorreu em todos os filmes nos respectivos tempos de armazenamento e em relação ao aumento da dose de radiação. Concomitantemente à diminuição do parâmetro $L^{*}$, houve um aumento significativo dos parâmetros $-a^{*} \mathrm{e}+b^{*}$ entre todas as amostras não irradiadas e irradiadas a partir de 20 kGy. Quando comparadas com relação ao tempo de armazenamento, a amostra BHTf 60 dias irradiada a $60 \mathrm{kGy}$ apresentou o maior valor de $+b^{*}(24,5 \pm 2,1)$, mesmo em comparação a amostra $\mathrm{BHT}^{60 \text { dias }}(21,8 \pm 0,4)$. O parâmetro de $+b^{*}$ dos filmes de 
GEL sem o antioxidante, BHTf, não irradiados apresentaram menor amarelamento do que as amostras com BHT; essa diferença foi significativa $(p \leq 0,05)$ apenas para as amostras $\operatorname{BHTf}^{7 \text { dias }}(5,2 \pm 0,5)$ e $\operatorname{BHTf}^{60 \text { dias }}(6,6 \pm 0,6)$ de acordo com o tempo de armazenamento. Os valores de croma e ângulo Hue estão em concordância ao amarelamento $\left(+b^{*}\right)$ dos filmes. Outros autores também encontraram que o uso do BHT afeta a luminosidade de filmes de gelatina (Jongjareonrak et al., 2008). 
TABELA 8 - Medidas de cor em amostras de filmes a base de gelatina (BHTf) e contendo BHT analisados 7, 14 e 60 dias após a irradiação no EB a 20, 40 e 60 kGy.

\begin{tabular}{|c|c|c|c|c|c|}
\hline \multirow{2}{*}{$\begin{array}{l}\text { Parâmetro } \\
\text { de Cor }\end{array}$} & \multirow{2}{*}{ Amostra } & \multicolumn{4}{|c|}{ Dose (kGy) } \\
\hline & & 0 & 20 & 40 & 60 \\
\hline \multirow{6}{*}{$L^{*}$} & $\mathrm{BHTf}^{7 d i a s}$ & $95,4 \pm 3,2^{\mathrm{Ba}}$ & $95,5 \pm 0,5^{\mathrm{BAc}}$ & $94,7 \pm 0,5^{\mathrm{BACc}}$ & $93,8 \pm 0,4^{\mathrm{DCa}}$ \\
\hline & BHTf ${ }^{14 d i a s}$ & $96,1 \pm 0,5^{\mathrm{Aa}}$ & $95,6 \pm 0,3^{\mathrm{Bca}}$ & $94,8 \pm 0,3^{\mathrm{Ccb}}$ & $93,8 \pm 0,5^{\text {Dcab }}$ \\
\hline & BHTf ${ }^{60 d i a s}$ & $96,0 \pm 0,2^{\mathrm{Aa}}$ & $95,6 \pm 0,3^{\mathrm{ABcab}}$ & $95,2 \pm 0,3^{\mathrm{CBa}}$ & $93,3 \pm 1,2^{\mathrm{Dcd}}$ \\
\hline & $\overline{\mathrm{BHT}^{7 d i a s}}$ & $95,4 \pm 0,4^{\mathrm{Aa}}$ & $95,2 \pm 1,4^{\mathrm{ABcabe}}$ & $94,0 \pm 0,3^{\mathrm{Cf}}$ & $90,8 \pm 0,4^{\mathrm{De}}$ \\
\hline & $\mathrm{BHT}^{14 d i a s}$ & $95,4 \pm 0,3^{\mathrm{Ba}}$ & $95,5 \pm 0,4^{\text {BAcabed }}$ & $94,0 \pm 0,4^{\mathrm{Cef}}$ & $90,6 \pm 0,5^{\text {Dfe }}$ \\
\hline & $\mathrm{BHT}^{60 \text { dias }}$ & $95,4 \pm 0,4^{\mathrm{Aa}}$ & $95,0 \pm 0,4^{\text {Bcfed }}$ & $94,2 \pm 0,2^{\text {Cdfe }}$ & $93,1 \pm 0,4^{\mathrm{Dd}}$ \\
\hline \multirow{6}{*}{$a^{*}$} & BHTf 7 dias & $-0,79 \pm 0,03^{A c}$ & $-2,05 \pm 0,10^{\mathrm{Bd}}$ & $-2,74 \pm 0,06^{\mathrm{Cc}}$ & $-2,86 \pm 0,17^{\mathrm{Dd}}$ \\
\hline & BHTf ${ }^{14 d i a s}$ & $-0,75 \pm 0,03^{\mathrm{Ab}}$ & $-1,93 \pm 0,07^{\mathrm{Bc}}$ & $-2,64 \pm 0,05^{\mathrm{Cb}}$ & $-2,78 \pm 0,15^{\mathrm{Ddc}}$ \\
\hline & BHTf 60 dias & $-1,16 \pm 0,08^{A f}$ & $-2,11 \pm 0,05^{\text {Bde }}$ & $-3,24 \pm 0,07^{\mathrm{Ce}}$ & $-3,87 \pm 0,08^{\mathrm{De}}$ \\
\hline & $\overline{\mathrm{BHT}^{7 d i a s}}$ & $-0,97 \pm 0,02^{\mathrm{Ad}}$ & $-1,87 \pm 0,08^{\mathrm{Bbc}}$ & $-2,92 \pm 0,08^{C d}$ & $-2,64 \pm 0,07^{\mathrm{Db}}$ \\
\hline & $\mathrm{BHT}^{14 d i a s}$ & $-0,51 \pm 0,04^{\mathrm{Aa}}$ & $-1,41 \pm 0,07^{\mathrm{Ba}}$ & $-2,42 \pm 0,10^{\mathrm{Ca}}$ & $-2,23 \pm 0,06^{\mathrm{Da}}$ \\
\hline & $\mathrm{BHT}^{60 \text { dias }}$ & $-1,07 \pm 0,05^{\mathrm{Ae}}$ & $-2,35 \pm 0,20^{\mathrm{Bf}}$ & $-3,31 \pm 0,12^{\mathrm{Cfe}}$ & $-4,06 \pm 0,10^{\mathrm{Df}}$ \\
\hline \multirow{6}{*}{$b^{*}$} & $\mathrm{BHTf}^{7 \mathrm{dias}}$ & $5,2 \pm 0,5^{\mathrm{Df}}$ & $9,8 \pm 0,3^{\mathrm{Cf}}$ & $15,8 \pm 0,5^{\mathrm{Be}}$ & $20,7 \pm 0,9^{\mathrm{Af}}$ \\
\hline & $\mathrm{BHTf}^{14 \text { dias }}$ & $5,5 \pm 0,4^{\mathrm{De}}$ & $10,0 \pm 0,4^{\mathrm{Cfe}}$ & $16,3 \pm 0,6^{\mathrm{Bec}}$ & $21,1 \pm 0,9^{\mathrm{Af}}$ \\
\hline & BHTf 60 dias & $6,6 \pm 0,6^{\mathrm{Da}}$ & $11,1 \pm 0,2^{\mathrm{Ca}}$ & $16,4 \pm 0,6^{\text {Becb }}$ & $24,5 \pm 2,1^{\mathrm{Aa}}$ \\
\hline & $\mathrm{BHT}^{7 \text { dias }}$ & $6,3 \pm 0,1^{\mathrm{Dda}}$ & $10,1 \pm 0,3^{\text {Cfec }}$ & $15,7 \pm 1,0^{\text {Becbf }}$ & $22,6 \pm 1,1^{\mathrm{Ac}}$ \\
\hline & $\mathrm{BHT}^{14 \mathrm{dias}}$ & $6,4 \pm 0,2^{\mathrm{Dbad}}$ & $10,0 \pm 0,5^{\mathrm{Cfedc}}$ & $15,9 \pm 1,0^{\text {Becbfd }}$ & $23,3 \pm 1,1^{\mathrm{Abc}}$ \\
\hline & $\mathrm{BHT} \mathrm{T}^{60 d i a s}$ & $6,4 \pm 0,4^{\text {Dcadb }}$ & $11,0 \pm 1,1^{\mathrm{Cba}}$ & $16,5 \pm 1,2^{\text {Becbad }}$ & $21,8 \pm 0,4^{\text {Adec }}$ \\
\hline \multirow{6}{*}{ Croma } & BHTf $^{7 \text { dias }}$ & $5,3 \pm 0,1^{\mathrm{Df}}$ & $10,0 \pm 0,4^{\mathrm{Ce}}$ & $15,9 \pm 0,5^{\mathrm{Bf}}$ & $20,9 \pm 0,9^{\mathrm{Af}}$ \\
\hline & BHTf ${ }^{14 d i a s}$ & $5,6 \pm 0,4^{\mathrm{Dfe}}$ & $10,1 \pm 0,4^{\mathrm{Ced}}$ & $16,5 \pm 0,6^{\mathrm{Bfc}}$ & $21,3 \pm 0,9^{\text {Afe }}$ \\
\hline & BHTf 60 dias & $6,8 \pm 0,6^{\mathrm{Da}}$ & $11,3 \pm 0,2^{\mathrm{Cb}}$ & $16,7 \pm 0,6^{\mathrm{Bbc}}$ & $24,8 \pm 2,1^{\mathrm{Aa}}$ \\
\hline & $\mathrm{BHT}^{7 \text { dias }}$ & $6,4 \pm 0,1^{\mathrm{Da}}$ & $10,4 \pm 0,4^{\text {Cedc }}$ & $16,0 \pm 0,9^{\mathrm{Bfcbe}}$ & $22,7 \pm 1,1^{A c}$ \\
\hline & $\mathrm{BHT}^{14 \mathrm{dias}}$ & $6,4 \pm 0,2^{\mathrm{Dbd}}$ & $10,0 \pm 0,4^{\text {Cedf }}$ & $16,1 \pm 1,0^{\text {Bfcbed }}$ & $23,4 \pm 1,1^{\mathrm{Abc}}$ \\
\hline & $\mathrm{BHT}^{60 \text { dias }}$ & $6,4 \pm 0,4^{\mathrm{Dcdb}}$ & $11,5 \pm 1,1^{\mathrm{Cab}}$ & $16,8 \pm 1,2^{\text {Bacbd }}$ & $22,2 \pm 0,4^{\text {Adec }}$ \\
\hline \multirow{6}{*}{$\begin{array}{l}\text { Ângulo } \\
\text { Hue }\end{array}$} & $\mathrm{BHTf}^{7 d i a s}$ & $98,5 \pm 0,3^{C d}$ & $101,7 \pm 0,3^{\mathrm{Ab}}$ & $99,9 \pm 0,4^{\mathrm{Bd}}$ & $97,9 \pm 0,4^{\mathrm{Dc}}$ \\
\hline & BHTf ${ }^{14 d i a s}$ & $97,7 \pm 0,6^{\mathrm{Ce}}$ & $101,0 \pm 0,1^{\mathrm{Ac}}$ & $99,2 \pm 0,4^{\mathrm{Be}}$ & $97,5 \pm 0,5^{\mathrm{CDcd}}$ \\
\hline & BHTf 60 dias & $99,8 \pm 0,4^{\mathrm{Ca}}$ & $100,7 \pm 0,2^{\mathrm{Bec}}$ & $101,2 \pm 0,2^{\mathrm{Ab}}$ & $99,0 \pm 0,7^{\mathrm{Db}}$ \\
\hline & $\overline{\mathrm{BHT}^{7 d i a s}}$ & $98,7 \pm 0,2^{\mathrm{Cdc}}$ & $100,8 \pm 0,7^{\text {Adce }}$ & $100,5 \pm 0,4^{\mathrm{BAc}}$ & $96,7 \pm 0,4^{\mathrm{De}}$ \\
\hline & $\mathrm{BHT}^{14 \mathrm{dias}}$ & $94,5 \pm 0,3^{\mathrm{Df}}$ & $98,3 \pm 0,2^{\mathrm{Bf}}$ & $98,6 \pm 0,2^{\mathrm{Af}}$ & $95,5 \pm 0,4^{\mathrm{Cf}}$ \\
\hline & $\mathrm{BHT}^{60 \mathrm{dias}}$ & $99,3 \pm 0,2^{\mathrm{Db}}$ & $101,8 \pm 0,4^{\mathrm{Aba}}$ & $101,4 \pm 0,5^{\mathrm{Bab}}$ & $100,5 \pm 0,3^{\mathrm{Ca}}$ \\
\hline
\end{tabular}

Médias na mesma linha com diferentes letras maiúsculas e médias na mesma coluna com diferentes letras minúsculas são significativamente diferentes $(p \leq 0,05)$ de acordo com o teste LSD. 
As FIG. 19, 20 e 21 apresentam os resultados da cinética de absorção de água de filmes a base de GEL com BHT e BHTf avaliados após 7, 14 e 60 dias da irradiação, respectivamente. A cinética de absorção mostrou que houve um aumento da absorção de água em função do tempo para todas as amostras; entretanto, para aquelas com BHT o aumento foi menor quando comparadas às amostras sem o antioxidante (BHTf). Foram observadas uma redução da absorção com o aumento da dose até 40 kGy e um decréscimo com o tempo de estocagem.

Segundo a literatura, os biopolímeros interagem naturalmente com água (Tabata \& Ikada, 1998), levando às transformações na textura (ocorrendo, por exemplo, transição de amorfo-cristalino), com forte impacto sobre a sua mobilidade molecular e propriedades funcionais (Kent \& Meyer, 1984; Kristo et al., 2007; Stubberud et al., 1996). 

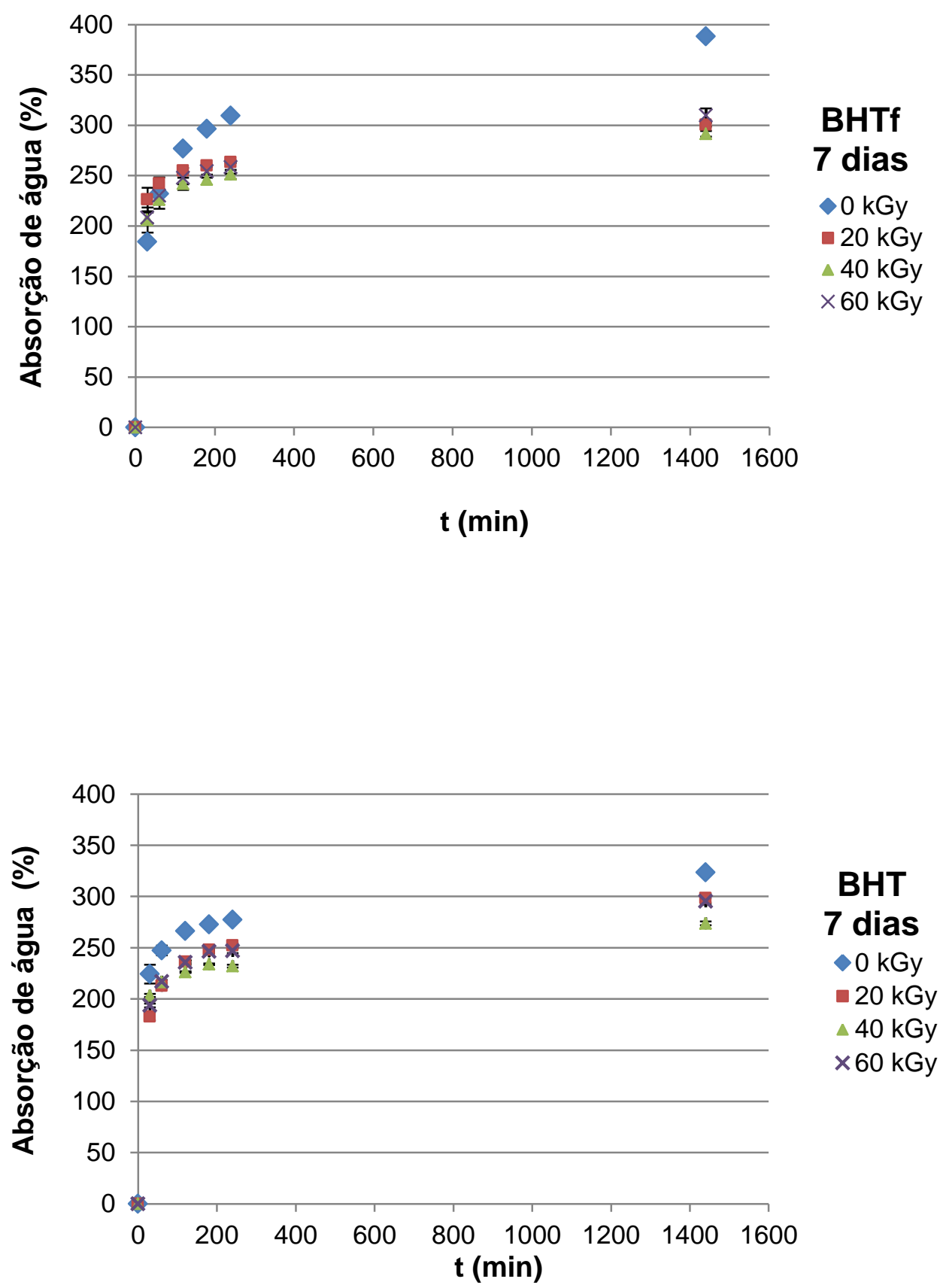

FIGURA 19 - Cinética de absorção de água em amostras de filmes a base de gelatina contendo BHT e não contendo (BHTf) analisadas 7 dias após a irradiação no EB a 20, 40 e 60 kGy 

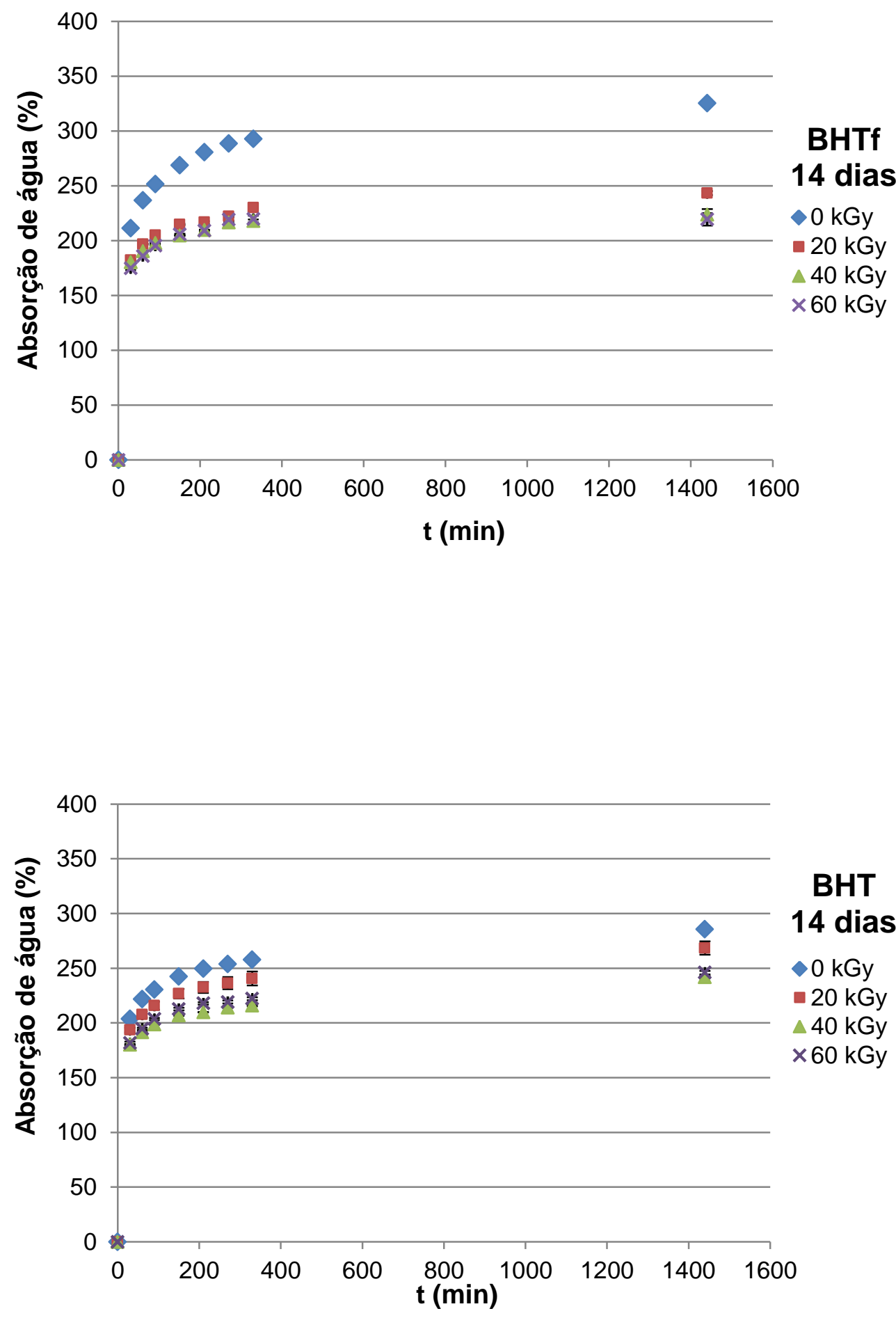

FIGURA 20 - Cinética de absorção de água em amostras de filmes a base de gelatina contendo BHT e não contendo (BHTf) analisadas 14 dias após a irradiação no EB a 20, 40 e 60 kGy. 

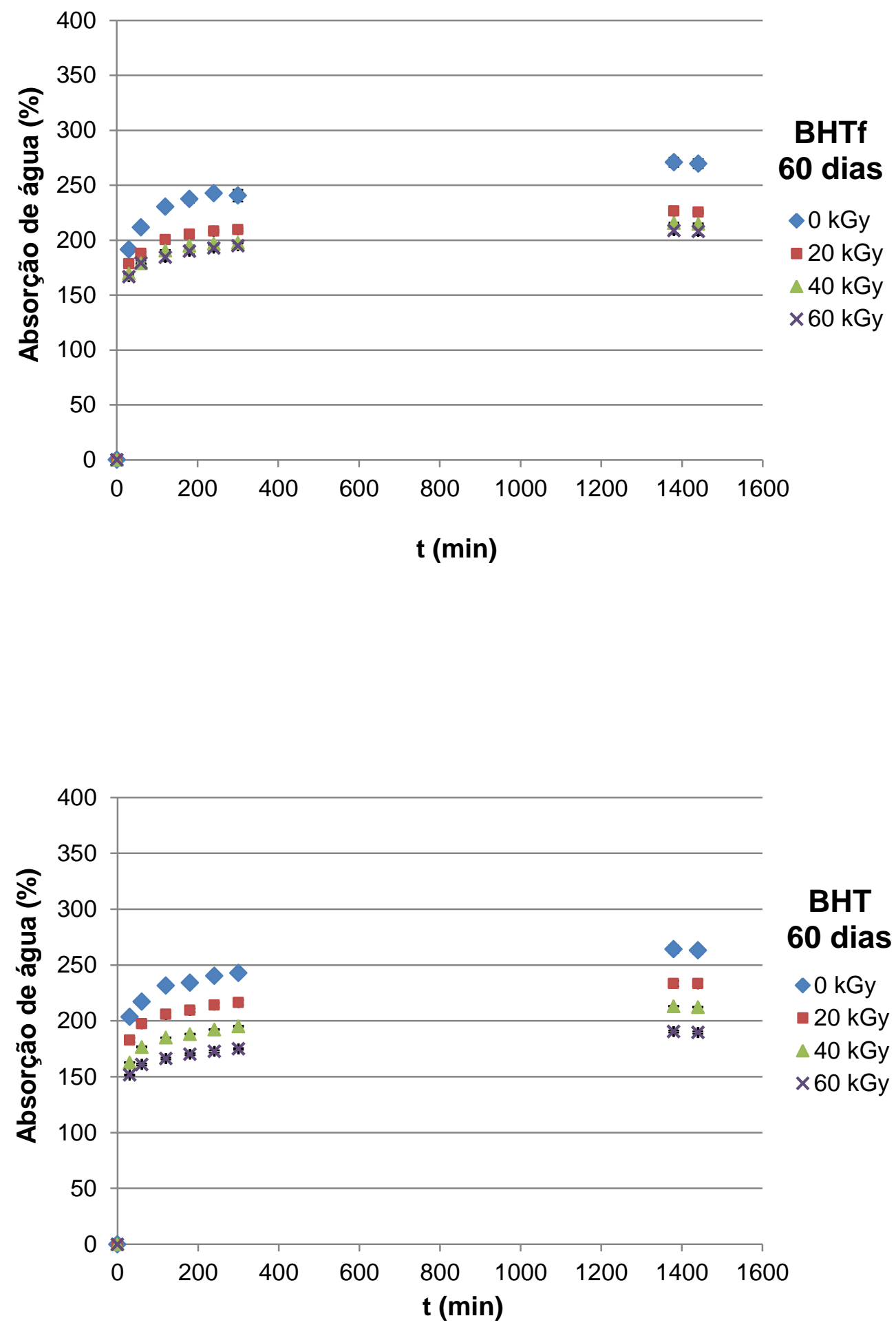

FIGURA 21 - Cinética de absorção de água em amostras de filmes a base de gelatina contendo BHT e não contendo (BHTf) analisadas 60 dias após a irradiação no EB a 20, 40 e 60 kGy. 
Com base nos resultados apresentados pelos filmes à base de gelatina com BHT pôde-se concluir que:

- A inclusão do antioxidante diminuiu significativamente a umidade $(p \leq 0,05)$.

- Dados de solubilidade também se mostraram inferiores nas amostras com adição do BHT. As discrepâncias encontradas não foram significativas.

- Os filmes sem BHT (BHTf $\left.{ }^{60 d i a s}\right)$ analisados após 60 dias de armazenamento apresentaram um aumento significativo da resistência à perfuração com o aumento da dose $(p \leq 0,05)$ entre as amostras não irradiadas $(110 \pm 8) \mathrm{N}$ e as irradiadas a $40 \mathrm{kGy}$ $(123 \pm 7) \mathrm{N}$.

- As amostras contendo BHT (BHT $\left.{ }^{60 d i a s}\right)$ avaliadas após 60 dias de armazenamento também apresentaram um aumento significativo da resistência à perfuração com o aumento da dose $(p \leq 0,05)$ entre as amostras não irradiadas $(90 \pm 8) \mathrm{N}$ e irradiadas a $20 \mathrm{kGy}$ $(106 \pm 6) \mathrm{N}$.

- A resistência à perfuração das amostras contendo BHT apresentaram geralmente valores inferiores do que aquelas BHTf correspondentes.

- Houve uma redução $(p \leq 0,05)$ da deformação entre as amostras $\mathrm{BHTf}^{7 \text { dias }}$ não irradiadas $(67,0 \pm 0,8) \%$ e as irradiadas a $20 \mathrm{kGy}$ $(55,3 \pm 0,2) \%$. As amostras $\mathrm{BHTf}^{14 \text { dias }}$ apresentaram o mesmo comportamento.

- As amostras $\mathrm{BHT}^{7 \text { dias }}$ não irradiadas $(66,4 \pm 0,8) \%$ e as irradiadas a 20 kGy $(56,8 \pm 0,4) \%$ exibiram uma redução $(p \leq 0,05)$ da deformação. Já as amostras $\mathrm{BHT}^{60 d i a s}$ apresentaram uma redução $(p \leq 0,05)$ entre a amostra não irradiada $(59,4 \pm 0,3) \%$ e irradiada a 40 kGy $(53,4 \pm 0,2) \%$.

- As amostras BHTf e BHT não irradiadas apresentaram uma diminuição da deformação $(p \leq 0,05)$ com o aumento do tempo de armazenamento. 
- Houve diminuição do parâmetro da luminosidade $\left(L^{*}\right)$ e aumento $(p \leq 0,05)$ do amarelamento $\left(+b^{*}\right)$ nas amostras irradiadas.

- Amostras BHTf 60 dias irradiadas a $60 \mathrm{kGy}$ apresentaram os maiores valores de $+b^{*}(24,5 \pm 2,1)$.

- A cinética de absorção de água mostrou que houve um aumento em função do tempo para todas as amostras; entretanto, para aquelas com BHT o aumento foi menor quando comparadas às amostras sem o antioxidante (BHTf).

- Foi observada uma redução da absorção com o aumento da dose até 40 kGy e um decréscimo com o tempo de estocagem.

- A adição de antioxidante BHT influenciou em algumas das propriedades dos filmes a base de GEL nas condições aplicadas.

- As alterações nas propriedades dos filmes a base de gelatina na presença ou não de aditivos como o PVA e BHT (antioxidante) devem ser levadas em consideração para o desenvolvimento de novos materiais irradiados, pois essas informações podem ser úteis na previsão de desempenho de filmes em aplicações finais. 


\section{NANO-HIDROGÉIS DE GELATINA}

Este capítulo é dedicado ao estudo de nano-hidrogéis de GEL, PEG e MIX, irradiados no acelerador de elétrons pulsado (LINAC) e por radiólise de raios gama. As propriedades dos materiais desenvolvidos são analisadas e discutidas neste capítulo.

\subsection{Síntese de nano-hidrogéis por radiação ionizante}

\subsubsection{Material}

Amostras de gelatina tipo B, bovina, de grau alimentício, da Gelita do Brasil Ltda (240Bloom/10mesh) foram utilizadas no desenvolvimento de hidrogéis. O polietileno glicol (PEG) da Bio World também foi empregado na composição para o desenvolvimento dos hidrogéis.

\subsubsection{Preparo das amostras}

As soluções de GEL, PEG e MIX (mistura de GEL e PEG) foram preparadas em água deionizada (DI) Millipore Direct $Q$ system com resistividade de 18,2 $\mathrm{M} \Omega$, da seguinte forma: 0,01\% (p/v) GEL; 0,1\% (p/v) PEG, e a MIX pela mistura na proporção (1:10) de GEL $(0,01 \%(\mathrm{p} / \mathrm{v}))$ e PEG $(0,1 \%(p / v))$. As amostras foram colocadas no ultrassom por 10 minutos, e então aquecidas em banho-maria a $60^{\circ} \mathrm{C}$ por 15 minutos sob constante agitação. Depois, cada solução foi transferida para frascos de vidro e tampa com septo de silicone de $10 \mathrm{~mL}$. Em seguida, o gás $\mathrm{N}_{2} \mathrm{O}$ foi usado para converter $\mathrm{o} \mathrm{e}_{\mathrm{aq}}{ }^{-}$em $\mathrm{HO}^{\bullet}$. $\mathrm{O}$ oxigênio dissolvido é substituído por $\mathrm{N}_{2} \mathrm{O}$ durante $\mathrm{o}$ processo de saturação e duplica a concentração de $\mathrm{HO}^{\bullet}$ da radiólise. 


\subsubsection{Irradiação}

Para a síntese dos nano-hidrogéis foi induzida a radiólise, tanto em estado estacionário (fonte de ${ }^{60} \mathrm{Co}$ ) mostrado na FIG. 16 e 17, quanto por feixe de elétrons pulsado mostrado na FIG. 15 da UMCP.

A fonte de ${ }^{60} \mathrm{Co}$ usada para a síntese de nano-hidrogéis foi a da UMCP. Nessa fonte, as cápsulas contendo dez lápis de ${ }^{60} \mathrm{Co}$ Neutron Products, modelo 200324 (atividade total de $2,42 \times 10^{15} \mathrm{~Bq}(65405 \mathrm{Ci}$ ) no momento das experiências), estão dispostas numa coroa circular (FIG. 16) que proporcionou taxa de dose de $70 \mathrm{kGy} \mathrm{h}^{-1}$. As paredes que protegem as áreas restritas são compostas de $2307 \mathrm{~kg} \mathrm{~m}^{-3}$ de concreto reforçado com barras de aço e possuem de 1,2-1,5 $\mathrm{m}$ de espessura. A entrada para 0 irradiador gama é por intermédio de uma porta interlocked, que é fechada durante a irradiação por uma porta de aço blindado de $0,5 \mathrm{~m}$ de espessura. A fonte é armazenada na parte inferior de um tanque de aço inoxidável cheio de água (1,2 $\mathrm{m}$ de diâmetro e 4,3 m de profundidade) que é colocado em um cilindro de concreto selado quando não está em uso (FIG. 17).

Nos experimentos utilizando feixe de elétrons pulsado, a energia do feixe de elétrons foi ajustado para $6,8 \mathrm{MeV}$ (gama sintonizável de entre 1 a $10 \mathrm{MeV}$ ), com feixe fixo e potência de $1,4 \mathrm{~kW}$. A taxa de repetição de pulso utilizado foi de 100 pulsos por segundo $(\mathrm{Hz})$. As condições de irradiação foram modificadas pela variação da taxa de dose de 16,5 Gy/pulso a 70,5 Gy/pulso e o total de dose utilizado variou de 1 a 15 kGy na maioria dos ensaios.

Os frascos contendo as amostras, fechados com tampa com septo de borracha, foram colocados a $10 \mathrm{~cm}$ e $55 \mathrm{~cm}$ da "janela" de elétrons, (FIG. 22), sendo a dose por pulso de 70,5 Gy/pulso e 16,5 Gy/pulso, respectivamente. 


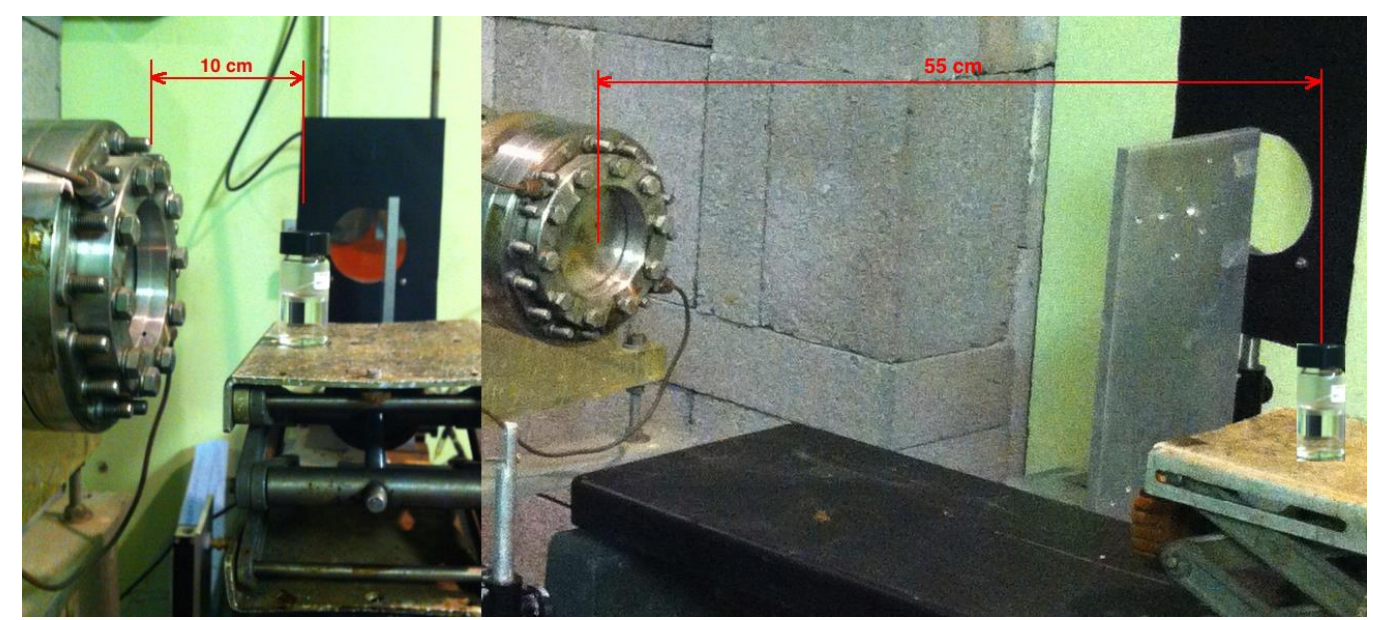

FIGURA 22 - Posição das amostras, $10 \mathrm{~cm}$ e $55 \mathrm{~cm}$, em relação à distância da janela do feixe de elétrons pulsado a uma taxa de dose de $70,5 \mathrm{~Gy} /$ pulso e 16,5 Gy/pulso, respectivamente.

\subsubsection{Dosimetria}

Dosimetria de estado sólido foi utilizada para localizar a linha central do feixe de elétrons e mapear a distribuição da dose em que a amostra está posicionada para verificar sua uniformidade. Foram utilizados filmes radiocrômicos da Far West Technology Inc. (FWT), CA, USA, modelo FWT-6000 , com dimensões de $1 \mathrm{~cm} \times 1 \mathrm{~cm} \times 0,425 \mu \mathrm{m}$. As alterações de absorbância após irradiação, de azul claro transparente, para azul intenso, foram lidas utilizando um espectrofotômetro Cary 300 Bio da Varian, software acoplado Simple Reads versão: 3.00 (182) a $605 \mathrm{~nm}$ (ou seja, no pico central de comprimento de onda para a mudança de cor). A dose absorvida é calculada a partir da relação proporcional numa curva de calibração. O intervalo de dose pode ser medido com precisão entre 1 a 30 kGy.

\subsubsection{Caracterização dos nano-hidrogéis}

A caracterização das partículas quanto à dimensão dos nano-hidrogéis provenientes das amostras não irradiadas e irradiadas de soluções de GEL, PEG e MIX foi realizada pela técnica de DLS e AF4. Para realizar os ensaios de DLS, foram necessários $2 \mathrm{~mL}$ de amostra para cada leitura. E para os ensaios no AF4, foi colocado $1 \mathrm{~mL}$ de amostra em frascos com septo de 1,5 mL. A análise topográfica da superfície das amostras de GEL 
e MIX foi realizada em meio líquido. Foi depositado $100 \mu \mathrm{L}$ da amostra diluída sobre o disco de mica clivada (PELCO) com 9,9 mm de diâmetro (FIG. 23).

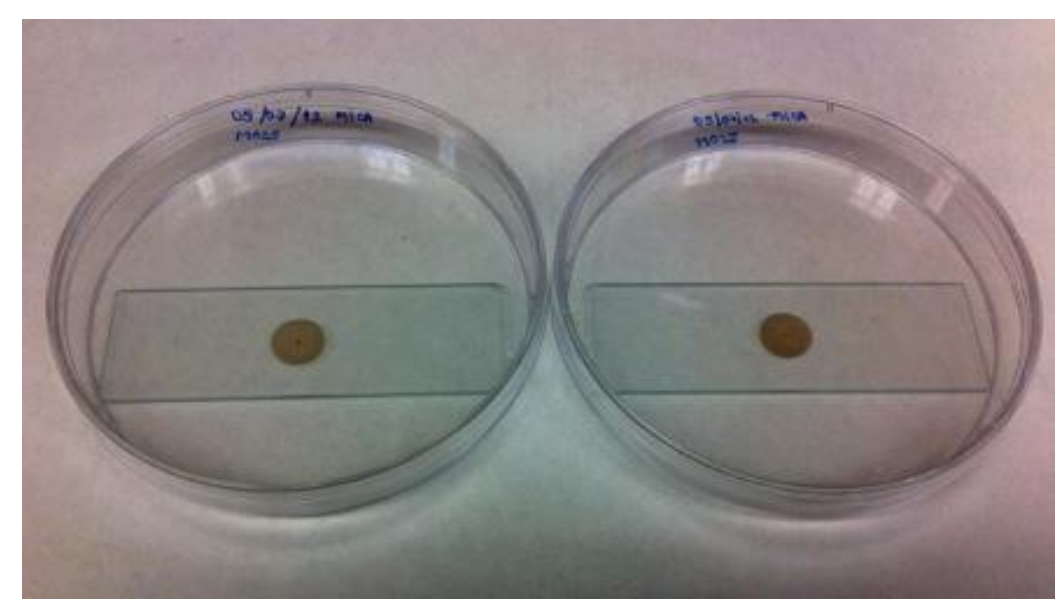

FIGURA 23 - Amostra depositada na mica recém clivada e mantida sob temperatura ambiente para secagem.

\subsection{Resultados e Discussão}

Observações descritas na literatura mencionam que a reticulação induzida pela radiação gama na ausência de ar pode formar um hidrogel estável a base de gelatina derivada de pele suína (Cataldo et al., 2008). Foi relatado que esse hidrogel incorporou toda água disponível em doses de radiação relativamente baixas (até $25 \mathrm{kGy}$ ). Também constam descrições de que em altas doses o hidrogel de gelatina apresentava melhores propriedades mecânicas, mas nesses casos, com maior densidade de reticulação, parte da água disponível teria sido comprimida pela estrutura reticulada e não incorporada ao hidrogel de gelatina. No entanto, Kojima et al. (2004) observaram discretas transformações nos hidrogéis mesmo nas doses de 200 kGy na ausência de ar.

No presente estudo as medições de AFM foram utilizadas para comparar a morfologia de superfície das nanopartículas de GEL e MIX em meio líquido sobre mica (FIG. 24). A amostra de GEL controle (a) apresentou um diâmetro médio de 30,5 nm. As amostras de GEL (b) e MIX (c) irradiados a 15 kGy apresentaram um diâmetro médio de $23,5 \mathrm{~nm}$ e $16,5 \mathrm{~nm}$, respectivamente. A adesão da amostra à superfície de um substrato sólido é 
imprescindível para evitar que a amostra seja arrancada durante a varredura. Este é um problema crítico para amostras orgânicas e biológicas que são frágeis e têm uma fraca interação com a maioria dos substratos (Filho et al., 1997).
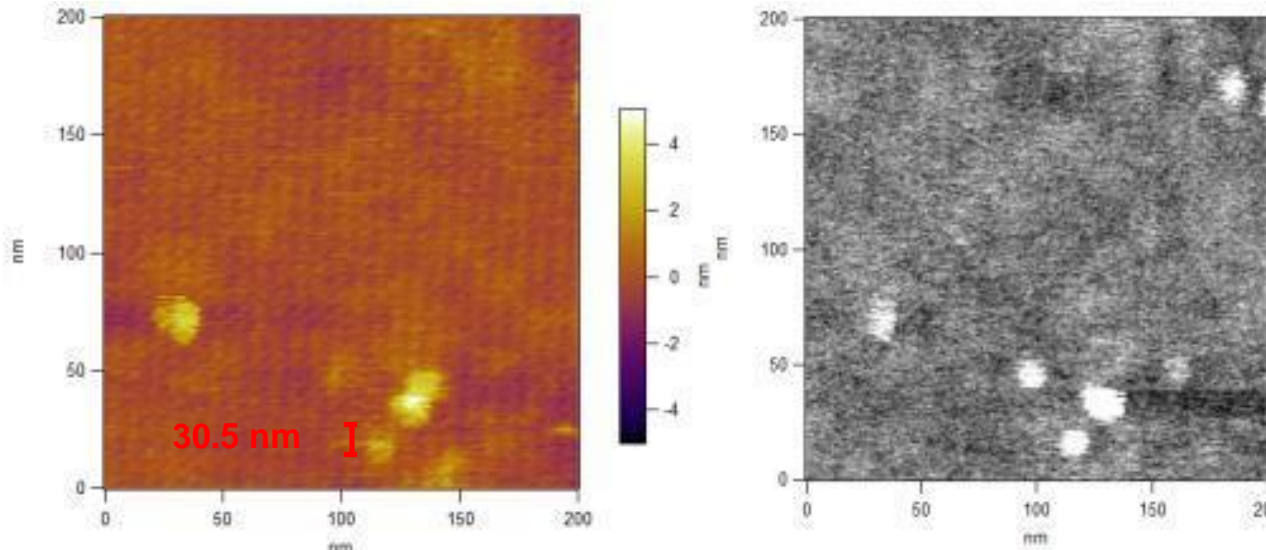

(a)
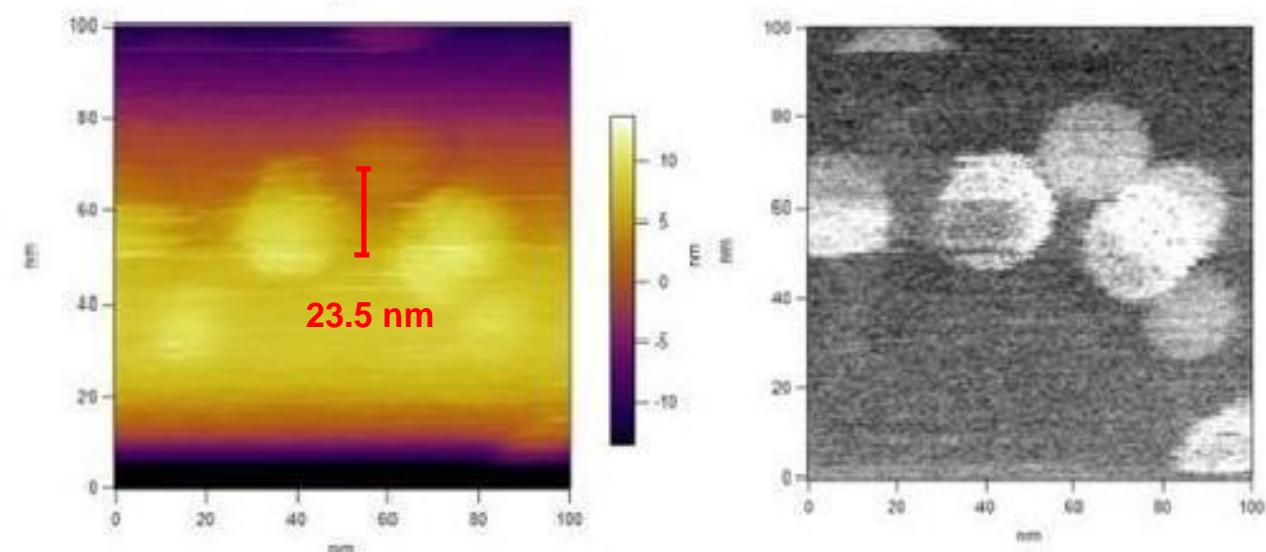

(b)
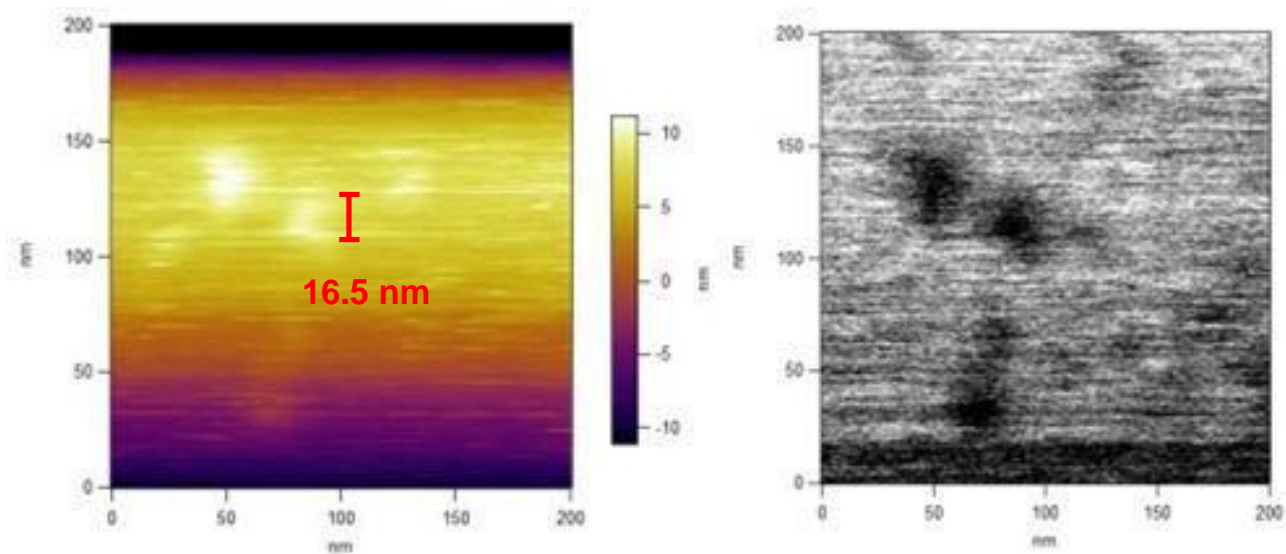

(c)

FIGURA 24 - Micrografias de AFM em meio líquido de nano-hidrogéis de gelatina (GEL) controle (a) e irradiados no EB pulsado a 15 kGy (b) e nano-hidrogéis de MIX a 15 kGy (c). 
As propriedades eletrostáticas da superfície de mica revestida com gelatina foram determinadas e consideradas dominantes na interação superfície-superfície em sistemas aquosos. É fato conhecido que a superfície de mica é carregada negativamente em água pura (Bele et al., 2000). Quando uma camada fina de gelatina é depositada em uma superfície de mica, a superfície de carga é composta por duas contribuições: carga da mica e a carga da gelatina (Israelachvili, 1992).

As alterações de diâmetro hidrodinâmico $\left(D_{h}\right)$ das amostras analisadas por DLS irradiadas a $77^{\circ} \mathrm{C}$ no EB pulsado a uma taxa de dose de $16,5 \mathrm{~Gy} /$ pulso e 70,5 Gy/pulso estão apresentadas nas FIG. 25 e 26 , respectivamente.

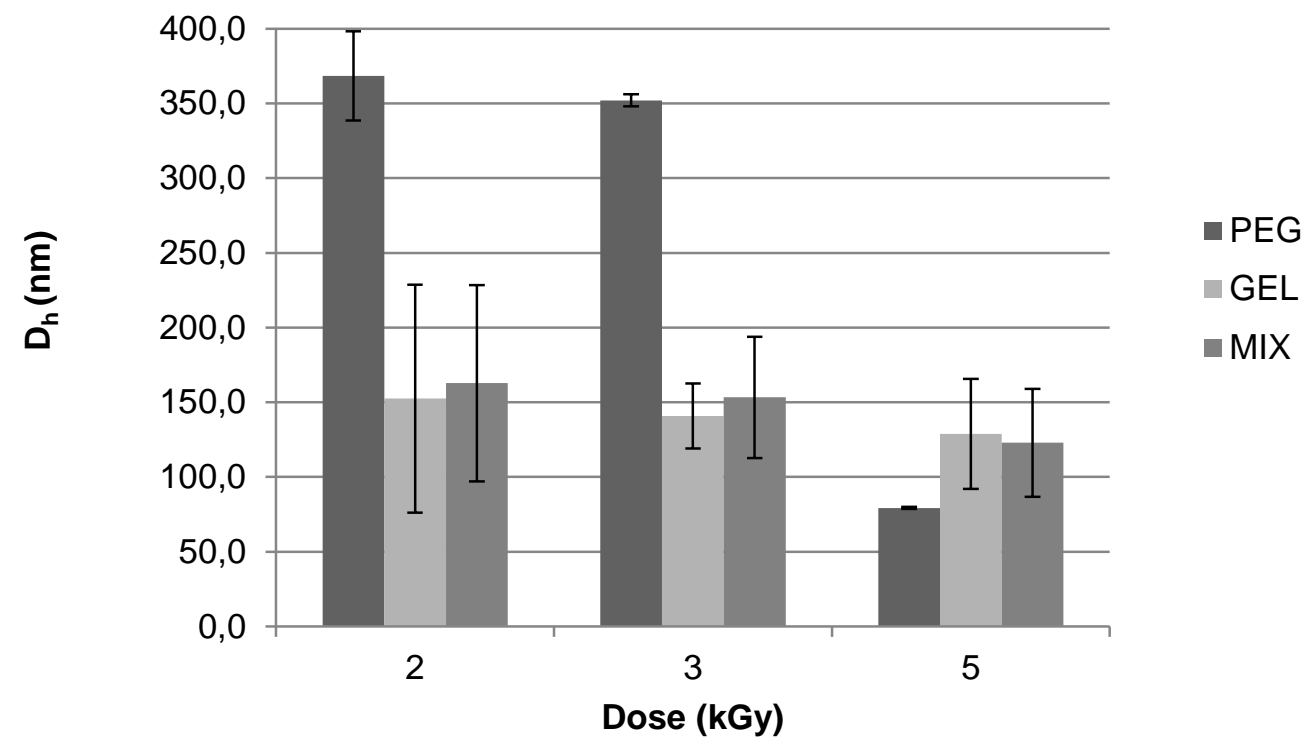

FIGURA 25 - Diâmetro hidrodinâmico $\left(D_{h}, n m\right)$ dos nano-hidrogéis de GEL, PEG e MIX sintetizados e irradiados no EB pulsado em uma taxa de dose de $16,5 \mathrm{~Gy} /$ pulso a $77^{\circ} \mathrm{C}$ analisados no DLS.

Pôde-se observar que $0 D_{h}$ das amostras diminuiu com o aumento da dose e da taxa de dose/pulso, como por exemplo para a amostra GEL 
irradiada a 16,5 Gy/pulso a 2 kGy $(152,4 \pm 76,2 \mathrm{~nm})$ e 5 kGy $(128,8 \pm 36,8 \mathrm{~nm})$ e a $70,5 \mathrm{~Gy} /$ pulso os valores variaram de $(132 \pm 23) \mathrm{nm}$ a $2 \mathrm{kGy}$ para $(125 \pm 19) \mathrm{nm}$ a $5 \mathrm{kGy}$, respectivamente. Para a MIX, houve uma queda nos valores de $D_{h}$ a $5 \mathrm{kGy}$ para as taxas de doses analisadas: 16,5 Gy/pulso $(122,8 \pm 36,2) \mathrm{nm}$ e $70,5 \mathrm{~Gy} /$ pulso $(50 \pm 3) \mathrm{nm}$. Amostras de PEG apresentaram valores do mesmo nível de magnitude a $5 \mathrm{kGy}$ nas mesmas taxas de dose/pulso: 16,5 Gy/pulso $(79,3 \pm 0,8 \mathrm{~nm}) \quad$ e 70,5 Gy/pulso $(58 \pm 2 \mathrm{~nm})$.

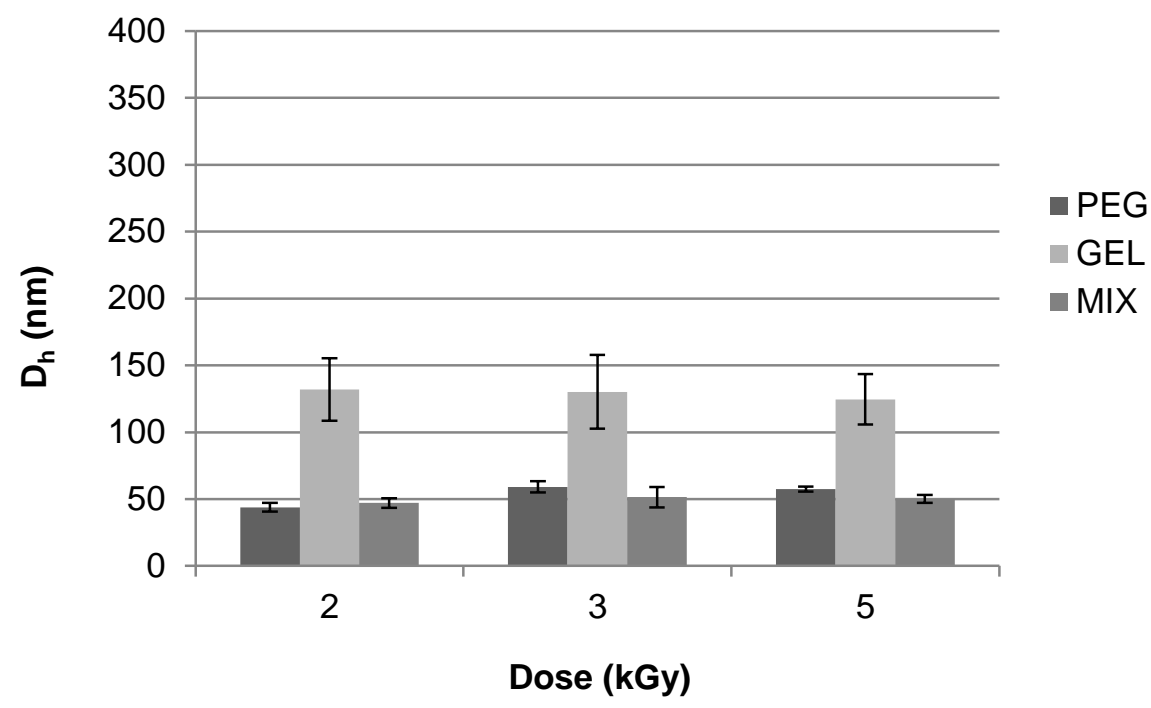

FIGURA 26 - Diâmetro hidrodinâmico $\left(D_{h}, n m\right)$ dos nano-hidrogéis de GEL, PEG e MIX sintetizados e irradiados no EB pulsado em uma taxa de dose de $70,5 \mathrm{~Gy} /$ pulso a $77^{\circ} \mathrm{C}$ analisados no DLS.

Os resultados de $D_{h}$ obtidos para as amostras irradiadas em fonte de ${ }^{60} \mathrm{Co}$ a $77 \stackrel{\circ}{\circ}$ estão apresentados na FIG. 27. As amostras de GEL irradiadas a 2 kGy e a 5 kGy apresentaram um $D_{h}$ de $(139,8 \pm 28,3) n m$ e $(94,9 \pm 16,8) n m$, respectivamente. A MIX apresentou $D_{h}$ menor comparado à amostra de GEL a 2 kGy $(60,2 \pm 6,8 \mathrm{~nm})$ e 5 kGy $(40,0 \pm 6,1 \mathrm{~nm})$. 


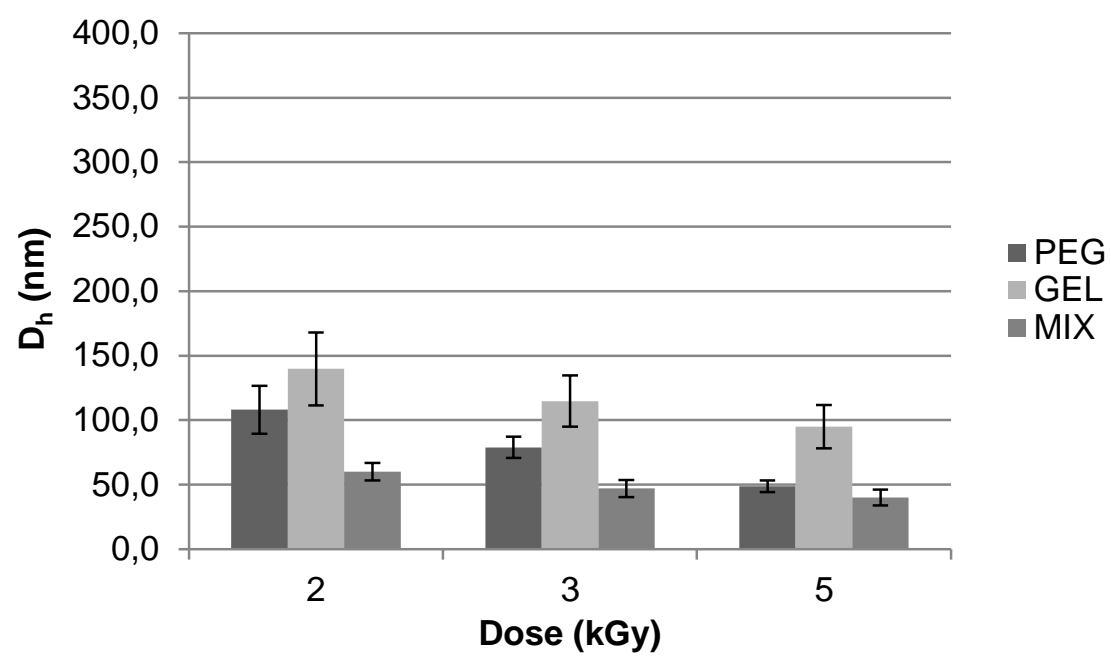

FIGURA 27 - Diâmetro hidrodinâmico $\left(D_{h}, n m\right)$ dos nano-hidrogéis de GEL, PEG e MIX sintetizados e irradiados em fonte de ${ }^{60} \mathrm{Co}$ a $70 \mathrm{kGy} \mathrm{h}^{-1} \mathrm{em}$ diferentes doses a $77^{\circ} \mathrm{C}$ analisados no DLS.

Nas TAB. 9 e 10 estão apresentados os $R_{h}$ dos hidrogéis sintetizados em alta temperatura $\left(77^{\circ} \mathrm{C}\right)$ por radiação de ${ }^{60} \mathrm{Co}$ e EB pulsado a uma taxa de dose de 70,5 Gy/pulso, analisados pela técnica de AF4. As amostras de GEL irradiadas na fonte gama apresentaram um $R_{h}$ de $(127 \pm 28) \mathrm{nm}$ a $2 \mathrm{kGy}$ e $(83 \pm 26) \mathrm{nm}$ a $5 \mathrm{kGy}$. A MIX apresentou $R_{\mathrm{h}}$ menores do que a GEL nas mesmas doses, respectivamente: $(68 \pm 25) \mathrm{nm}$ e $(35 \pm 4) \mathrm{nm}$. Os nano-hidrogéis irradiados com EB pulsado também apresentaram $R_{h}$ menores do que os irradiados na fonte gama, conforme os valores apresentados para MIX a $5 \mathrm{kGy}:{ }^{60} \mathrm{Co}(35 \pm 4 \mathrm{~nm})$ e EB pulsado (26 $\pm 9 \mathrm{~nm}$ ). Assim, pôde-se observar uma diminuição do tamanho dos nano-hidrogéis com o aumento da dose por ambas as técnicas, DLS e AF4. Os dados foram próximos e coerentes, revelando que a reticulação intramolecular foi favorecida mediante o emprego de ambos processos de irradiação. Além disso, o uso de alta taxa de dose (dose/pulso, 70,5 Gy/pulso) mostrou-se particularmente eficaz em temperaturas elevadas $\left(77^{\circ} \mathrm{C}\right)$. 
TABELA 9 - Raio hidrodinâmico $\left(R_{h}, n m\right)$ dos nano-hidrogéis de GEL, PEG e MIX sintetizados e irradiados em fonte de ${ }^{60} \mathrm{Co}$ a $70 \mathrm{kGy} \mathrm{h}^{-1} \mathrm{em}$ diferentes doses a $77^{\circ} \mathrm{C}$ analisados no AF4.

\begin{tabular}{cccc}
\hline $\begin{array}{c}\text { Dose } \\
\text { (kGy) }\end{array}$ & \multicolumn{3}{c}{$\mathbf{R}_{\mathbf{h}}(\mathbf{n m})$} \\
\hline $\mathbf{2}$ & GEL & PEG & MIX \\
$\mathbf{3}$ & $94 \pm 28$ & $73 \pm 28$ & $68 \pm 25$ \\
$\mathbf{5}$ & $83 \pm 26$ & $50 \pm 4$ & $48 \pm 11$ \\
\hline
\end{tabular}

TABELA 10 - Raio hidrodinâmico $\left(R_{h}, n m\right)$ dos nano-hidrogéis de GEL, PEG e MIX sintetizados e irradiados no EB pulsado em diferentes doses em uma taxa de dose de 70,5 Gy/pulso a $77^{\circ} \mathrm{C}$ analisados no AF4.

\begin{tabular}{cccc}
\hline $\begin{array}{c}\text { Dose } \\
\text { (kGy) }\end{array}$ & \multicolumn{3}{c}{$\mathbf{R}_{\mathbf{h}}(\mathbf{n m})$} \\
\cline { 2 - 4 } & \multicolumn{1}{c}{ GEL } & \multicolumn{1}{c}{ PEG } & MIX \\
\hline $\mathbf{5}$ & $84 \pm 8$ & $38 \pm 25$ & $26 \pm 9$ \\
$\mathbf{1 0}$ & $67 \pm 8$ & $27 \pm 12$ & $25 \pm 10$ \\
$\mathbf{1 5}$ & $62 \pm 48$ & $28 \pm 13$ & $30 \pm 15$ \\
\hline
\end{tabular}

Ulański \& Rosiak (1999) observaram a formação de nanogéis em soluções aquosas desoxigenadas diluídas de polímeros hidrofílicos; e que a irradiação com alta relação dose/pulso levou à formação simultânea de diversos radicais nas cadeias poliméricas, que sofreriam recombinação preferencialmente intramoleculares.

Mpofu et al.( 2004) consideraram que em temperaturas acima de $50^{\circ} \mathrm{C}$, ocorre o colapso das moléculas de GEL e PEG. Assim, as interações entre as unidades de repetição de uma mesma cadeia de polímero tornam-se mais favoráveis em virtude do rompimento das pontes de hidrogênio entre água-polímero, levando a uma conformação mais enrolada ou contraída . Esse efeito pode reduzir a distância média dos radicais de GEL, PEG e MIX gerados dentro de uma única cadeia e, subsequentemente, conduzir à formação de nano-hidrogéis mais compactos, que são reticulados por recombinação intramolecular. Furusawa et al. (2004), estudaram hidrogéis de gelatina obtidos após irradiação com ${ }^{60} \mathrm{Co}$, mas com taxa de dose de apenas $10 \mathrm{kGy} \mathrm{h}^{-1} \mathrm{e}$ a $20^{\circ} \mathrm{C}$. Eles consideraram que na estrutura do hidrogel há a contribuição mista da tripla hélice própria do colágeno e da estrutura aleatória (random coil). Com 
aumento da temperatura, ocorria a quebra da estrutura tripla hélice ocorrendo transição gel-sol e assim a conformação aleatória se tornaria predominante. A radiação produziria um encurtamento da distância entre os pontos reticulados no nanogel o que impediria exibir a dependência com a temperatura, mesmo que a estrutura aleatória (random coil) esteja sendo prevalente.

Um maior tempo em média de [HO•] em altas taxas de repetição pulsada pode gerar mais radicais livres de carbono central na mesma cadeia de GEL do que os obtidos em baixa taxa de repetição pulsada. Uma vez que aumenta o número de radicais de carbono coexistindo na mesma cadeia por unidade de tempo, promove-se a recombinação radical intramolecular em vez da reação de radicais intermoleculares conduzida por difusão (von Sonntag et al., 1995b; An et al., 2011).

As massas molares dos hidrogéis de GEL, PEG e MIX sintetizados e irradiados em ${ }^{60} \mathrm{Co}$ e por EB pulsado em diferentes doses a $77^{\circ} \mathrm{C}$ estão apresentadas nas FIG. 28 e 29, respectivamente. O aumento da dose de radiação levou a uma diminuição da massa molar da MIX, como observado a $3 \mathrm{kGy}\left(7,9 \mathrm{E}+08 \pm 163,7 \mathrm{~g} \mathrm{~mol}^{-1}\right)$ e a $10 \mathrm{kGy} \quad\left(2,3 \mathrm{E}+08 \pm 120,0 \mathrm{~g} \mathrm{~mol}^{-1}\right)$. Ulański et al. (2002) observaram que a massa molecular se manteve quase constante em nanogéis de ácido poliacrílico, indicando que houve baixa contribuição da recombinação intermolecular. Assim, eles mostraram que reações induzidas por radiação conduzem a reticulação intramolecular. Porém, não se pode descartar que o aumento na massa molar seja compensada por um processo paralelo de cisão de cadeia.

A variação da massa molar das amostras irradiadas pode ser atribuída à reações de reticulação inter ou intramolecular, como já mencionado. $\mathrm{Na}$ reticulação intramolecular, onde a reticulação ocorre dentro da cadeia polimérica, sem alteração da massa molar, são produzidas partículas de tamanho reduzido, o que é mais favorável em materiais destinados às aplicações de liberação controlada de drogas (An et al., 2011). 


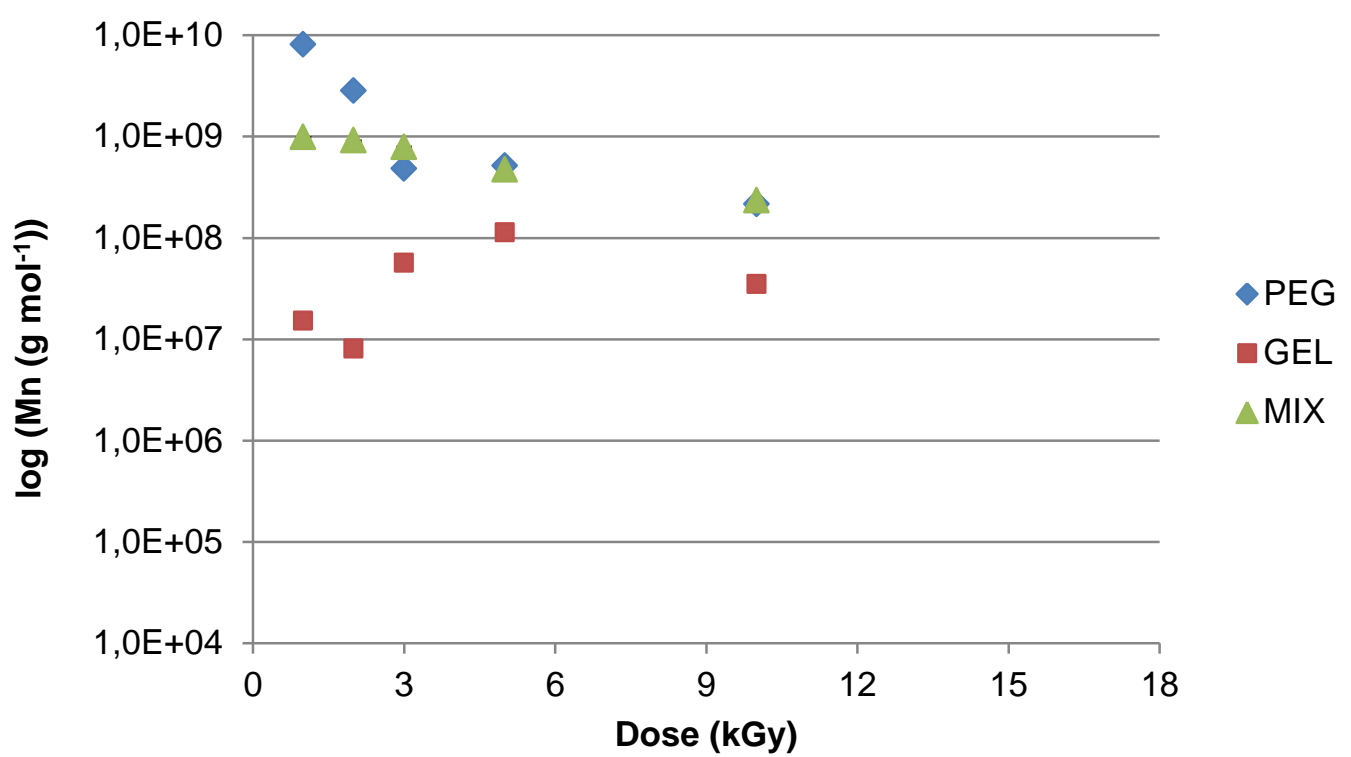

FIGURA 28 - Massa molar médio (Mn, $\mathrm{g} \mathrm{mol}^{-1}$ ) dos nano-hidrogéis de GEL, PEG e MIX sintetizados e irradiados em fonte de ${ }^{60} \mathrm{Co}$ a $70 \mathrm{kGy} \mathrm{h}^{-1} \mathrm{em}$ diferentes doses a $77^{\circ} \mathrm{C}$ analisados no AF4.

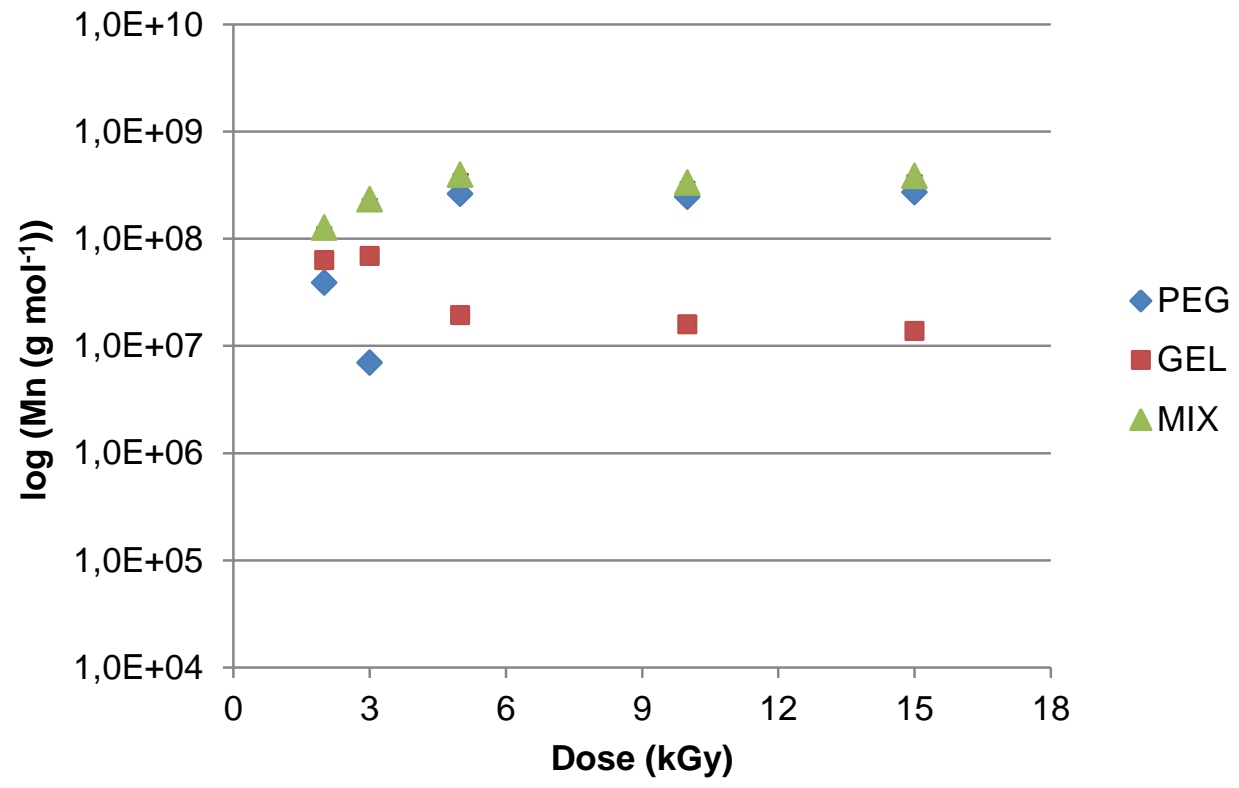

FIGURA 29 - Massa molar médio (Mn, $\mathrm{g} \mathrm{mol}^{-1}$ ) dos nano-hidrogéis de GEL, PEG e MIX sintetizados e irradiados no EB pulsado em diferentes doses em uma taxa de dose de 70,5 Gy/pulso a $77^{\circ} \mathrm{C}$ analisados no AF4. 
Os parâmetros utilizados neste trabalho, tais como a massa molar, a concentração e as condições de irradiação, foram escolhidos para otimizar a formação da ligação intramolecular. Com o aumento das doses de radiação e, consequentemente, maiores concentrações de ligações intramoleculares, menores produtos poliméricos, como determinado pelo raio hidrodinâmico $\left(R_{h}\right)$, são produzidos, já que as condições de irradiação podem ser adaptadas para produzir materiais para aplicações específicas. No caso descrito por Querner et al. (2004), a irradiação do poli (vinil metil éter), a reticulação intermolecular predominou em doses baixas ( $<5 \mathrm{kGy}$ ), enquanto a reticulação intramolecular predominou em doses mais elevadas.

$\mathrm{Na}$ FIG. 30 são mostradas as soluções da MIX em diferentes concentrações após a irradiação. Todas as amostras foram saturadas com $\mathrm{N}_{2} \mathrm{O}$ antes da irradiação e inicialmente eram soluções visualmente transparentes. $A$ solução da amostra "A" manteve o seu estado líquido transparente original após a irradiação com EB pulsado a $77^{\circ} \mathrm{C}$. Assim, foi fixada essa concentração nessa proporção (1:10) (GEL: 0,01\% (p/v); PEG: 0,1\% (p/v)) para todos os ensaios. A amostra "B" apresentou uma leve translucidez comparada à amostra irradiada com EB pulsado, utilizando a mesma concentração. As outras amostras testadas apresentaram diferentes comportamentos com formação de géis macroscópicos separados da fase líquida devido às diferentes concentrações das amostras C: (1:1); D: (1:4); D: (1:40) de GEL e PEG, respectivamente. A amostra $\mathrm{MIX}(1: 10)$ irradiada a $5 \mathrm{kGy}$ a $77^{\circ} \mathrm{C}$ a $70,5 \mathrm{~Gy} /$ pulso produziu um $\mathrm{D}_{\mathrm{h}}$ menor $(50 \pm 3 \mathrm{~nm})$ que os preparados a $16,5 \mathrm{~Gy} /$ pulso $(122,8 \pm 36,2 \mathrm{~nm})$ na mesma temperatura. Este comportamento pode ser atribuído à conformação termicamente colapsada da cadeia polimérica, produzida em temperaturas elevadas, e favorável à reticulação intramolecular em virtude da formação de estruturas mais densamente reticuladas, conforme descrito por An et al. (2011). 


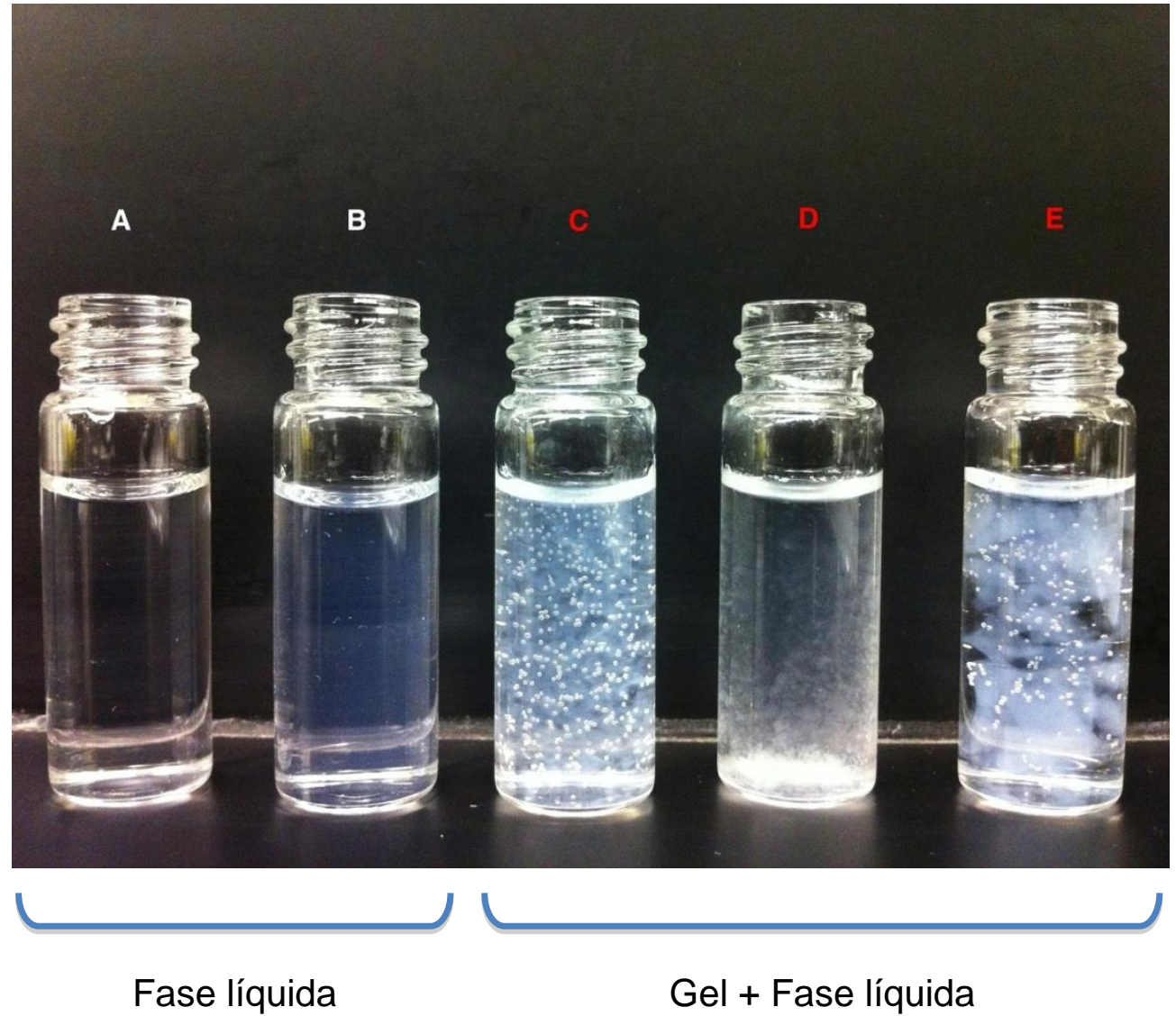

FIGURA 30 - Amostras irradiadas a $15 \mathrm{kGy}$ por raios- $\gamma$ e sintetizadas a 20 ㄷ em diferentes concentrações de soluções de MIX (B a E) e amostra A irradiada a 15 kGy no EB pulsado sintetizada a $77^{\circ} \mathrm{C}$.

A formação radioinduzida de nanogéis em soluções diluídas homogêneas (cada macromolécula está separada) já foi descrita por autores que estudaram e descreveram o processo: em poli(vinil pirrolidone) (Ulański et al., 1998), poli (vinil álcool) (von Sonntag et al., 1995b), e ácido poliacrílico (Ulański et al., 2002). Em soluções não homogêneas a reação de reticulação ocorreria de forma inter e intramolecular. Entretanto, para estruturas complexas, a reticulação intermolecular dominaria o sistema.

Zwiorek et al. (2008) verificaram que a gelatina oferece muitas vantagens para preparação de sistemas de liberação controlada de drogas coloidais. Esta estrutura proteica fornece sítios para ligações seletivas de várias funcionalidades, alta tolerância fisiológica, biocompatibilidade e biodegradabilidade, como já mencionado. Esses géis de gelatina podem ser 
modificados por agentes de reticulação para melhorar a estabilidade térmica e propriedades mecânicas (Choi et al., 2008) e ser usados com fármacos, pois dependendo da temperatura podem estar na forma de sol ou gel, ampliando ainda mais o seu uso (Curcio et al., 2010).

Segundo Harrington \& Rao (1970), as dobras das cadeias da gelatina podem proceder por duas vias e os padrões da medida da dobra reversa (intramolecular) e dobra paralela (intermolecular) da tripla hélice dependem tanto da concentração de proteína quanto da temperatura (FIG. 31). Drake \& Veis (1964) observaram que em soluções muito diluídas (não gelificadas) de aproximadamente $2 \mathrm{mg} / \mathrm{mL}$ de gelatina, as ligações dos segmentos intermoleculares e intramoleculares podem apresentar a mesma probabilidade de ocorrer. Nesta diluição, as ligações intramoleculares seriam favorecidas. Eles observaram também que as dobras reversas das triplas hélices podem se formar em sistemas de gelatina resfriadas e em baixas concentrações.

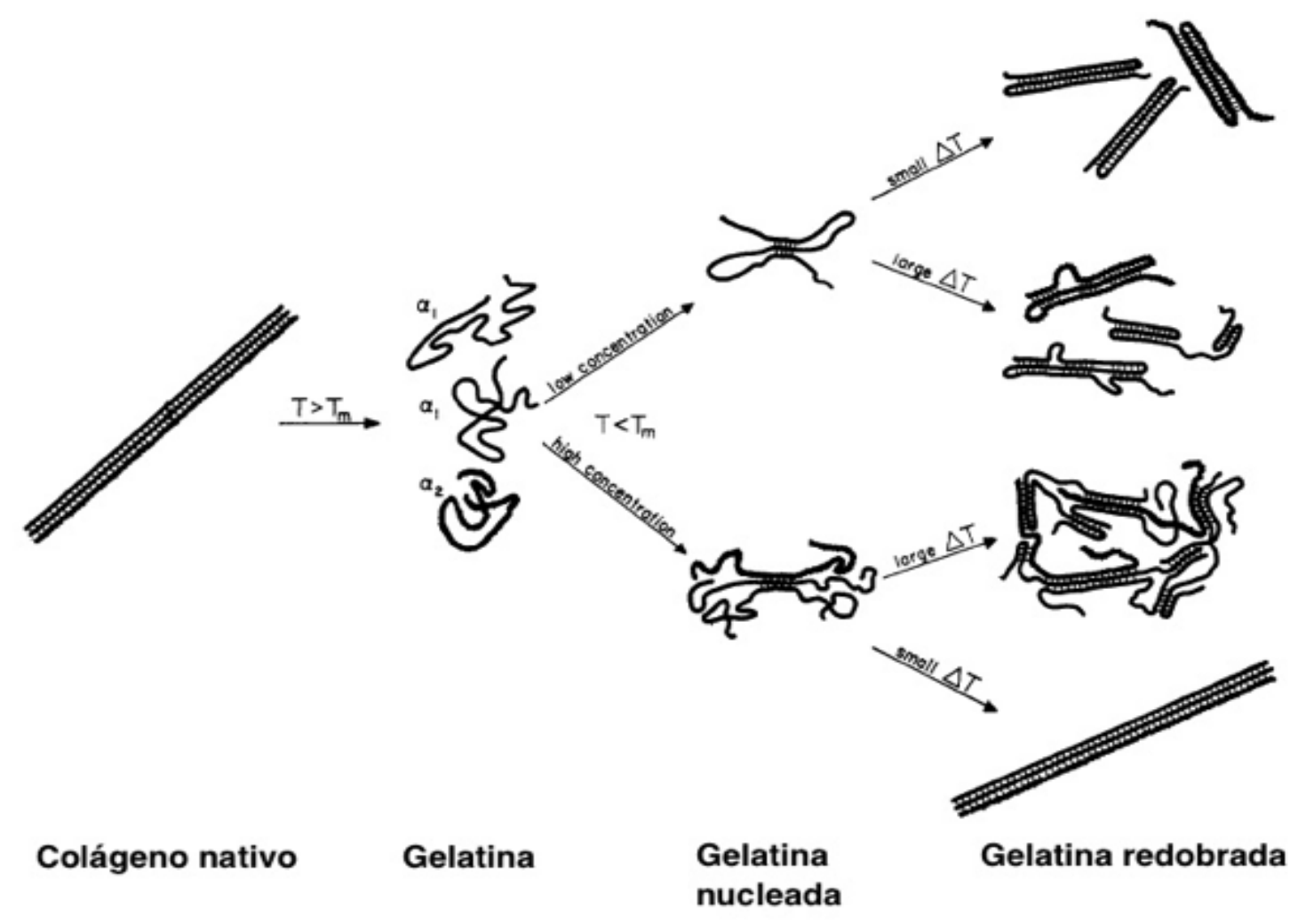

FIGURA 31 - Esquema sugerido para dependência da concentração com duas vias para dobramento de cadeia Tm (temperatura de fusão) em polipeptídeos de cadeia única derivada de colágeno (Harrington \& Rao, 1970). 
Com base nos resultados da síntese de nano-hidrogéis de GEL, PEG e MIX por radiação ionizante pôde-se concluir que:

- Há uma diminuição da dimensão dos nano-hidrogéis de gelatina com o aumento da dose de radiação observada pelas técnicas de caracterização utilizadas (AFM, DLS e AF4).

- Pelo DLS, o $D_{\mathrm{h}}$ das amostras diminuiu com o aumento da dose e da taxa de dose/pulso, como ocorreu na amostra GEL irradiada a 16,5 Gy/pulso a 2 kGy $(152,4 \pm 76,2 \mathrm{~nm})$ e $5 \mathrm{kGy}$ $(128,8 \pm 36,8 \mathrm{~nm})$ e a $70,5 \mathrm{~Gy} /$ pulso os valores variaram de $(132 \pm 23) \mathrm{nm}$ a $2 \mathrm{kGy}$ para $(125 \pm 19) \mathrm{nm}$ a $5 \mathrm{kGy}$, respectivamente.

- Pelo DLS, a MIX apresentou uma queda nos valores de $D_{h}$ a $5 \mathrm{kGy}$ para as taxas de doses analisadas: 16,5 Gy/pulso $(122,8 \pm 36,2) \mathrm{nm}$ e 70,5 Gy/pulso $(50 \pm 3) \mathrm{nm}$.

- Os nano-hidrogéis irradiados com EB pulsado apresentaram $R_{h}$ menores do que os irradiados na fonte gama, conforme os valores apresentados para MIX a $5 \mathrm{kGy}$ : ${ }^{60} \mathrm{Co}(35 \pm 4 \mathrm{~nm})$ e EB pulsado $(26 \pm 9 \mathrm{~nm})$.

- A alta taxa de dose (dose/pulso, 70,5 Gy/pulso) mostrou-se particularmente eficaz a $77^{\circ} \mathrm{C}$.

- A diminuição do tamanho dos nano-hidrogéis com o aumento da dose, associado à massa molar constante, revelaram, mediante o emprego de ambos os processos de irradiação, que a reticulação intramolecular foi favorecida.

- Os resultados mostram que houve obtenção de nanoestruturas na dimensão inferior a $100 \mathrm{~nm}$, isto é, característico de nanotecnologia pela síntese induzida pela radiação ionizante, possibilitando a aplicação desta técnica para uso em diversos sistemas biológicos ou liberação controlada de drogas.

- A conformação termicamente colapsada da cadeia polimérica, produzida em temperaturas elevadas, é favorável a reticulação intramolecular em virtude da formação de estruturas mais densamente reticuladas. 
- A diminuição do tamanho dos nano-hidrogéis com o aumento da dose, associado à massa molar constante, revelaram que a reticulação intramolecular foi favorecida mediante o emprego de ambos processos de irradiação.

- A elevada taxa de repetição por pulso da irradiação por feixe de elétrons produz preferencialmente menores nano-hidrogéis reticulados intramolecularmente.

- O uso de diferentes tipos de radiação ionizante, ${ }^{60} \mathrm{Co}$ e EB pulsado, e outros parâmetros possibilitaram um estudo comparativo de síntese de nano-hidrogéis de GEL, PEG e MIX.

- É essencial o controle do processo e das condições, tais como concentração, temperatura, taxa de dose (taxa de repetição por pulso), presença ou ausência de ar e outros parâmetros, podem determinar resultados e aplicações diversas. 


\section{CONSIDERAÇÕES FINAIS}

A caracterização de biopolímeros de gelatina obtidos pela ação da radiação ionizante e a síntese radioinduzida de nano-hidrogéis de gelatina utilizando fonte gama e feixe de elétrons contínuo e pulsado foi o objetivo alcançado neste trabalho de tese.

A tecnologia nuclear na sua aplicação em polímeros, particularmente polímeros naturais, como mostra o presente trabalho, continua a ser destaque dentro das aplicações benéficas da energia nuclear para o desenvolvimento de países ricos em recursos naturais como é o caso do Brasil. A indústria de alimentos e a biomedicina são os destinatários iniciais dos avanços nesse campo de pesquisa. Por outro lado, há ainda uma miríade de desafios a superar para alcançar os objetivos que o País requer.

A partir deste trabalho original e precursor, cabe propor 0 desenvolvimento de filmes a base de gelatina utilizando outros tipos de fibras da biodiversidade brasileira. Também, como mostrado neste trabalho, podem ser incorporados antioxidantes tanto naturais quanto sintéticos e preparar diferentes blendas com polissacarídeos, lipídeos ou polímeros sintéticos biodegradáveis. Assim, abre-se a perspectiva de extensão da presente aplicação em diversos materiais avançados.

A obtenção de nanoestruturas na dimensão inferior a $100 \mathrm{~nm}$, isto é, característico de nanotecnologia pela síntese induzida pela radiação ionizante, possibilita a aplicação desta técnica para uso nos mais diversos sistemas biológicos, como a liberação controlada de drogas, encapsulamento de compostos bioativos (substâncias responsáveis pelo sabor, pigmentos, acidulantes, nutrientes, enzimas, conservantes) em cápsulas comestíveis.

Esta proposta pioneira, contudo, evidencia a necessidade do prosseguimento da investigação e desenvolvimento: cálculo da distribuição espacial das moléculas poliméricas, a fração de cada molécula polimérica individual; aprofundar na química da radiação envolvida para poder propor 
modelos de comportamento, por exemplo, na síntese de nano-hidrogéis sob o efeito da temperatura em diferentes taxa de repetição por pulso; obtenção de nano-hidrogéis funcionais, bioativos e/ou inteligentes; obtenção de nano-hidrogéis contendo núcleos magnéticos. 


\section{REFERÊNCIAS BIBLIOGRÁFICAS}

1. ABD EL-REHIM, H.A. Characterization and possible agricultural application of polyacrylamide/sodium alginate crosslinked hydrogels prepared by ionizing radiation. J. Appl. Polym. Sci., v. 101, n. 6, p. 3572-3580, 2006.

2. ABUCHOWSKI, A. Effects of covalent attachment of polyethylene glycol on bovine serum albumin and bovine catalase. New York: State University of New Jersey, p. 186, 1975.

3. ABUCHOWSKI, A.; DAVIS, F.F. Soluble polymer-enzyme adducts. Enzymes. In:

HOLCENBERG, J.C. (Ed.). Enzymes as Drugs. New York: John Wiley and Sons, 1981.

4. AJJI, Z.; OTHMAN, I.; ROSIAK, J.M. Production of hydrogel wound dressings using gamma radiation. Nucl. Instr. Met. Phys. Res. B, v. 229, n. 3-4, p. 375-380, 2005.

5. AL-ASSAF, S., PHILLIPS, G.O., WILLIAMS, P.A. DU PLESSIS, T.A. Application of ionizing radiations to produce new polysaccharides and proteins with enhanced functionality. Nucl. Instr. Meth. Phys. Res. B, v. 265 , p. $37-43,2007$.

6. AL-SHEIKHLY, M. Future trends of nuclear and radiation applications in nanotechnology. In.: LAS/ANS. Rio de Janeiro, jun.21-25, 2010.

Proceedings... Rio de Janeiro: LAS/ANS, 2010.

7. AMAZONAS, Governo do Estado. Secretaria Executiva Adjunta de Extrativismo da Secretaria de Estado do Meio Ambiente de Desenvolvimento Sustentável (SDS). Cadeia produtiva da castanha-do-Brasil no estado do Amazonas. Série Técnica Meio Ambiente e Desenvolvimento Sustentável, 3. In: MENEZES, M.; PINHEIRO, M.R.; GUAZZELI, A.C.; MARTINS, F. (Ed.). I CONFERÊNCIA ESTADUAL DAS POPULAÇÕES TRADICIONAIS DO AMAZONAS, 08-11 nov., 2004, Manaus. p. 28. Proceedings... Manaus, 2005. (A479).

8. AMIN, S.; USTUNOL, Z. Solubility and mechanical properties of heat-cured whey protein-based edible films compared with that of collagen and natural casings. Int. J. Dairy Tech., v. 60, n. 2, p. 149-153, 2007. 
9. AN, J.-C.; WEAVER, A.; KIM, B.; BARKATT, A.; POSTER, D.; VREELAND, W.N.; SILVERMAN, J.; AL-SHEIKHLY, M. Radiation-induced synthesis of poly(vinylpyrrolidone) nanogel. Polym., v. 52, n. 25, p. 5746-5755, 2011.

10. ANBAR, M.; MEYERSTEIN, D. NETA, P. Reactivity of Aromatic Compounds toward Hydroxyl Radicals. The J. Physical Chem., v. 70, n. 8, p. 2660-2662, 1966.

11. ANTONIEWSKI M.N., BARRINGER, S.A., KNIPE, C.L., ZERBY, H.N. Effect of gelatin coating on the shelf life of fresh meat. J. Food Sci., v. 72, n. 6, p. E382-E387, 2007.

12. ANTONIEWSKI, M.N.; BARRINGER, S.A. Meat shelf-life and extension using collagen/gelatin coatings: a review. Crit. Rev. Food Sci.Nutr., v. 50, n. 7, p. 644-653, 2010.

13. AQUINO, R.C.M.P; D'ALMEIDA, J.R.M \& MONTEIRO, S.N. Propriedades de compósitos de piaçava com matriz polimérica, In: 55 CONGRESSO ANUAL DA ABM, 24-27 jul., 2000, p. 2898, Rio de Janeiro. Resumos... Rio de Janeiro.

14. ARAÚJO, J.M.A. Química de Alimentos - Teoria e Prática, Ed.UFV, Viçosa, MG, 2006.

15. ARFVIDSSON, C.; WAHLUND, K-G. Mass overloading in the flow field-flow fractionation channel studied by the behaviour of the ultra-large wheat protein glutenin. J. Chromat. A, v. 1011, p. 99-109, 2003.

DOI: 10.1016/S0021-9673(03)01145-2.

16. ARVANITOYANNIS, I.; KOLOKURIS, I.; NAKAYAMA, A.; YAMAMOTO, N.; AIBA, S. Physico-chemical studies of chitosan-poly(vinyl alcohol) blends plasticized with sorbitol and sucrose. Carbohydrate Polymers, v. 34, n. 1-2, p. 9-19, 1997.

17. ASKARIEH, G.; HEDHAMMAR, M.; NORDLING, K.; SAENZ, A.; CASALS, C.; RISING, A.; JOHANSSON. J.; KNIGHT, S.D. Self-assembly of spider silk proteins is controlled by a $\mathrm{pH}$-sensitive relay. Nature, v. 465, n. 7295, p. 236-238, 2010.

18. AUDETTE-STUART, M.; HOUÉE-LEVIN, C.; POTIER, M. Radiation-induced protein fragmentation and inactivation in liquid and solid aqueous solutions. Role of $\mathrm{OH}$ and electrons. Radiat. Phys. Chem., v. 72, n. 2-3, p. 301-306, 2005.

19. AZZAM, E.I.; JAY-GERIN, J.P.; PAIN, D. Ionizing radiation-induced metabolic oxidative stress and prolonged cell injury. Cancer Lett., v. 327, p. 48-60, 2012. 
20. BALLANTYNE, B.; JORDAN, S.L. Toxicological, medical and industrial hygiene aspects of glutaraldehyde with particular reference to its biocidal use in cold sterilization procedures. J. Appl. Toxicol., v. 21, n. 2, p. 131-151, 2001.

21. BARDAJEE, G.R.; POURJAVADI, A.; SOLEYMAN, R.; SHEIKH, N. Irradiation mediated synthesis of a superabsorbent hydrogel network based on polyacrylamide grafted onto salep. Nucl. Instr. Met. Phys. Res. B, v. 266 , n. 18 , p. 3932-3938, 2008.

22. BARRETO, P.L.M.; PIRES, A.T.N.; SOLDI, V. Thermal degradation of edible films based on milk proteins and gelatin in inert atmosphere. Polym. Degradat. Stabil., v. 79, n. 1, p. 147-152, 2003.

23. BEATRIZ, A.; ARAÚJO, Y.J.K.; LIMA, D.P. Glicerol: Um breve histórico e aplicação em sínteses estereosseletivas. Química nova, v. 34, n. 2, p. 306-319, 2011.

24. BEHR, M.; ROSENTRITT, M.; DÜMMLER, F.; HANDEL, G. The influence of electron beam irradiation on fibre-reinforced composite specimens. J. Oral Rehab. v. 33; p. 447-451, 2006.

25. BELE, M.; KOČEVAR, K.; PEJOVNIK, S.; BESENHARD, J.O.; MUŠEVIČ, I. Molecular Bridging between Water-Dispersed Particles and Gelatin-Coated Surfaces. Langmuir., v. 16, n. 22, p. 8334-8342, 2000.

26. BERGO, P.; SOBRAL, P.J.A. Effect of plasticizer on physical properties of pigskin gelatin films. Food Hydrocol., v. 21, p. 1285-1289, 2007.

27. BERNARDIN, A.M.; RIELLA, H.G. Variação de Tonalidades em Placas Cerâmicas e Escalas Colorimétricas: CMC x CIELAB x CIELCH. Cerâmica Industrial, v. 4, n. 1-6, p. 43-46, 1999.

28. BERNE, B.J.; PECORA, R. Dynamic Light Scattering: With Applications to Chemistry, Biology, and Physics. New York: Wiley, 1976.

29. BIGI, A.; BRACCI, B.; COJAZZI, G.; PANZAVOLTA, S.; ROVERI, N. Drawn gelatin films with improved mechanical properties. Biomaterials, v. 19, n. 24, p. 2335-2340, 1998.

30. BIGI, A.; COJAZZI, G.; RUBINI, K.; ROVERI, N. Mechanical and thermal properties of gelatin Ims at different degrees of glutaraldehyde crosslinking. Biomaterials, v. 22, n. 8, p. 763-768, 2001.

31. BINNING, G.; QUATE, C.F. GERBER, C. Atomic Force Microscope. Physical rev. letters, v. 56, n. 9, p. 930-933, 1986. 
32. BLY, J.H. Electron Beam Processing. Yardley, PA: International Information Associates, 1988.

33. BOEDTKER, H.; DOTY, P.A. Study of Gelatin Molecules, Aggregates and Gels. J. Phys. Chem., v. 58, n. 11, p. 968-983, Nov. 1954.

DOI: $10.1021 / \mathrm{j} 150521 \mathrm{a} 010$

34. BONELLI, C.M.C.; ELZUBAIR, A.; SUAREZ, J.C.M.; MANO, E.B. Comportamento Térmico, Mecânico e Morfológico de Compósitos de Polietileno de Alta Densidade Reciclado com Fibra de Piaçava. Polímeros: Ciência e Tecnologia, v. 15, n. 4, p. 256-260, 2005.

35. BRASKEM. MORITA, A. Polímeros Verdes. In: CONGRESSO BRASILTEC 2013, 14 ago 2013, São Paulo, Brasil. Proceedings... São Paulo: SPE \& IPEN-CNEN/SP, 2013.

36. BRITO, G.F.; AGRAWAL, P.; ARAÚJO, E.M.; MÉLO, T.J.A. Biopolímeros, Polímeros Biodegradáveis e Polímeros Verdes. Rev. Eletrôn. Mat. Proc., v. 62 , p. 127-139, 2011.

37. BURNS, P., DREWELL, N.H.; MCKEOWN, J. The measurement, control, and validation of critical parameters in an electron beam sterilization facility. Nucl. Instr. Met. Phys. Res. B, v. 113, n. 1-4, p. 96-98, 1996.

38. BYRNE, M.E.; SALIAN, V. Molecular imprinting within hydrogels. II. Progress and analysis of the field. International Journal of Pharmacy, v. 364, p. 188-212, 2008.

39. CAO, N.; FU, Y.; HE, J. Mechanical properties of gelatin films cross-linked, respectively, by ferulic acid and tannin acid. Food Hydrocol., v. 21, n. 4, p. 575-584, 2007.

40. CARVALHO, R.A.; SOBRAL, P.J.A.; MENEGALLI, F.C. Mechanical and water vapor properties of gelatin-based films as function of relative humidity, temperature, and film thickness. In: Water properties of food pharmaceutical biological materials. Capt. 26. p. 431-436, Taylor \& Francis Group, LLC., 2006.

41. CASCONE, M.G.; LAZZERI, L.; CARMIGNANI, C.; ZHU, Z. Gelatin nanoparticles produced by a simple WO emulsion as delivery system for methotrexate. J. of materials science: materials in medicine., v. 13, p. 523-526, 2002.

42. CATALDO, F.; URSINI, O.; LILLA, E.; ANGELINI, G. Radiation-induced crosslinking of collagen gelatin into a stable hydrogel. J. Radioanal. Nucl. Chem., v. 275, n. 1, p. 125-131, 2008. 
43. CHAPIRO, A. Chemical modifications in irradiated polymers. Nucl. Instrum. Met. Phys. Res. B, v. 32, p. 111-114, 1988.

44. CHAPIRO, A. Radiation chemistry in the field of biomaterials. Radiat. Phys. Chem., v. 46, n. 2, p. 159-160, 1995.

45. CHAPLIN, M. Water structure and science. Gelatin. London, U.K., July, 2007. Disponível em: <http://www.lsbu.ac.uk/water/hygel.html\#319>. Acesso em: 29 nov. 2007.

46. CHATTERJEE, A. Interaction of ionizing radiation with matter. In: FARHATAZIZ, J.; RODGERS, M.A. (Ed.). Radiation Chemistry, Principles and Applications. New York: VCH Publishers Inc., 1987. p. 1-28.

47. CHIONO, V.; PULIERI, E.; VOZZI, G.; CIARDELLI, G.; AHLUWALIA, A.; GIUSTI, P. Genipin-crosslinked chitosan gelatin blends for biomedical applications. J. Mater. Sci.: Mater. Med., v. 19, p. 889-898, 2008.

48. CHMIELEWSKI, A.G.; HAJI-SAEID, M. IAEA programme in the field of radiation technology. Nucl. Instr. Meth. Phys. Res. B, v. 236, n. 1-4, p. 38-43, 2005.

49. CHOI, H. Y.; HAN, S. O.; LEE, J. S. Surface morphological, mechanical and thermal characterization of electron beam irradiated fibers. App. Surf. Sci., v. 255 , p. 2466-2473, 2008.

50. CIE. CIE DS 014-4.3/E:2007. Colorimetry - Part 4: CIE 1976 L*a*b* Colour Space. Vienna, Austria: CIE Central Bureau, 2007.

51. CIESLA, K.; SALMIERI, S.; LACROIX, M. Modification of the properties of milk protein films by gamma radiation and polysaccharide addition. J. Sci. Food Agricult., v. 86, n. 6, p. 908-914, 2006.

52. CLOUGH, R.L. High-energy radiation and polymers: A review of commercial processes and emerging applications. Nucl. Instr. Meth. Phys. Res. B, v. 185, n. 1-4, p. 8-33, 2001.

53. COLLA, E.; SOBRAL, P.J.A.; MENEGALLI, F.C. Amaranthus cruentus flour edible films: influence of stearic acid addition, plasticizer concentration, and emulsion stirring speed on water vapor permeability and mechanical properties. J. Agric. Food Chem., v. 54, n. 18 p. 6645-6653, 2006.

54. CORADIN, T.; BAH, S.; LIVAGE, J. Gelatin/silicate interactions: from nanoparticles to composite gels. Col. Surf. B: biointerfaces, v. 35, n. 1, p. $53-58,2004$. 
55. COURTS, A.; STAINSBY, G. Recent advances gelatin and glue research. Pergamon Press, New York, p. 100, 1958.

56. CUI, L.; JIA, J.; GUO, Y.; LIU, Y.; ZHU, P. Preparation and characterization of IPN hydrogels composed of chitosan and gelatin cross-linked by genipin. Carbohydrate polym., v. 99, p. 31-38, 2014.

57. CURCIO, M., SPIZZIRRI, U.G., IEMMA, F., PUOCI, F., CIRILLO, G., PARISI, O.I., PICCI, N. Grafted thermo-responsive gelatin microspheres as delivery systems in triggered drug release. Europ. J. Pharmac.

Biopharmac., v. 76, p. 48-55, 2010.

58. CZVIKOVZKY, T. Chemistry and technology of radiation processed composite materials. Radiat. Phys. Chem., v. 25. n. 4-6, p. 439-449, 1985.

59. CZVIKOVSZKY, T. Electron-beam processing of wood fiber reinforced polypropylene. Radiat. Phys. Chem., v. 47, n. 3, p. 425-430, 1996.

60. DAHLAN, K.Z.HJ. M. Radiation processing facilities: Malaysian experience. In: TECHNICAL MEETING HELD IN VIENNA, Apr. 28-30, 2003, Vienna. Emerging applications of radiation processing. Proceedings... Vienna: IAEA, 2004. (IAEA-TECDOC-1386).

61. DARWIS, D.; HILMY, N.; HARDNTNGSIH, L.; ERLINDA, T. Poly(nvinylpyrrolidone) hydrogels: 1 . Radiation polymerization and crosslinking of n-vynilpyrrolidone. Radiat. Phys. Chem.,v. 42, n. 4-6, p. $907-910,1993$.

62. DEARFIELD, K.L.; DOUGLAS, G.R.; EHLING, U.H.; MOORE, M.M.; SEGA, A.; BRUSICK, D.J. Acrylamide: a review of its genotoxicity and an assessment of heritable genetic risk. Mutat. Res., v. 330, p. 71-99, 1995.

63. DEMERLIS, C.C.; SCHONEKER, D.R. Review of the oral toxicity of polyvinyl alcohol (PVA). Food Chem Toxicol., v. 41, n. 3, p. 319-326, 2003.

64. DINTCHEVA, N.T.; JILOV, N.; MANTIA, F.P. Recycling of plastics from packaging. Polym. Degrad. Stab., v. 57, p. 191-203, 1997.

65. DIOP, J.M. Preparation and Characterization of Gelatin and Chitosan films. 2009. Tese (doutorado). Department of Chemical \& Biological Engineering, Tufts University, Medford, MA.

66. DJABOUROV, M.; LEBLOND, J.; PAPON, P. Gelation of aqueous gelatin solutions. I. Structural investigation. J. Phys. France, v. 49, n. 2, p. 319-332, 1988. 
67. DOERGE, D.R.; YOUNG, J.F.; CHEN, J.J.; DINOVI, M.J.; HENRY, S.H. Using dietary exposure and physiologically based pharmacokinetic/pharmacodynamic modeling in human risk extrapolations for acrylamide toxicity. J. Agric. Food Chem., v. 56, n. 15, p. 6031-6038, 2008. doi: $10.1021 / \mathrm{jf073042g}$.

68. DONG, L.; HOU, F.; LI, Y.; WANG, L.; GAO, H.; TANG, Y. Preparation of continuous carbon nanotube networks in carbon fiber/epoxy composite. Composite: Part A, v. 56, p. 248-255, 2014.

69. DONHOWE, I.G.; FENNEMA, O. The effect of relative humidity on water vapor permeance of lipid - hydrocolloid bilayer films, Journal of the American Oil Chemists' Society, JAOCS, v. 69, n. 11, p. 1081-1087, 1992.

70. DORSCHNER, H.; LAPPAN, U.; LUNKWITZ, K. Electron beam facility in polymer research: radiation induced functionalization of polytetrafluoroethylene, Nucl. Instr. Met. Phys. Res. B, v. 139, p. 495-501, 1998.

71. DRAGAN, E.S.; PERJU, M.M.; DINU, M.V. Preparation and characterization of IPN composite hydrogel based on polyacrylamide and chitosanand their interaction with ionic dyes. Carbohydrate polym., v. 88, p. 270-281, 2012.

72. DRAKE, M.P.; VEIS, A. Interchain Interactions in Collagen-Fold Formation. I. The Kinetics of Renaturation of $\mathrm{y}$-Gelatin*. Biochemistry, v. 3, n. 2, p. $135-145,1964$. DOI: $10.1021 /$ bi00890a001

73. EL-DIN, A.; BEKHIT, A.; HOPKINS, D.L.; FAHRI, F.T.; PONNAMPALAM, E.N. Oxidative Processes in Muscle Systems and Fresh Meat: Sources, Markers, and Remedies. Comprehensive Rev. Food Sci. Food Safety, v.12, n. 5, p. 565-597, 2013.

74. EMBRAPA, Empresa Brasileira de Pesquisa Agropecuária - Meio Ambiente. Disponível em:

<http://www.cnpma.embrapa.br/unidade/unidade.php?it=8> Acesso em: 08/11/2013.

75. FAO. Food and Agriculture Organization. Glycerol. In: 20TH JECFA (JOINT FAO/WHO EXPERT COMMITTEE ON FOOD ADDITIVES), 1976.

Proceedings... Disponível em: <http://www.fao.org/ag/agn/jecfaadditives/specs/Monograph1/Additive-211.pdf> Acesso em: 18 nov. 2013. 
76. FAO. Food and Agriculture Organization. Butylated hydroxytoluene. In: 37TH JECFA (JOINT FAO/WHO EXPERT COMMITTEE ON FOOD ADDITIVES), 1990. Proceedings... Disponível em:

<http://www.fao.org/ag/agn/jecfa-additives/specs/Monograph1/Additive069.pdf> Acesso em: 18 nov. 2013.

77. FAO. Food and Agriculture Organization. Polyvinyl alcohol (PVA). Chemical and technical assessment (CTA). Saxena, S.K. In: 61ST JECFA (JOINT FAO/WHO EXPERT COMMITTEE ON FOOD ADDITIVES), 2004.

Proceedings... Disponível em: <http://www.fao.org/food/food-safetyquality/scientific-advice/jecfa/technical-assessments/en/> Acesso em: 18 nov. 2013.

78. FARHATAZIZ, J.; RODGERS, M.A. Radiation Chemistry, Principles and Applications. New York: VCH Publishers, Inc., 1987.

79. FDA. FOOD AND GRUG ADMINISTRATION. Gelatin, 1975. (SCOGS-Report Number: 58; ID Code: 9000-70-8) Disponível em: <http://www.fda.gov/food/ingredientspackaginglabeling/gras/scogs/ucm261 307.htm>. Acesso em: 23 nov. 2013.

80. FDA. FOOD AND GRUG ADMINISTRATION. Polyvinyl alcohol notification. 2003. Disponível em: $<$ http://www.accessdata.fda.gov/scripts/fcn/gras_notices/grn_141.pdf> Acesso em: 21 nov. 2013.

81. FELBERG, I.; ANTONIASSI, R.; DELIZA, R.; FREITAS, S.C.; MODESTA, R.C.D. Soy and Brazil nut beverage: processing, composition, sensory, and color evaluation. Ciênc. Tecnol. Aliment., v. 29, n. 3, p. 609-617, 2009.DAMODARAN, S.; PARKIN, K.L.; FENNEMA, O.R. Química de alimentos.Porto Alegre, RS: Artmed 4 ed.,2010.

82. FILHO, R.B.; OSIRO, D.; COLNAGO, L.A. Preparação de amostras de DNA em vidro e mica, para realização de microscopia de força atômica. Embrapa. CNPDIA, n. 20, p. 1-4, dez. 1997.

83. FINCH, C.A. Polyvinyl Alcohol-Development. Chichester, England: Wiley, p. 754, 1992.

84. FONTES, L.C.B.; RAMOS, K.K.; SIVI, T.C.; QUEIROZ, F.P.C. Biodegradable edible films from renewable sources-potencial for their application in fried foods. American jornal of food technology, v. 6, n. 7, p. 555-567, 2011. DOI: 10.3923/ajft.2011.555.567

85. FRAUNHOFER, W.; WINTER, G. The use of asymmetrical flow field-flow fractionation in pharmaceutics and biopharmaceutics. Europ. J. Pharm. Biopharm., v. 58, p. 369-383, 2004. doi:10.1016/j.ejpb.2004.03.034. 
86. FUERTGES, F.; ABUCHOWSKI, A. The clinical efficacy of poly(ethylene glycol)-modified proteins. J. Contr. Rel., v. 11, n. 1-3, p. 139-148, 1990.

87. FURUSAWA, K.; TERAO,K.; NAGASAWA, N.; YOSHII, F.; KUBOTA, K.; DOBASHI, T. Nanometer-sized gelatin particles preparedby means of gamma-ray irradiation. Colloid Polym. Sci., v. 283, p. 229-233, 2004.

88. GALDEANO, M.C. Filmes e laminados biodegradáveis de amido de aveia com diferentes plastificantes, produzidos por casting e extrusão. 2007. Tese (Doutorado) - Universidade Estadual de Londrina, Paraná.

89. GARCIA, M.A.; MARTINO, M.N.; ZANITZKY, N.E. Microstructural characterization of plasticized starch-based films. Stärke, v. 52, n. 4, p. 118-124, 2000a.

90. GARCIA, M.A.; MARTINO, M.N.; ZARITZKY, N.E. Lipid addition to improve barrier properties of edibel starch-based films and coatings. J. food Sci., v. 65 , n. 6 , p. $941-947,2000$ b.

91. GARCIA, M.A.; PINOTTI, A.; ZARITZKY, N.E. Physicochemical, Water Vapor Barrier and Mechanical Properties of Corn Starch and Chitosan Composite Films. Stärke, v. 58, n. 9, p. 453-463, 2006.

92. GENNADIOS, A.; MCHUGH, T.H.; WELLER, C.L.; KROCHTA, J.M. Edible coating and films based on proteins. In:

KROCHTA, J.M.; BALDWIN, E.A.; NISPEROS-CARRIEDO, M. (Ed.). Edible coating and films improve food quality. Lancaster, PA:

Technomic Pub. Co. Inc., 1994. p. 210.

93. GIDDINGS, J.C. Conceptual Basis of Field-Flow Fractionation. J. Chem. Education, v. 50, n. 10, p. 667-669, 1973.

94. GIDDINGS, J.C. Field-flow fractionation: A versatile new separation method. Science, v. 193, n. 4259, p. 1244-1245, 1976.

95. GIDDINGS, J.C.; MYERS, M.N.; LIN, G.C.; MARTIN, M.; Polymer Analysis and Characterization by Field-Flow Fractionation (One-Phase Chromatography). J. Chromat., v. 142, p. 23-38, 1977a.

96. GIDDINGS, J.C.; YANG, F.J.; MYERS, M.N. Flow field-flow fractionation as a methodology for protein separation and characterization. Anal. Biochem., v. 81, n. 2, p. 395-407, 1977b.

97. GIDDINGS, J.C. Field-flow fractionation: analysis of macromolecular, coloidal, and partciple materials. Science, v. 260, p. 1456-1465, 1993. 
98. GIOFFRE, M.; TORRICELLI, P.; PANZAVOLTA, S.; RUBINI, K.; BIGI, A. Role of $\mathrm{pH}$ on stability and mechanical properties of gelatin films. J. Bioact. Compat. Polym., v. 27 n. 1, p. 67-77, 2012.

99. GIRAUDIER, S.; HELLIO, D.; DJABOUROV, M.; LARRETA-GARDE, V. Influence of weak and covalent bonds on formation and hydrolysis of gelatin networks. Biomacromolec., v. 5, n. 5, p. 1662-1666, 2004.

100. GÓMEZ-ESTACA, J., GÓMEZ-GUILLÉN, M.C., FERNÁNDEZ-MARTÍN, F., MONTERO, P. Effects of gelatin origin, bovine-hide and tuna-skin, on the properties of compound gelatin-chitosan films. Food Hydrocol., v. 25, p. 1461-1469, 2011.

101. GÓMEZ-GUILLÉN, M.C., GIMÉNEZ, B., LÓPEZ-CABALLERO, M.E., MONTERO, M.P. Functional and bioactive properties of collagen and gelatin from alternative sources: A review. Food Hydrocol., 2011. doi:10.1016/j.foodhyd.2011.02.007.

102. GORGIEVA, S.; KOKOL, V. Collagen- vs. Gelatine-Based Biomaterials and Their Biocompatibility: Review and Perspectives. Capt. 2. In: PIGNATELLO, R. (Ed.). Biomaterials Applications for Nanomedicine. Croatia: InTech Europe., 2011, p. 17-52.

103. GSFA. Codex General Standard for Food Additives. Butylated hydroxytoluene (BHT) (321). In: 36th Session of the Codex Committee on food additives and contaminants alimentarius comission. Proceedings... Disponível em: <http://www.codexalimentarius.net/gsfaonline/additives/details.html?id=189 \&d-3586470-o=1\&d-3586470-s=4 > Acesso em: 18 nov. 2013.

104. GUERRERO, P.; STEFANI, P.M.; RUSECKAITE, R.A. DE LA CABA., K. Functional properties of films based on soy protein isolate and gelatin processed by compression molding. J. Food Eng., v. 105, n. 1,p. 65-72, 2011.

105. GUIMARÃES, J.L.; SATYANARAYANA, K.G.; WYPYCH, F.; RAMOS, L.P. Preparo de compósitos biodegradáveis a partir de fibras de bananeira plastificadas com amido e glicerina bruta derivada de alcoólise de óleos vegetais. Biodisel. p. 28-33. 2006. Disponível em: $<$ http://www.biodiesel.gov.br/docs/congressso2006/CoProdutos/PreparoCompositos6.pdf> Acesso em: 02/02/2010.

106. GÜVEN, O. New Opportunities for the Utilization of Electron Accelerators in Polymer Processing Industries. IAEA-CN-115-68, 2005. Disponível em: http://www-pub.iaea.org/MTCD/publications/PDF/P1251-cd/papers/43.pdf Acesso em: 15/10/2013. 
107. HAJI-SAEID, M.; SAMPA, M.H.; RAMAMOORTHY, N.; GÜVEN, O.; CHMIELEWSKI, A.G. The role of IAEA in coordinating research and transferring technology in radiation chemistry and processing of polymers. Nucl. Met. Phys. Res. B, v. 265, n. 1, p. 51-57, 2007.

108. HARPER, B.A.; BARBUT, S.; LIM, L.-T.; MARCONE, M.F. Characterization of wet alginate and composite films containing gelatin, whey or soy protein. Food research international, v. 52, n. 2, p. 452-459, 2013.

109. HARRINGTON, W.F.; HIPPEL, P.H. Formation and stabilization of the collagen-fold. Arch. Biochem. Biophys., v. 92, n. 1, p. 100-113, 1961.

110. HARRINGTON, W.F.; RAO, N.V. Collagen Structure in Solution I Kinetics of Helix Regeneration in Single-Chain Gelatins. Biochem., v. 9, n. 19, p. 3714-3724, 1970.

111. HARRIS, J.M. Poly(ethylene glycol) Chemistry: biotechnical and biomedical applications. New York: Plenum Press, 1992.

112. HENGLEIN A., SCHNABEL W., WENDENBURG J. Einfuhrung im die strahlenchemie mit partischen anleitungen. Weinheim/Bergstr: Verlag Chemie, GMBH, 1969.

113. HOFFMAN, A.S., STAYTON, P.S., PRESS, O., MURTHY, N., LACKEY, C.A., CHEUNG, C., BLACK, F., CAMPBELL, J., FAUSTO, N., KYRIAKIDES, T.R., BORNSTEIN, P. Design of "smart" polymers that can direct intracellular drug delivery. Polym. Adv. Tech., v. 13, n. 10-12, p. 992-999, 2002.

114. IAEA. International Atomic Energy Agency. Directory of Gamma Processing Facilities in Member States, IAEA-DGPF/CD, Vienna, Austria, IAEA, 2004a. Disponível em: <http://wwwpub.iaea.org/MTCD/publications/PDF/dgpf-cd/PDF/Contents.pdf> Acesso em: 28 nov. 2013.

115. IAEA. International Atomic Energy Agency. Emerging applications of radiation processing, IAEA-TECDOC-1386, In: PROCEEDINGS OF A TECHNICAL MEETING HELD IN VIENNA. Apr. 28-30, 2003, Vienna, Austria. Proceedings... Vienna: IAEA, 2004b. Disponível em: < http://wwwpub.iaea.org/MTCD/publications/PDF/te_1386_web.pdf> Acesso em: 28 nov. 2013.

116. IBGE. Instituto Brasileiro de Geografia e Estatística. Brasil em Síntese. Disponível em: <http://brasilemsintese.ibge.gov.br/contas-nacionais/rendanacional-disponivel-bruta> Acesso em: 08/11/2013. 
117. IFST. Institute of Food Science \& Technology. Acrylamide in foods. Oct. 2012. Disponível em:

$<w w w . i f s r . o r g / s c i e n c e$ technology_resources/for_food_professionals/> Acesso em: 02 dez. 2013.

118. IMRAN, M.; REVOL-JUNELLES, A.M.; MARTYN, A.; TEHRANY, E.A.; JACQUOT, M.; LINDER, M.; DESOBRY, S. Active Food Packaging Evolution: Transformation from Micro- to Nanotechnology. Critical Reviews in Food Science and Nutrition., v. 50, n. 9, p. 799-821, 2010. DOI: 10.1080/10408398.2010.503694

119. INAMURA, P.Y.; SHIMAZAKI, K.; SOUZA, C.M.; COLOMBO, M.A.; MOURA, E.A.B.; MASTRO, N.L. Electron beam effects on gelatin polymer. In: INTERNATIONAL NUCLEAR ATLANTIC CONFERENCE. INAC 2009, 2009, Rio de Janeiro. Proceedings... Rio de Janeiro, Brazil: INAC, 2009.

120. INAMURA, P.Y.; KASAWA, C.T.S.; COLOMBO, M.A.; MOURA, E.A.B.; MASTRO, N.L. del. Changes in Gelatin/Brazil Nut Shell Fiber Composite Treated by Electron Beam Radiation. In: 3RD ASIA PACIFIC SYMPOSIUM ON RADIATION CHEMISTRY, Sept.14-17, 2010, Lonavala, India.

Proceedings... India: APSRC, 2010.

121. ISMAIL, H.; NURDIN, H.I. Tensile Properties and Scanning Electron Microscopy Examination of the Fracture Surface of Oil Palm Wood Flour/Natural Rubber Composites. Iranian Polym. J., v. 7, n. 1, p. 53-58, 1998.

122. ISRAELACHVILI, J.N. Intermolecular and surface forces. London, En.: Academic Press, 1992.

123. JIPA, J.M.; STROESCU, M.; STOICA-GUZUN, A.; DOBRE, T.; JINGA, S.; ZAHARESCU, T. Effect of gamma irradiation on biopolymer composite films of poly(vinyl alcohol) and bacterial cellulose. Nucl. Instr. Met. Phys. Res. B, v. 278, p. 82-87, 2012.

124. JO, C.; KANG, H.; LEE, N.Y.; KWON, J.H.; BYUN, M.W. Pectin- and gelatin-based film: effect of gamma irradiation on the mechanical properties and biodegradation. Radiat. Phys. Chem., v. 72, p. 745-750, 2005.

125. JOHN, V.M. Pesquisa e desenvolvimento de mercado para resíduos. In: WORKSHOP RECICLAGEM E REUTILIZAÇÃO DE RESÍDUOS COMO MATERIAIS DE CONSTRUÇÃO CIVIL, São Paulo,. Anais... São Paulo, Antac., p.21-30, 1996.

126. JONES, C.G. Radiation-induced remediation of polychlorinated biphenyls contained in industrial transformer oil from electrical generating stations, 2001. 
127. JONES, R.A.; GROVES, D.J.; WARD, I.M.; TAYLOR, D.J.R.; STEPTO, R.F.T. Gel fractions and chain reactions in irradiated polyethylenes. Nucl. Instr. Met. Phys. Res. B, v. 151, n. 1-4, p. 213-217, 1999.

128. JONGJAREONRAK, A., BENJAKUL, S., VISESSANGUAN, W., TANAKA, M. Antioxidative activity and properties of fish skin gelatin films incorporated with BHT and $\alpha$-tocopherol. Food Hydrocol., v. 22, p. 449-458, 2008.

129. JOSHI, S.V.; DRZAL, L.T.; MOHANTY, A.K.; ARORA, S. Are natural fiber composites environmentally superior to glass fiber reinforced composites? Composites: Part A, v. 35, p. 371-376, 2004.

130. KADLUBOWSKI, S.; GROBELNY, J.; OLEJNICZAK, W.; CICHOMSKI, M.; ULANSKI, P. Pulses of fast electrons as a tool to synthesize poly(acrylic acid) nanogels. Intramolecular cross-linking of linear polymer chains in additive-free aqueous solution. Macromol., v. 36, n. 7, p. 2484-2492, 2003.

131. KAMINŚKA, A.; SIONKOWSKA, A. The effect of UV radiation on the thermal parameters of collagen degradation. Polym. Degrad. Stab., v. 51, n. 1, p. 15-18, 1996.

132. KANMANI, P.K.; RHIM, J.W. Physicochemical properties of gelatin/silver nanoparticle antimicrobial composite films. Food chem., v. 148, p. 162-169, 2014.

133. KECHICHIAN, V.; DITCHFIELD, C.; VEIGA-SANTOS, P.; TADINI, C.C. Natural antimicrobial ingredients incorporated in biodegradable films based on cassava starch. LWT - Food Sci. Tech., v. 43, n. 7, p. 1088-1094, 2010.

134. KEENAN, T.R. Gelatin. In:

KIRK, R.E.; OTHMER, D.F.; KROSCHWITZ, J.I.; HOME-GRANT, M. (Ed.). Encyclopedia of chemical technology. New York: Wiley, 1998. v. 12. p. $436-448$.

135. KENT, M.; MEYER, W. Complex permittivity spectra of protein powders as a function of temperature and hydration J. Phys. D: Appl. Phys., v. 17, p. 1687-1698, 1984.

136. KHADEMHOSSEINI, A., LANGER, R. Microengineered hydrogels for tissue ENGINEERING. Biomat., v. 28, n. 34, p. 5087-5092, 2007.

137. KHAN, F.; AHMAD, S.R.; KRONFLI, E. Stability of jute fibers on exposure to ionizing radiation. Polym. Degrad. Stab., v. 63, p. 79-84, 1999. 
138. KHAN, M.; KHAN, R.A.; HAYDARUZZAMAN; HOSSAIN, A.; KHAN, A.H. Effect of Gamma Radiation on the Physico-Mechanical and Electrical Properties of Jute Fiber-Reinforced Polypropylene. Compos. J. Reinf. Plast. Compos., v. 00, n. 00/2008, p. 1-10, 2008.

139. KI, C.S., BAEK, D.H., GANG, K.D., LEE, K.H., UM, I.C., PARK, Y.H. Characterization of gelatin nanofiber prepared from gelatin-formic acid solution. Polym., v. 46, n. 14, p. 5094-5102, 2005.

140. KLEIN, K.; HAUER, B.; STOIB, B.; TRATWEIN, M.; MATICH, S.; HUEBL, H.; ASTAKHOV, O.; FINGER, F.; BITTL, R.; STUTZMANN, M.; BRANDT, M.S. The electrically detected magnetic resonance microscope- Combining conductive atomic force microscopy with electrically detected magnetic resonance. Rev. scient. instr., v. 84, p. 103911, 2013.

DOI: $10.1063 / 1.4827036$

141. KO, D.Y.; SHINDE, U.P.; YEON, B.; JEONG, B. Recent progress of in situ formed gels for biomedical applications. Progress in polymer science, v. 38, p. 672-701, 2013.

142. KOJIMA, T., BESSHO, M., FURUTA, M., OKUDA, S., HARA, M. Characterization of biopolymer hydrogels produced by $\gamma$-ray irradiation. Radiat. Phys. Chem., v. 71, p. 233-236, 2004.

143. KONG, Y.-Q.; LI, D.; WANG, L.-J.; ADHIKARI, B. Preparation of gelatin microparticles using water-in-water (w/w) emulsification technique. J. Food Eng., v. 103, p. 9-13, 2011.

144. KOWALKOWSKI, T.; BUSZEWSKI, B.; CANTADO, C.; DONDI, F. FieldFlow Fractionation Theory Techniques Applications Challenges. Crit. Rev. Anal. Chem., v. 36, p. 129-135, 2006.

145. KOZLOV, P.V.; BURDYGINA, G.I. The structure and properties of solid gelatin and principles of their modification. Polymer, v. 24, n. 6, p. 651-666, 1983.

146. KRISTO, E.; BILIADERIS, C.G.; ZAMPRAKA, A. Water vapour barrier and tensile properties of composite caseinate-pullulan films: Biopolymer composition effects and impact of beeswax lamination. Food Chem., v. 101, p. $753-764,2007$.

147. KROCHTA, J. M.; DE MULDER-JOHNSTON, C. Edible and biodegradable polymer films: challenges and opportunities. Food Technology, v. 51, n. 2, p. 60-74, Feb. 1997. 
148. KUAN, Y.-H.; BHAT, R.; PATRAS, A.; KARIM, A.A. Radiation processing of food proteins - A review on the recent ddevelopments. Trends Food Sci. Tech., v. 30, p. 105-120, 2013.

149. LAZAREV, Y.A.; GRISHKOVSKY, B.A.; KROMOVA, T.B.; LAZAREVA, A.V.; GRECHISHKO, V.S. Bound water in the collagen-like triple-helical structure. Biopolymers, v. 32, n. 2, p. 189-195, 1992.

150. LEE, M.; SEBRANEK, J.; PARRISH JR., F.C. Accelerated Postmortem Aging of Beef Utilizing Electronbeam Irradiation and Modified Atmosphere Packaging. J. Food Sci., v. 61, n. 1, p. 133-136, 1996.

151. LEE, S.Y.; SONG, J.M.; SOHN, J.Y.; SHUL, Y.G.; SHIN, J. Radiation-induced crosslinking of poly(styrene-butadiene-styrene) block copolymers and their sulfonation. Nucl. Instr. Met. Phys. Res. B, v. 316, p. $71-75,2013$.

152. LI, C.; DING, S.; LEI, W.; ZHANG, X.; WANG, B. Enhanced field emission from vertically aligned carbon nanotubes on metal mesh electrode. Applied Surface Science Part B, v. 285, n. 15, p. 505-508, nov. 2013.

153. LI, G.; SHROTRIYA, V.; HUANG, J.; TAO, Y.; MORIARTY, T.; EMERY, K.; YANG, Y. High-efficiency solution processable polymer photovoltaic cells by self-organization of polymer blends. Nature mat., vol. 4, n. 11, p. 864-868, 2005. DOI:10.1038/nmat1500

154. LIANG, S.; HUANG, Q.; LIU, L.; YAM, K.L. Microstructure and molecular interaction in glycerol plasticized chitosan-poly(vinyl alcohol) blending films. Macromol. Chem. Phys., v. 210, n. 10, p. 832-839, 2009.

155. LIN, C.C.; METTERS, A.T. Hydrogels in controlled release formulations: network design and mathematical modeling. Adv. Drug Delivery Rev., v. 58, n. 12-13, p. 1379-1408, 2006.

156. LIN, J.J.; TSAI, W.C.; WANG, C.H. Formation of Hierarchical Molecular Assemblies from Poly(oxypropylene)-Segmented Amido Acids under AFM Tapping. Langmuir, v. 23, n. 8, p. 4108-4111, 2007.

157. LIU, M.; YIN, Y.; FAN, Z.; ZHENG, X.; SHEN, S.; DENG, P.; ZHENG, C.; TENG, H.; ZHANG, W. The effects of gamma-irradiation on the structure, thermal resistance and mechanical properties of the PLA/EVOH blends. Nucl. Instr. Met. Phys. Res. B, v. 274, p. 139-144, 2012.

158. LIU, Y.S.; WANG, Q.; LI, L. Biodegradable PVA/Gelatin blends prepared by reactive extrusion. Soc. Leather Techn. Chem., v. 96, n. 3, p. 106-113, 2012. 
159. LUKASIK, K.V.; LUDESCHER, R.D. Molecular mobility in water and glycerol plasticized cold- and hot-cast gelatin films. Food Hydrocol., v. 20, n. 1, p. 96-105, 2005.

160. LUYKX, D.M.A.M.; PETERS, R.J.B.; VAN RUTH, S.M.; BOUWMEESTER, $H$. A Review of Analytical Methods for the Identification and Characterization of Nano Delivery Systems in Food. J. agric. food chem., v. 56, n. 18, p. 8231-8247, 2008.

161. MA, W.; TANG, C.H.; YIN, S.W.; YANG, X.Q.; WANG, Q.; LIU, F.; WEI, Z.H. Characterization of gelatin-based edible fi Ims incorporated with olive oil. Food res. int., v. 49, n .1, p. 572-579, 2012.

162. MACHI, S. New trends of radiation processing applications. Radiat. Phys. Chem., v. 47, n. 3, p. 333-336, 1996.

163. MAGEE, J.L.; CHATTERJEE, A. Theoretical aspects of radiation chemistry. In: RODGERS, M.A.; FARHATAZIZ, J. (Ed.). Radiation Chemistry, Principles and Applications. New York: VCH Publishers Inc., 1987, p. 148.

164. MALI, S. SAKANAKA, L.S.; YAMASHITA, F.; GROSSMANN, M.V.E. Water sorption and mechanical properties of cassava starch films and their relation to plasticizing effect. Carb. Polym., v. 60, p. 283-289, 2005.

165. MALIK, R.; ALVAREZ, N.; HAASE, M.; RUFF, B.; SONG, Y.; SUBERU, B.; SHEREEN, D.; MAST, D.; GILPIN, A.; SCHULZ, M.; SHANOV, V. Chapter 13 - Carbon Nanotube Sheet: Processing, Characterization and Applications. Nanotube Superfiber Materials, Changing Engineering Design., p. 349-387, 2014.

166. MMA. Ministério do Meio Ambiente do Governo Federal. Plano nacional de resíduos sólidos. Disponível em: <http://www.mma.gov.br/cidadessustentaveis/residuos-solidos> Acesso em: 08/11/2013.

167. MARINELLI, A.L.; MONTEIRO, M.R.; AMBRÓSIO, J.D.; BRANCIFORTI, M.C.; KOBAYASHI, M.; NOBRE, A.D. Desenvolvimento de compósitos poliméricos com fibras vegetais naturais da biodiversidade: uma contribuição para a sustentabilidade da Amazônica. Pol. Ciência Tecn., v. 18, n. 2, p. 92-99, 2008.

168. MARINIELLO, L.; DI PIERRO, P.; ESPOSITO, C.; SORRENTINO, A.; MASI, P.; PORTA, R. Preparation and mechanical properties of edible pectin-soy flour films obtained in the absence or presence of transglutaminase. J. Biotechnology, v. 102, n. 2, p. 191-198, 2003. 
169. MARTINS, J.T., CERQUEIRA, M.A., BOURBON, A.I., PINHEIRO, A.C., SOUZA, B.W.S., VICENTE, A.A. Synergistic effects between K-carrageenan and locust bean gum on physicochemical properties of edible films made thereof. Food hydrocol., v. 29, p. 280-289, 2012.

170. MATSUMURA, S.; KURITA, H.; SHIMOKOBE, H. Anaerobic biodegradability of polyvinyl alcohol. Biotechnol. Lett., v. 15, n. 7, p. 749-754, 1993.

171. MATSUMURA, S.; TOMIZAWA, N.; TOKI, A.; NISHIKAWA, K.; TOSHIMA, K. Novel poly(vinyl alcohol)-degrading enzyme and degradation mechanism. Macromol., v. 32, n. 23, p. 7753-7761, 1999.

172. MCGUIRE, R.G. Reporting of Objective Color Measurements. HortSci., v. 27, n. 12 , p. 1254-1255, 1992.

173. MENDIETA-TABOADA, O.; SOBRAL, P.J.A.; CARVALHO, R.A.; HABITANTE, A.M.B.Q. Thermomechanical properties of biodegradable films based on blends of gelatin and poly(vinyl alcohol), Food Hydrocol., v. 22, n. 8, p. 1485-1492, 2008. doi:10.1016/j.foodhyd.2007.10.001

174. MENDIS, E.; RAJAPAKSE, N.; KIM, S.K. Antioxidant properties of a radicalscavenging peptide purified from enzymatically prepared fish skin gelatin hydrolysate. J. Agric. Food Chem., v. 53, n. 3, p. 581-587, 2005.

175. MESSAUD, F.A.; SANDERSON, R.D.; RUNYON, J.R.; OTTE, T.; PASCH, H.; RATANATHANAWONGS WILLIAMS, S.K. An overview on field-flow fractionation techniques and their applications in the separation and characterization of polymers. Prog. Polym. Sci., v. 34, p. 351-368, 2009.

176. MEYER, G.; AMER, N.M. Novel optical approach to atomic force microscopy. Appl. Phys. Letters, 53, n. 12, p. 1045-1047, 1988. DOI:10.1063/1.100061

177. MONTEIRO, S.N.; AQUINO, R.C.M.P.; LOPES, F.P.D.; D'ALMEIDA, J.R.M. Tenacidade ao Entalhe por Impacto Charpy de Compósitos de Poliéster Reforçados com Fibras de Piaçava. Revista Matéria, v. 11, n. 3, p. 204-210, 2006.

178. MORTAIN, L.; DEZ, I.; MADEC, P.J. Development of new composites materials, carriers of active agents, from biodegradable polymers and wood. Comptes Rendus Chimie, v. 7, n. 6-7, p. 635-640, 2004. 
179. MOURA, E.A.B.; NOGUEIRA, B.R.; ORTIZ, A.V. Changes in physicochemical, morphological and thermal properties of electron-beam irradiated ethylene-vinyl alcohol copolymer (EVOH) as a function of radiation dose. In: INTERNATIONAL TOPICAL MEETING ON NUCLEAR RESEARCH APPLICATIONS AND UTILIZATION OF ACCELERATORS (ACCAPP), May 4-8, 2009, Vienna. Proceedings... Vienna: IAEA, 2010.

180. MPOFU, P.; ADDAI-MENSAH, J.; RALSTON, J. Temperature influence of nonionic polyethylene oxide and anionic polyacrylamide on flocculation and dewatering behavior of kaolinite dispersions. J. Col. Interf. Sci., v. 271, n. 1, p. 145-156, 2004.

181. MU, C.; LI, X.; GUO, J.; BI, C.; LI, D. Effects of Montmorillonite on the Structure and Properties of Gelatin-Polyethylene Glycol Composite Fibers. J. Appl. Polym. Sci., v. 129, n. 2, p. 773-778, 2013.

182. NAGAOKA, S.; MORI, Y.; TAKIUCHI, H.; YOKOTA, K. TANZAWA, H. NISHIUMI, S. Interaction between blood components and hydrogels with poly(oxyethylene) chain. In:

SHALABY, C.S.W.; WOFFMAN, A.S.; RATNER, B.D.; HORBETT, T.A. (Ed.) Polymer as biomaterials. New York: Plenum Press, p. 361-374, 1984.

183. NAGASAWA, N.; KANEDA, A.; KANAZAWA, S.; YAGI, T.; MITOMO, H.; YOSHII, F.; TAMADA, M. Application of poly(lactic acid) modified by radiation crosslinking. Nucl. Instr. Met. Phys. Res. B, v. 236, n. 1-4, p. 611-616, 2005.

184. NAIDU, B.V.K., PAULSON, A.T. A new method for the preparation of gelatin nanoparticles: Encapsulation and drug release characteristics. J.Appl. Pol. Sci. v. 121, n. 6, p. 3495-3500, 2011. DOI: 10.1002/app.34171.

185. NOBREGA, M.M.; OLIVATO, J.B.; GROSSMANN, M.V.E.; BONA, E.; YAMASHITA, F. Effects of the incorporation of saturated fatty acids on the mechanical and barrier properties of biodegradable films. J. Appl. Polym. Sci., v. 124, n. 5, p. 3695-3703, 2012.

186. ONG, S.Y., WU, J., MOOCHHALA, S.M., TAN, M.H., LU, J. Development of a CHITOSAN-based wound dressing with improved hemostatic and antimicrobial properties. Biomat., v. 29, n. 32, p. 4323-4332, 2008.

187. ORTIZ-ZARAMA, M.A.; JIMÉNEZ-APARICIO, A.; PEREA-FLORES, M.J.; SOLORZA-FERIA, J. Barrier, mechanical and morpho-structural properties of gelatin films with carbon nanotubes addition. J. food eng., v. 120, p. 223-232, 2014. 
188. PAGLIARO, M.; ROSSI, M. The Future of Glycerol - New Usages for a Versatile Raw Material, Cambridge: RSC Publishing, 2008.

189. PAL, K.; BANTHIA, A.K.; MAJUMDAR, D.K. Biomedical evaluation of poly vinyl alcohol-gelatin esterified hydrogel for wound dressing. J. Mater. Sci.: Mater. Med., v. 18, p. 1889-1894, 2007.

190. PAL, K.; BANTHIA, A.K.; MAJUMDAR, D.K. Polyvinyl Alcohol-Gelatin Patches of Salicylic Acid: Preparation, Characterization and Drug Release Studies. J. Biomater. Appl., v. 21, n. 1, p. 75-91, 2006. DOI: $10.1177 / 0885328206056312$

191. PARK, J.W.; WHITESIDE, W.S.; CHO, S.Y. Mechanical and water vapor barrier properties of extruded and heat-pressed gelatin films. $\mathbf{L W T}-$ Food Sci. Tech., v. 41, n. 4, p. 692-700, 2008.

192. PASCH, H.; TRATHNIGG, B. HPLC of Polymers. Springer Desktop Editions of Chemistry., New York: Springer, 1999.

193. PATEL, Z.S.; MIKOS, A.G. Angiogenesis with biomaterial-based drug- and cell-delivery systems. J. Biomater. Sci. Polym. Ed., 15, p. 701-726, 2004.

194. PATTANAPIPITPAISAL, P.; BROWN, N.L.; MACASKIE, L.E. Chromate reduction by Microbacterium liquefaciens immobilised in polyvinyl alcohol. Biotechnol. Lett., v. 23, p. 61-65, 2001.

195. PAUKSZTA, D.; BORYSIAK, S. The Influence of Processing and the Polymorphism of Lignocellulosic Fillers on the Structure and Properties of Composite Materials-A Review. Materials, v. 6, p. 2747-2767, 2013. doi:10.3390/ma6072747

196. PECORA, R, Dynamic light scattering: applications of photon correlation spectroscopy. New York: Plenum Press, 1985.

197. PEÑA, C.; DE LA CABA, K.; ECEIZA, A.; RUSECKAITE, R.; MONDRAGON, I. Enhancing water repellence and mechanical properties of gelatin films by tannin addition. Bioresource Techn., v. 101, n. 17, p. 6836-6842, 2010.

198. PEPPAS, N.A.; HILT, J.Z.; KHADEMHOSSEINI, A.; LANGER, R. Hydrogels in biology and medicine: From molecular principles to bionanotechnology. Advanced Materials, v. 18, n. 11, p. 1345-1360, 2006.

199. PHILLIES, G.D.J. Quasi-Elastic Light-Scattering. Analytical Chemistry, v. 62, n. 20, p. A1049-A1057, 1990. 
200. POLY, J.; WILSON, D.J.; DESTARAC, M.; TATON, D. Synthesis of Poly(vinyl acetate) Nanogels by Xanthate-Mediated Radical Crosslinking Copolymerization. Macromolec. Rapid Commun., v. 29, n. 24, p. 1965-1972, 2008.

201. PRADELLA, J.G.C. Biopolímeros e intermediários químicos. Centro de tecnologia de processos e produtos. Centro de Gestão e Estudos Estratégicos. CGEE. Relatório técnico no 84 396-205, 2006.

202. QUERNER, C.; SCHMIDT, T.; ARNDT, K.-F. Characterization of Structural Changes of Poly(vinyl methyl ether) $y$-Irradiated in Diluted Aqueous Solutions. Langmuir. v. 20, n. 7, p. 2883-2889, 2004.

203. QIU, Z.B.; FUJINAMI, S.; KOMURA, M.; NAKAJIMA, K.; IKEHARA, T.; $\mathrm{NISHI}, \mathrm{T}$. Structure and properties of biodegradable polymer-based blends. Macromol. Symp., v. 216, p. 255-263, 2004.

204. RAAFAT, A.I.; EID, M.; EL-AMAOUTY, M.B. Radiation synthesis of superabsorbent CMC based hydrogels for agriculture applications. Nucl. Instr. Met.Phys. Res.B, v. 283, p. 71-76, 2012.

205. RAHMAN, M.D.A.; KHAN, M.A.; TAREQ, S.M. Preparation and Characterization of Polyethylene Oxide (PEO)/Gelatin Blend for Biomedical Application: Effect of Gamma Radiation. J. Appl. Polym. Sci., v. 177, n. 4, p. 2075-2082, 2010.

206. RAMESH, M.; PALANIKUMAR, K.; HEMACHANDRA REDDY, K. Mechanical property evaluation of sisal-jute-glass fiber reinforced polyester composites. Composites: part B, v. 48, p. 1-9, 2013.

207. RAMIRES, E.C.; OLIVEIRA, F.; FROLLINI, E. Composites based on renewable materials: Polyurethane-type matrices from forest byproduct/vegetable oil and reinforced with lignocellulosic fibers. J. Appl. Polym. Sci., v. 129, n. 4, p. 224-2233, 2013. DOI: 10.1002/APP.38934

208. RATNAM, C.T.; RAJU, G.; YUNUS, W.Z.W. Oil palm empty fruit bunch (OPEFB) fiber reinforced PVC/ENR blend-electron beam irradiation. Nucl. Instr. Met. Phys. Res. B. v. 265, p. 510-514, 2007.

209. RATNAM, C.T.; ZAMAN, K. Effect of electron beam irradiation on surgical rubber gloves. Nucl. Instr. Met. Phys. Res. B, v. 140, n. 1-2, p. 171-177, 1998.

210. RATNER, B.D.; TSUKRUK, V.V. Scanning Probe Microscopy of Polymers. ACS Symposium Series. Washington, DC: American Chemical Society, 1996. 
211. RESSOUANY, M.; VACHON, C.; LACROIX, M. Irradiation dose and calcium effect of the mechanical properties of cross-linked caseinate films. J. Agri. Food Chem., v. 46, n.4, p. 1618-1623, 1998.

212. RIVALDI, J.D.; SARROUB, B.F.; FIORILO, R. Glicerol de biodiesel. Biotecnologia Ciência \& Desenvolvimento, Ano X. n. 37, p. 44-51, 2007. Disponível em: <http://www.biotecnologia.com.br/edicoes/ed37.php> Acesso em: 18/11/2013.

213. ROESSNER, D., Field Flow Fractionation - Basics and Method Development. Wyatt Technology Europe, 2006.

214. ROSE, P.I. Gelatin. In: MARK, H.F.; BIKALES, N.M.; OVERBERGER, C.G.; MENGES, G.; KROSCHWITZ, J.I. (Ed). Encyclopedia of Polymer Science and Engineering. New York: John Wiley \& Sons, 1985, v. 7, p. 488-513.

215. ROSIAK, J.M. Hydrogel dressings. In: RADIATION EFFECTS ON POLYMERS, p. 271, 1991. Washington, D.C.: ACS Book Ser. 475.

216. ROSIAK, J.M.; ULANSKI, P.; PAJEWSKI, L.A.; YOSHII, F.; MAKUUCHI, K. Radiation formation of hydrogels for biomedical purposes. Some remarks and comments. Radiat.Phys. Chem., v. 46, p. 161-168, 1995.

217. ROSS, P.I. Gelatin. In: MARK H. F.; BIKALES, N.M.; OVERBERGER, C.G.; MENGES, G. (Eds). Encyclopedia of Polymer Science and Engineering. New York: John Wiley \& Sons, v. 7, p. 488, 1987.

218. ROSS-MURPHY, S. B. Structure and rheology of gelatin gels. Recent progress. Polym., v. 33, n. 12, p. 2622-2627, 1992.

219. RUNYON, J.R.; ULMIUS, M.; NILSSON, L. A perspective on the characterization of colloids and macromolecules using asymmetrical flow field-flow fractionation. Col. Surf. A: Physicochem. Eng. Aspects, In press, Corrected proof, april 2013. Disponível em:

<http://dx.doi.org/10.1016/j.colsurfa.2013.04.010> Acesso em: 20/10/2013.

220. SAHEB, D.N,; JOG, J.P. Natural fiber polymer composites: A Review. Adv. Polym. Tech., v.18, p.351-63, 1999.

221. SANCHÉZ, A.C.; POPINEAU, Y.; MANGAVEL, C.; LARRÉ, C.; GUÉGUEN, $J$. Effect of different plasticizers on the mechanical and surface properties of wheat gliadin films. J. Agric. Food Chem., v. 46, n. 11, p. 4539-4544, 1998. 
222. SANTOS, J.F.; FERNANDES, E.A.; COELHO, A.B. Crescimento econômico e emissão de $\mathrm{CO}_{2}$ por combustíveis fósseis: uma análise da hipótese da curva de Kuznets ambiental. Análise econômica, ano 30, n. 57, p. 287-312, mar. 2012.

223. SANTULLI, C.; SARASINI, F.; TIRILLÒ, J.; VALENTE, T.; VALENTE, M.; CARUSO, A.P.; INFANTINO, M.; NISINI, E.; MINAK, G. Mechanical behaviour of jute cloth/wool felts hybrid laminates. Materials and design, v. 50, p. 309-321, 2013.

224. SATYANARAYANA, K.G.; ARIZAGA, G.G.C.; WYPYCH, F. Biodegradable composites based on lignocellulosic fibers - an overview. Prog. Polym. Sci., v. 34, n. 9, p. 982-1021, 2009.

225. SHEIEN B.; SLABAC L.A.; BARKY B.K. Handbook of Health Physics and Radiological Health. Baltimore: Williams \& Wilkins, 1998.

226. SCHERZER, T. Barrier layers against oxygen transmission on the basis of electron beam cured methacrylated gelatin. Nucl. Instr. Met. Phys. Res., v. 131, p. 382-391, 1997.

227. SCHIMPF, M.; CALDWELL, K.; GIDDINGS, J.C. Field-Flow Fractionation Handbook. Wiley-Interscience. New York: John Wiley \& Sons, Inc., 1 ed. 2000.

228. SCHMITZ, K.S. An introduction to dynamic light scattering by macromolecules. San Diego: Academic Press Inc., 1990.

229. SCHRIEBER, R.; GAREIS, H. Gelatine Handbook: theory and industrial practice. New York, N.Y.: Wiley-VCH, 2007. Disponível em: <http://www.wiley.com/WileyCDA/WileyTitle/productCd-3527315489.html>. Acesso em: 29 nov. 2007.

230. SCHWARTZ, P.V. Molecular Transport from an Atomic Force Microscope Tip: A Comparative Study of Dip-Pen Nanolithograph. Langmuir, v. 18, n. 10 , p. 4041-4046, 2002. DOI: 10.1021/la011652j

231. SCHUCHMANN, M.N.; VON SONNTAG, C. Radiation-Chemistry of Carbohydrates. 14. Hydroxyl Radical Induced Oxidation of D-Glucose in Oxygenated Aqueous-Solution. J. Chem. Society-Perkin Transactions, v. 2, n. 14, p. 1958-1963, 1977.

232. SENGUPTA, R.; SABHARWAL, S.; TIKKU, V.K.; SOMANI, A.K.; CHAKI, T.K.; BHOWMICK, A.K. Effect of Ambient-Temperature and High-Temperature Electron-Beam Radiation on the Structural, Thermal, Mechanical, and Dynamic Mechanical Properties of Injection-Molded Polyamid-6,6. J. Appl. Polym. Sci., v. 99, n. 4, p. 1633-1644, 2006. 
233. SIDDIQUE, R.; MEHTA, A. Effect of carbon nanotubes on properties of cement mortars. Construction and Building Materials. v. 50, p. 116-129, 15 Jan. 2014.

234. SINGH, A., SILVERMAN, J. Radiation Processing of Polymers. New York, NY: Oxford University Press, 1992.

235. SIRPAL, S.; GATTÁS-ASFURA, K.M.; LEBLANC, R.M. A photodimerization approach to crosslink and functionalize microgels. Col. Surf. B:

Biointerfaces. v. 58, p. 16-120, 2007.

236. SKOTAK, M., LEONOV, A.P., LARSEN, G., NORIEGA, S., SUBRAMANIAN, A. Biocompatible and biodegradable ultrafine fibrillar scaffold materials for tissue engineering by facile grafting of I-lactide onto chitosan. Biomacromolec., v. 9(7), p. 1902-1908, 2008.

237. SOBRAL, P.J.A., CARVALHO, R.A.; MORAES, I.C.F.; HABITANTE, A.M.Q.B.; MONTERREY-QUINTERO, E.S. Phase transitions in biodegradable films based on gelatin and poly(vinyl alcohol). Ciênc. Tecn. Alim., v. 31, n. 2, p.372-379, 2011.

238. SOBRAL, P.J.A., MENEGALLI, F.C.; HUBINGUER, M.D.; ROQUES, M.A. Mechanical, water vapor barrier and thermal properties of gelatin based edible films. Food hydrocol. v. 15, n. 4-6, p. 423-432, 2001.

239. SOUZA, A.C.; GOTO, G.E.O.; MAINARDI, J.A.; COELHO, A.C.V.;

TADINI,C.C. Cassava starch composite films incorporated with cinnamon essential oil: Antimicrobial activity, microstructure, mechanical and barrier properties. LWT - Food Sci. Tech., v. 54, n. 2, p. 346-352, 2013.

240. SOUZA, M. L.; MENEZES, H. C. Processamentos de amêndoa e torta de castanha-do-Brasil e farinha de mandioca: parâmetros de qualidade.

Ciênc. Tecn. Alim., v. 24, n. 1, p. 120-128, 2004.

241. SOUZA, M. L.; MENEZES, H. C. Extrusão de misturas de castanha do Brasil com mandioca. Ciênc. Tecn. Alim., v. 28, n. 2, p. 451-462, 2008.

242. SPINKS J.W.T.; WOODS R.J. An Introduction to Radiation Chemistry. New York: John Wiley and Sons, Inc., 1990. 3rd ed.

243. SPIZZIRRI, U.G.; IEMMA, F.; PUOCI, F.; CIRILLO, G.; CURCIO, M.; PARISI, O.I.; PICCI, N. Synthesis of Antioxidant Polymers by Grafting of Gallic Acid and Catechin on Gelatin. Biomacromol., v. 10, p. 1923-1930, 2009. 
244. STEENKEN, S.; O'NEILL, P. Selectivity of addition of the hydroxyl radical to ring positions of pyridine and pyridine mono- and dicarboxylic acids, An electron spin resonance investigation. J. Physical Chem., v. 82, p. 372-374, 1978.

245. STRAUSS, G., GIBSON, S.M. Plant phenolics as cross-linkers of gelatin gels and gelatin-based coacervates for use as food ingredients. Food Hydrocol. v. 18, p. 81-89, 2004.

246. STUBBERUD, L.; ARWIDSSON, H.G.; LARSSON, A.; GRAFFNER, C. Water solid interactions II. Effect of moisture sorption and glass transition temperature on compactibility of microcrystalline cellulose alone or in binary mixtures with polyvinyl pyrrolidone. Int. J. Pharm., v. 134, p. 79-88, 1996.

247. SUZUKI, T.; ICHIHARA, Y.; YAMADA, M.; TONOMURA, K. Some Characteristics of Pseudomonas O-3 which Utilizes Polyvinyl Alcohol. Agric. Biol. Chem., v. 37, n. 4, p. 747-756, 1973.

248. TABATA, Y. Radiation-induced crosslinking. Radiat. Phys. Chem., v. 14, n. 1-2, p. 235-243, 1979.

249. TABATA, Y.; IKADA, Y. Protein release from gelatin matrices, Adv. Drug Deliv. Rev., v. 31, n. 3, p. 287-301,1998.

250. TABATA, Y.; SATO, S.; OMICHI, H. Preface. Radiat. Phys. Chem., v. 46, n. 2, p. 157, 1995.

251. TAKEDA, S.; NAKAMURA, C.; KAGESHIMA, M.; TOKUMOTO, H.; MIYAKE, J. Investigation of enzyme activities of the enzyme immobilized on an AFM tip. AIP Conf. Proc., v. 696, p. 401, 2003.

252. TANAKA, Y.; GONG, J.P.; OSADA, Y. Novel hydrogels with excellent mechanical performance. Prog. Polym. Sci., v. 30, n. 1, p. 1-9, 2005.

253. TERAO, K.; NAGASAWA, N.; NISHIDA, H.; FURUSAWA, K.; MORI, Y. YOSHII, F. DOBASHI, T. Reagent-free crosslinking of aqueous gelatin: manufacture and characteristics of gelatin gels irradiated with gamma-ray and electron beam. J. Biomater. Sci. Polymer Edn., v. 14, n. 11, p. 1197-1208, 2003.

254. THARANATHAN, R.N. Biodegradable films and composite coatings: past, present and future. Trends in Food Sci. \& Tech., v. 14, n. 3, p. 71-78, 2003.

255. THOMAZINE, M.; CARVALHO, R.A.; SOBRAL, P.J.A. Physical properties of gelatin films plasticized by blends of glycerol and sorbitol. J. Food Sci., v. 70, p. E72-E76, 2005. 
256. TISSOT, C.; GRDANOVSKA, S.; BARKATT, A.; SILVERMAN, J.; AL-SHEIKHLY, M. On the mechanisms of the radiation-induced degradation of cellulosic substances. Radiat. Phys. Chem., v. 84, p. 185-190, 2013.

257. TOKIWA, Y.; FAN, H.; HIRAGURI, H.; KURANE, R.; KITAGAWA, M.; SHIBATANI, S.; MAEKAWA, Y. Biodegradable of a sugar branched polymer consisting of sugar, fatty acid and poly(vinyl alcohol). Macromol., v. 33, p. 1636-1639, 2000.

258. TOKIWA, Y.; KAWABATA, G.; JARERAT, A. A modified method for isolating poly(vinyl alcohol)-degrading bacteria and study of their degradation patterns. Biotechnology Letters, v. 23, p. 1937-1941, 2001.

259. TSANG, F. F. Y.; JIN, Y. Z.; YU, K. N.; WU, C. M. L.; LI, R. K. Y. Effect of $\gamma$ irradiation on the short beam shear behavior of pultruded sisal-fiber/glassfiber/polyester hybrid composites. J. Mat. Sci. Letters. v. 19, p. 1155-1157, 2000.

260. ULAŃSKI, P.; BOTHE, E.; ROSIAK, J.M.; VON SONNTAG, C. $\mathrm{OH}$-radical-induced crosslinking and strand breakage of poly(vinyl alcohol) in aqueous solution in the absence and presence of oxygen. A pulse radiolysis and product study. Macromol. Chem. Phys., v. 195, n. 4, p. 1443-1461, 1994.

261. ULAŃSKI, P.; JANIK, I.; ROSIAK, J.M. Radiation formation of polymeric nanogels. Radiat. Phys. Chem., v. 52, n. 1-6, p. 289-294, 1998.

262. ULAŃSKI, P.; ROSIAK, J.M. The use of radiation technique in the synthesis of polymeric nanogels. Nucl. Instr. Met. Phys. Res. B., v. 151, n. 1-4, p. 356-360, 1999.

263. ULAŃSKI, P.; KADŁUBOWSKI, S.; ROSIAK, J.M. Synthesis of poly(acrylic acid) nanogels by preparative pulse radiolysis. Radiat. Phys. Chem., v. 63, n. 3-6, p. 533-537, 2002.

264. ULAŃSKI, P.; ROSIAK, J.M. Encyclopedia of Nanoscience and Nanotechnology. Stevenson Ranch, CA: American Scientific Publishers. 2004. v. 8, p. 845-871: NALWA, H.S. (Ed).

265. VANIN, F.M.; SOBRAL, P.J.A.; MENEGALLI, F.C.; CARVALHO, .RA.; HABITANTE, A.M.Q.B. Effects of plasticizers and their concentrations on thermal and functional properties of gelatin-based films. Food Hydrocol., v. 19, n. 5, p. 899-907, sept. 2005.

266. VEIS, A. The macromolecular Chemistry of Gelatin. Academic Press Inc., New York, v. 5, 1964. 
267. VIEIRA, F.F.; DEL MASTRO, N.L. Comparison of gamma-radiation and electron beam irradiation effects on gelatin. Radiat. Phys. Chem., v. 63, n.3-6, 331-332, 2002.

268. VIJAYABASKAR, V.; STEPHAN, M.; KALAIVANI, S.; VOLKE, S.; HEINRICH, G.; DORSCHNER, H.; BHOWMICK, A.K.; WAGENKNECHT, U. Influence of radiation temperature on the crosslinking of nitrile rubber by electron beam irradiation. Radiat. Phys. Chem., v. 77, p. 511-521, 2008.

269. VON SONNTAG, C. The Chemical Basis of Radiation Biology. Philadelphia: Taylor \& Francis, 1987.

270. VON SONNTAG, C. Trends of research in radiation chemistry. In: ADVANCED RADIATION CHEMISTRY RESEARCH: CURRENT STATUS. p. 11, oct. 1995, Vienna. Proceedings... Vienna: IAEA, 1995a. (IAEA-TECDOC-834).

271. VON SONNTAG, C.; BOTHE, E.; ULAŃSKI, P.; DEEBLE, D.J. Pulse radiolysis in model studies toward radiation processing. Radiat. Phys. Chem., v. 46, n. 4-6, p. 527-532, 1995b.

272. VOSS, D.H. Relating colorimeter measure-ment of plant color to the Royal Horticultural Society colour chart. HortSci., v. 27, p. 1256-1260, 1992.

273. WANG, B.; MUKATAKA, S.; KODAMA, M.; KOKUFUTA, E. Viscosimetric and Light Scattering Studies on Microgel Formation by $\mathrm{Y}$-Ray Irradiation to Aqueous Oxygen-free Solutions of Poly(vinyl alcohol). Langmuir, v. 13, n. 23, p. 6108-6114, 1997.

274. WANG, M.; XU, L.; HU, H.; ZHAI, M.; PENG, J.; NHO, Y.; LI, J.; WEI, G. Radiation synthesis of PVP/CMC hydrogels as wound dressing. Nucl. Instr. Met. Phys. Res. B, v. 265, n. 1, p. 385-389, 2007.

275. WHO. World Health Organization. IPCS-International Programme on Chemical Safety. Safety evaluation of certain food additives and contaminants. In: PREPARED BY THE SIXTY-FIRST MEETING OF THE JOINT FAO/WHO EXPERT COMMITTEE ON FOOD ADDITIVES (JECFA), 2003. WHO food additives series: 52 . Geneva, Switzerland: WHO Pres, 2004. Disponível em: <http://whqlibdoc.who.int/publications/2004/924166052x.pdf> Acesso em: 21 nov. 2013.

276. WILLIAMS, S.K.R.; LEE, D. Field-flow fractionation of proteins, polysaccharides, synthetic polymers, and supramolecular assemblies, Review. J. Sep. Sci., v. 29, p. 1720-1732, 2006. DOI 10.1002/jssc.200600151 
277. WINDHOLZ, M. (Ed.); BUDAVARI, S. (Co-Ed.); BLUMETTI, F.R.; OTTERBEIN, E.S. The Merck Index. 10. ed. New Jersey, N.J.: Merck \& Co, Inc, p. 1013, 1983.

278. WONG, D.W.S. Química de los Alimentos: mecanismos y teoría. Zaragoza, Esp.: Acribia S.A., 1995.

279. WOODS, R.J.; PIKAEV A.K. Applied Radiation Chemistry, Radiation Processing. New York: John Wiley and Sons, Inc., 1994.

280. WU, J.C.; CHEN, C.C.; CHEN, K.H.; CHANG, Y.C. Controlled growth of aligned $\alpha$-helical-polypeptide brushes for tunable electrical conductivity. Appl. Phys. Lett., v. 98, p. 133304, 2011.

281. WU, J.; CHEN, S.; GE, S.; MIAO, J.; LI, J.; ZHANG, Q. Preparation, properties and antioxidant activity of an active film from silver carp (Hypophthalmichthys molitrix) skin gelatin incorporated with green tea extract. Food Hydrocol.,v. 32, p. 42-51, 2013.

282. WYATT, P.J. Light scattering and the absolute characterization of macrolomecules. Anal. Chim Acta, v. 272, p. 1-40, 1993.

283. YAKIMETS, I.; WELLNER, N.; SMITH, A. C.; WILSON, R. H.; FARHAT, I.; MITCHELL, J. Mechanical properties with respect to water content of gelatin films in glassy state. Polym., v. 46, n. 26, p. 12577-12585, 2005.

284. YAKIMETS, I.; PAES, S.S.; WELLNER, N.; SMITH, A.C.; WILSON, R.H.; MITCHELL, J.R. Effect of Water Content on the Structural Reorganization and Elastic Properties of Biopolymer Films: A Comparative Study.

Biomacromolec., v. 8, n. 5, p. 1710-1722, 2007.

285. YANG, H.; WANG, Y.; REGENSTEIN, J.M.; ROUSE, D.B. Nanostructural characterization of catfish skin gelatin using atomic force microscopy. Journal of Food Science. v. 72, n. 8, p. C430-C440, 2007.

286. YUAN, Y.; REECE, T.J.; SHARMA, P.; PODDAR, S.; DUCHARME, S.; GRUVERMAN, A.; YANG, Y.; HUANG, J. Efficiency enhancement in organic solar cells with ferroelectric polymers. Nat. mat., vol. 10, n. 4, p. 296-302, 2011. DOI:10.1038/NMAT2951

287. ZAHEDI, M.; TABARSA, T.; ASHORI, A.; MADHOUSHI, M.; SHAKERI, A. A Comparative Study on Some Properties of Wood Plastic Composites Using Canola Stalk, Paulownia, and Nanoclay, J. Appl. Polym. Sci., v. 129, n. 3, p. 1491-1498, 2013. 
288. ZALIPSKY, S.; LEE, C. Use of functionalized poly(ethylene glycol)s for modification of polypeptides. In:

HARRIS, J.M. (Ed.). Polyethylene Glycol Chemistry: Biotechnical and Biomedical Applications. NewYork: Plenum Press. 1992. p. 347-370.

289. ZAMAN, H.U.; KHAN, M.A.; KHAN, R.A. Studies on the Thermo-Mechanical Properties of Gelatin Based Films Using 2-Hydroxyethyl Methacrylate by Gamma Radiation. Open J. Composite Mater., v. 2, p. 15-21, 2012.

290. ZAMAN, H.U.; BEG, M.D.H.; KHAN, M.A.; RUHUL, A.; KHAN, R.A. A comparative study of gamma and ultraviolet radiation on gelatin film with 2ethylhexyl acrylate. J. Adhesion Sci. Technol., v. 27, n. 24, p. 2653-2665, 2013.

291. ZEGOTA, $\mathrm{H}$. The effect of $\gamma$-irradiation on citrus pectinin $\mathrm{N}_{2} \mathrm{O}$ and $\mathrm{N}_{2} \mathrm{O} / \mathrm{O}_{2}$ satured aqueous solutions. Food Hydrocol., v. 13, p. 51 - 58, 1999.

292. ŻENKIEWICZ, M.; KURCOK, M. Effects of compatibilizers and electron radiation on thermomechanical properties of composites consisting of five recycled polymers. Polymer Testing, v. 27, p. 420-427, 2008.

293. ZHOU, X.; ZHENG, F.; LV, C.; TANG, L.; WEI, K.; LIU, X.; DU, G.; YONG, Q.; XUE, G. Properties of formaldehyde-free environmentally friendly lignocellulosic composites made from poplar fibres and oxygen-plasmatreated enzymatic hydrolysis lignin. Composites Part B: Engineering, v. 53, p. 369-375, 2013.

294. ZWIOREK, K.; BOURQUIN, C.; BATTIANY, J.; WINTER, G.; ENDRES, S.; HARTMANN, G.; COESTER, C. Delivery by Cationic Gelatin Nanoparticles Strongly Increases the Immunostimulatory Effects of $\mathrm{CpG}$ Oligonucleotides.

Pharmac. Res., v. 25, n. 3, p. 552 - 561, 2008. 